\title{
Rh(I)-Catalyzed Intramolecular Decarbonylation of Thioesters
}

Han Cao, ${ }^{\dagger}$ Xuejing Liu, ${ }^{*}{ }^{\dagger}$ Fusheng Bie ${ }^{\dagger}$ Yijun Shi,${ }^{\dagger}$ Ying Han,${ }^{\dagger}$ Peng Yan, ${ }^{\dagger}$ Michal Szostak, ${ }^{*}$, and Chengwei Liu*,§

'Shandong Lunan Coal Chemical Research Institute of Engineering and Technology, Zaozhuang University, 1 Bei'an Road, Zaozhuang, Shandong 277160, China

${ }^{\ddagger}$ Department of Chemistry, Rutgers University, 73 Warren Street, Newark, New Jersey 07102, United States

${ }^{\S}$ Chemistry Research Laboratory, University of Oxford, 12 Mansfield Road, Oxford, OX1 3TA, United Kingdom

lxj3786749@126.com; michal.szostak@rutgers.edu; chengwei.liu@chem.ox.ac.uk

\section{Supporting Information}

Table of Contents

${ }^{1} \mathrm{H}$ NMR and ${ }^{13} \mathrm{C}$ NMR and ${ }^{19}$ F NMR Spectra

\section{Corresponding Author:}

Prof. Dr. X. Liu

Zaozhuang University 1xj3786749@126.com
Prof. Dr. M. Szostak

Rutgers University michal.szostak@rutgers.edu
Dr. C. Liu

University of Oxford chengwei.liu@chem.ox.ac.uk 
06012020-CH-S-1. 1. fid -<smiles>O=C(Sc1ccccc1)c1ccccc1</smiles>

(400 MHz, $\mathrm{CDCl}_{3}$ )

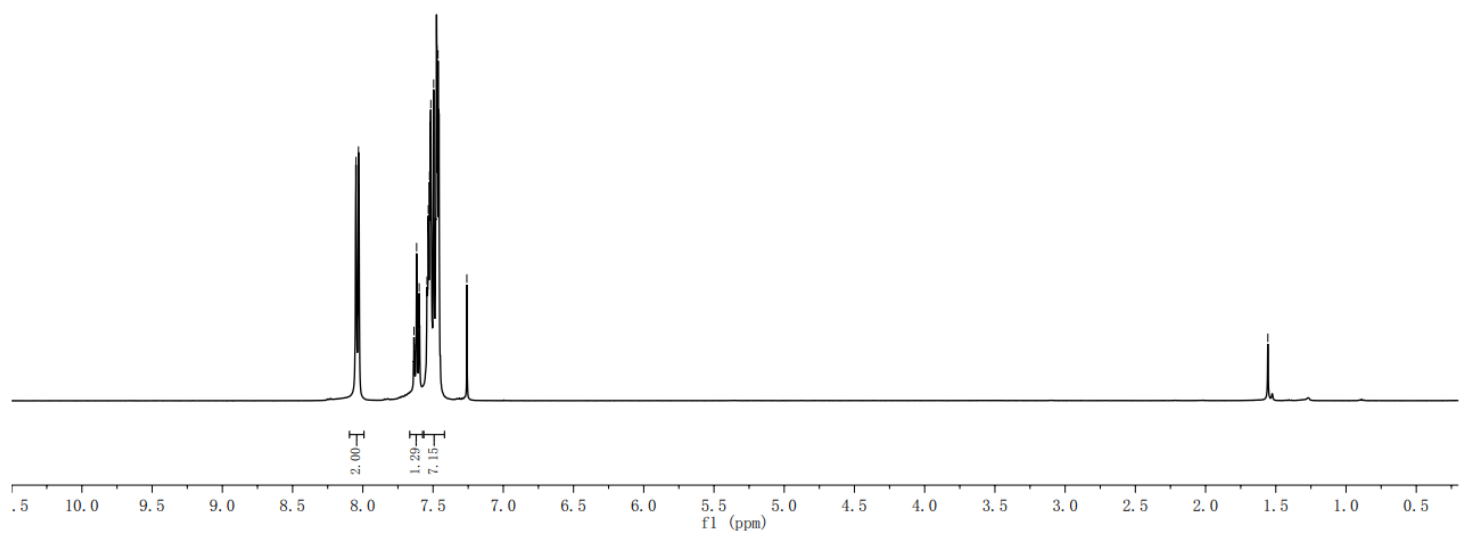

06012020-CH-S-1.2.1.1r -

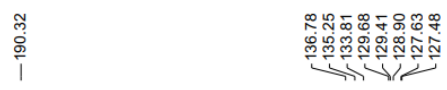<smiles>O=C(Sc1ccccc1)c1ccccc1</smiles>

(100 $\mathrm{MHz} \mathrm{CDCl}_{3}$ )
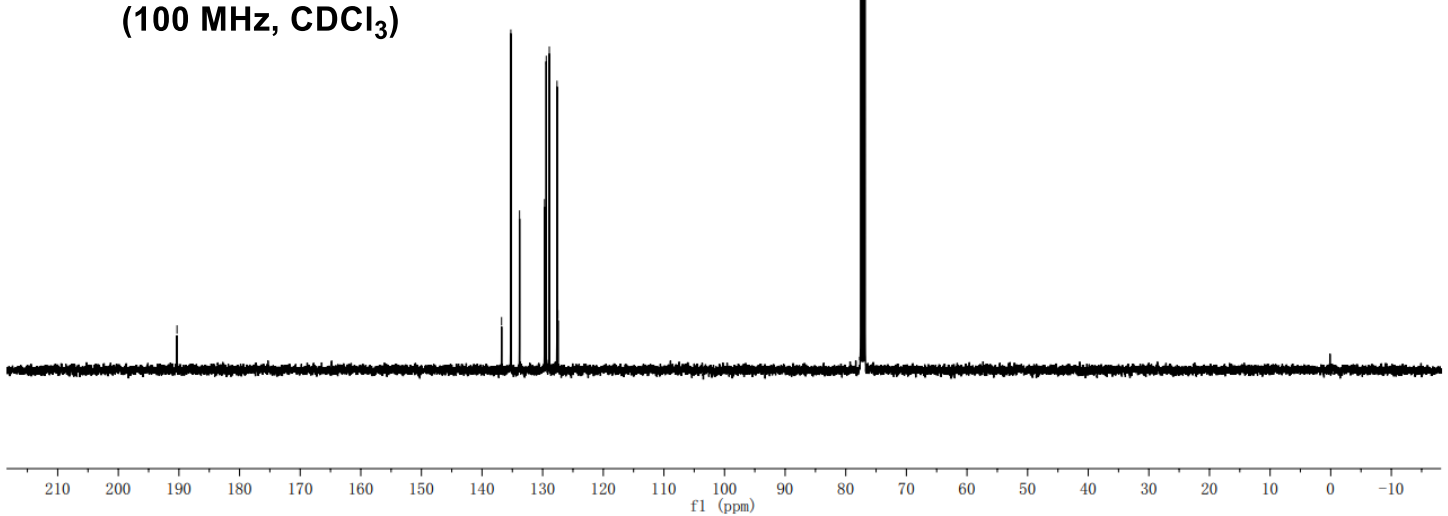


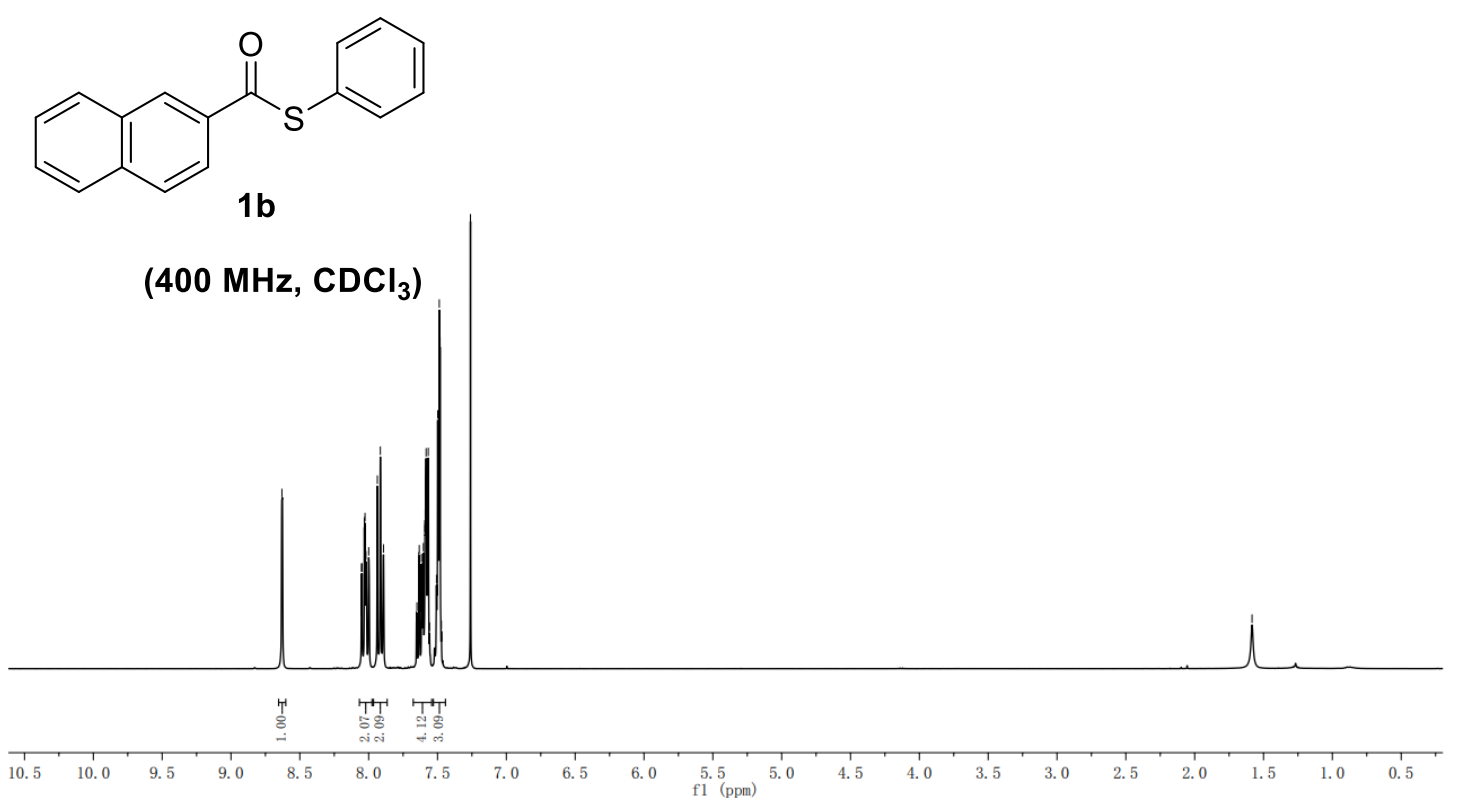

07152020-ch-s-20.2.1.1r -

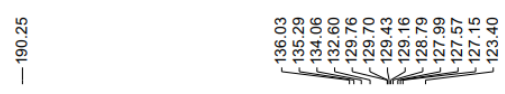<smiles>O=C(Sc1ccccc1)c1ccc2ccccc2c1</smiles>

$1 b$

$\left(100 \mathrm{MHz} \mathrm{CDCl}_{3}\right)$
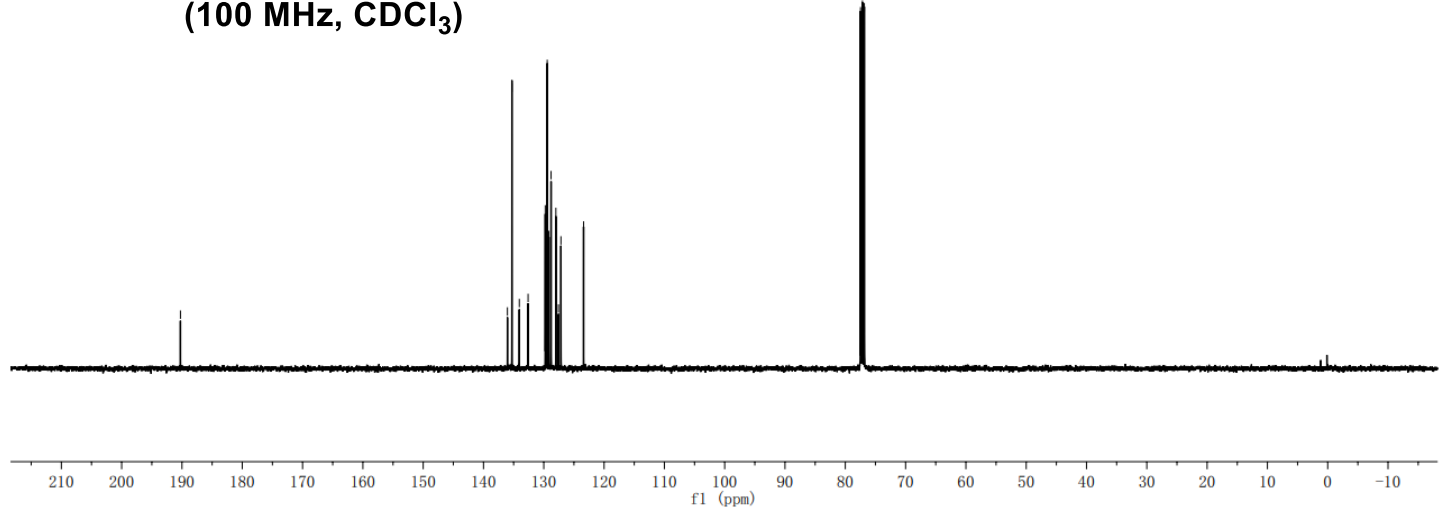
06102020-ch-s-3. 1. fid -

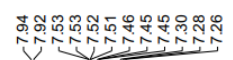

素少<smiles>Cc1ccc(C(=O)Sc2ccccc2)cc1</smiles>

(400 $\mathrm{MHz}, \mathrm{CDCl}_{3}$ )

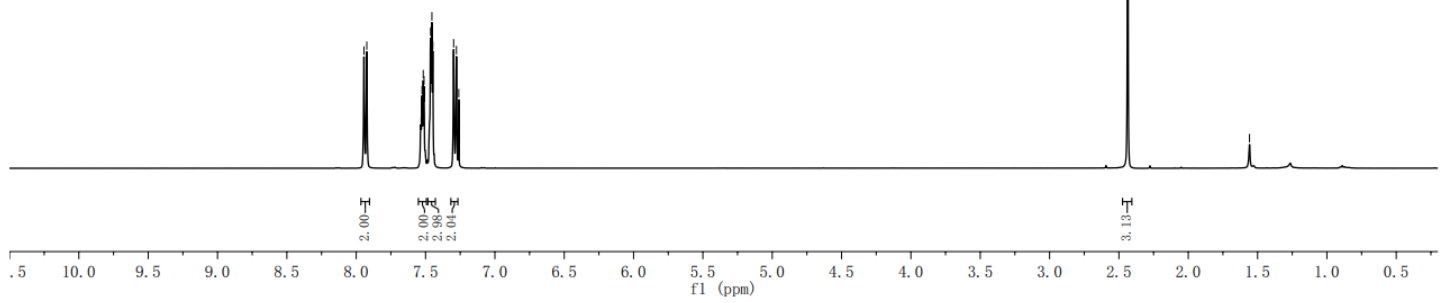

06102020-ch-s-3. 2. fid -

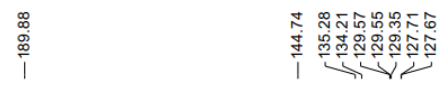<smiles>Cc1ccc(C(=O)Sc2ccccc2)cc1</smiles>

$\left.\left(100 \mathrm{MHz}^{\mathrm{CDCl}}\right)_{3}\right)$
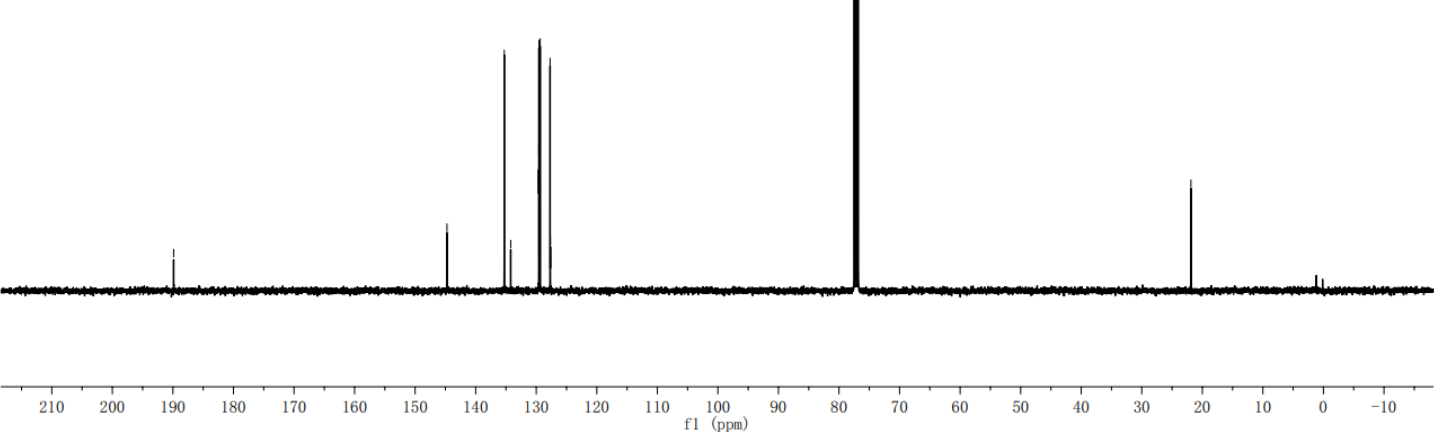
<smiles>COc1ccc(C(=O)Sc2ccccc2)cc1</smiles>

$1 d$

(400 $\mathrm{MHz}, \mathrm{CDCl}_{3}$ )
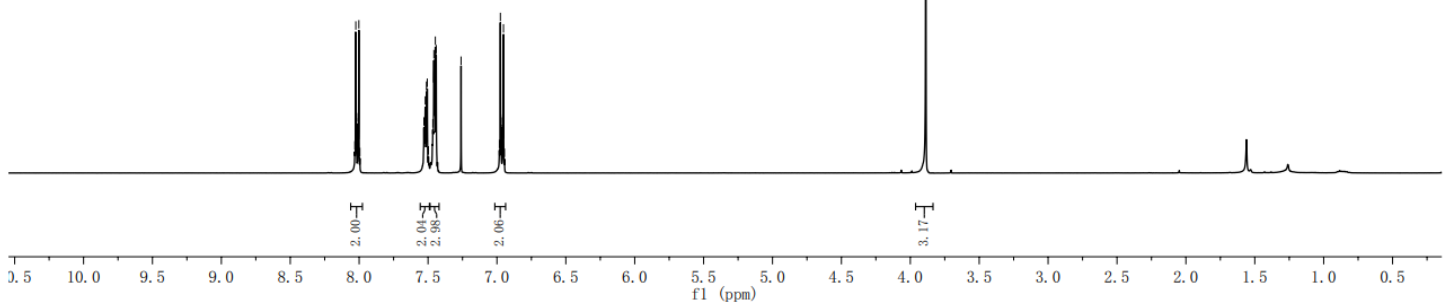

06102020-ch-s-4.2.1.1r -

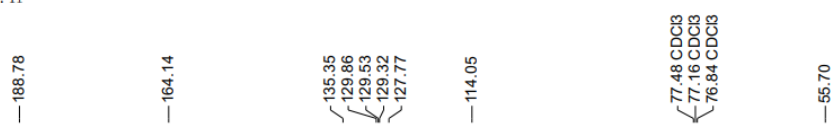<smiles>COc1ccc(C(=O)Sc2ccccc2)cc1</smiles>

1d

(100 $\mathrm{MHz}, \mathrm{CDCl}_{3}$ )
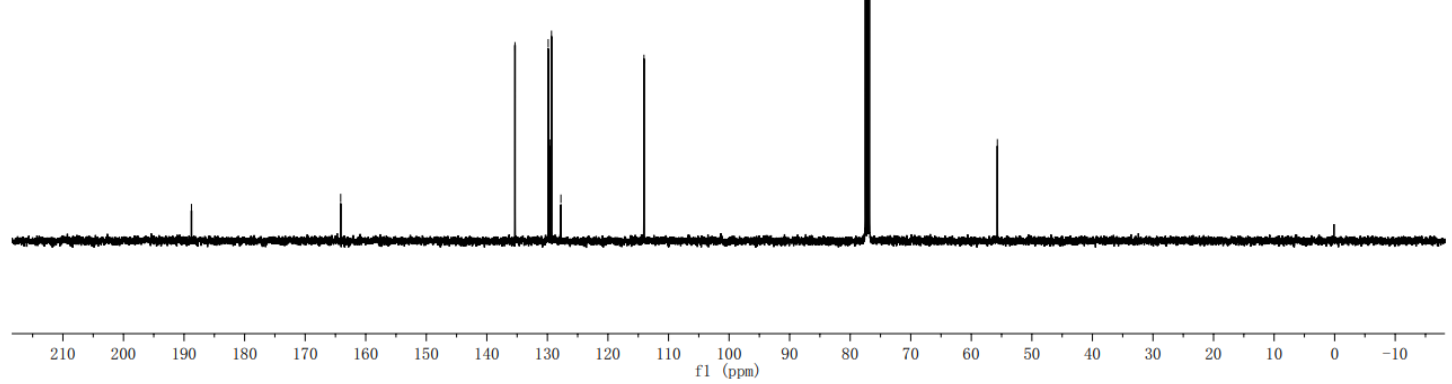


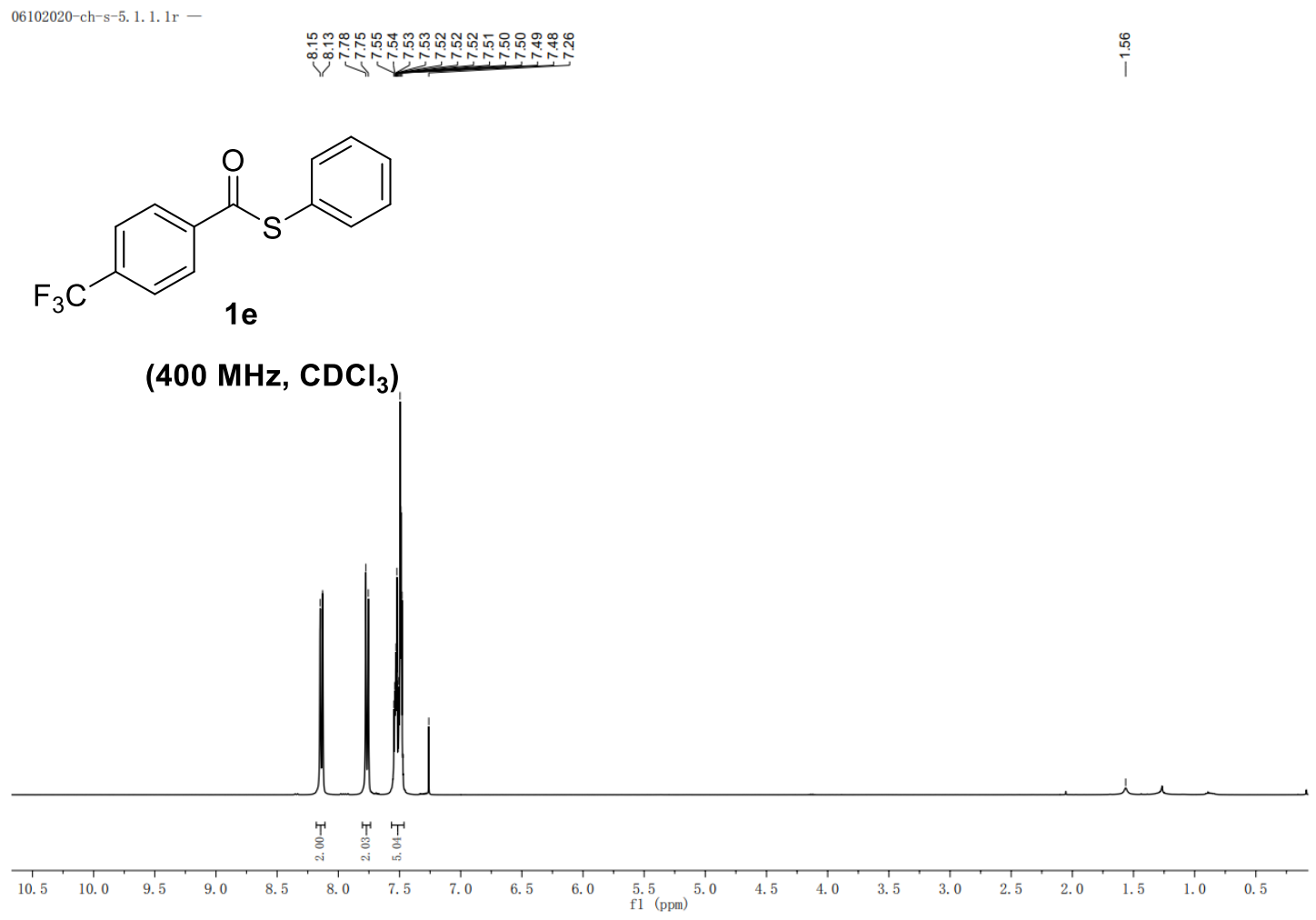

06102020-ch-s-5.2.1.1r -

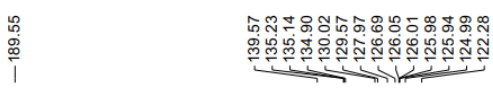<smiles>O=C(Sc1ccccc1)c1ccc(C(F)(F)F)cc1</smiles>

$\left(100 \mathrm{MHz} \mathrm{CDCl}_{3}\right)$

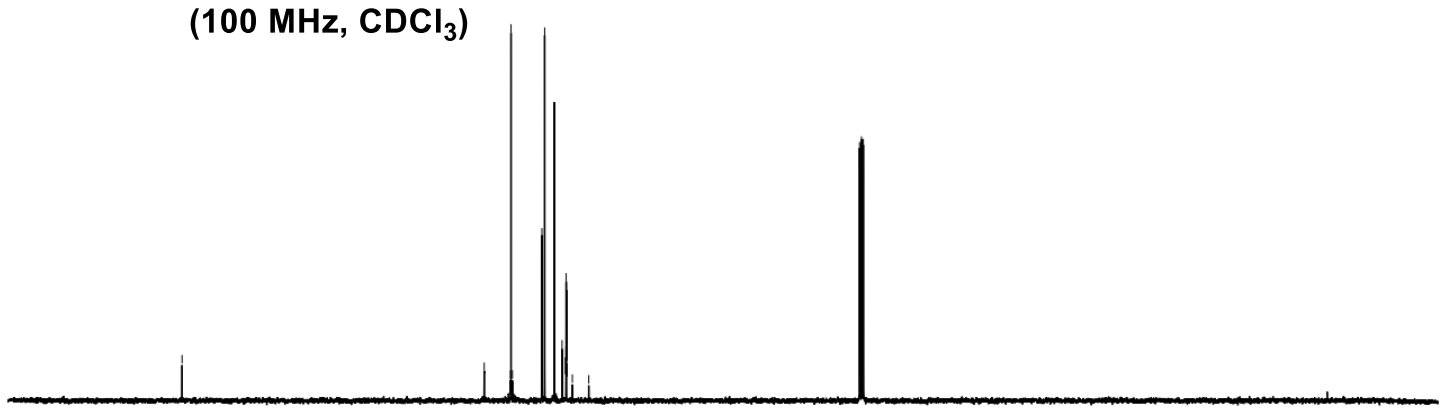

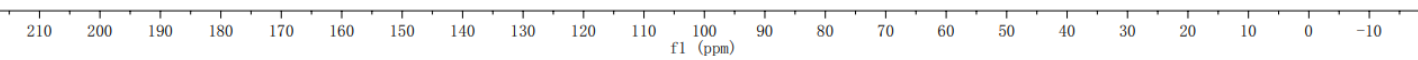


<smiles>O=C(Sc1ccccc1)c1ccc(C(F)(F)F)cc1</smiles>

(376 $\mathrm{MHz}, \mathrm{CDCl}_{3}$ )

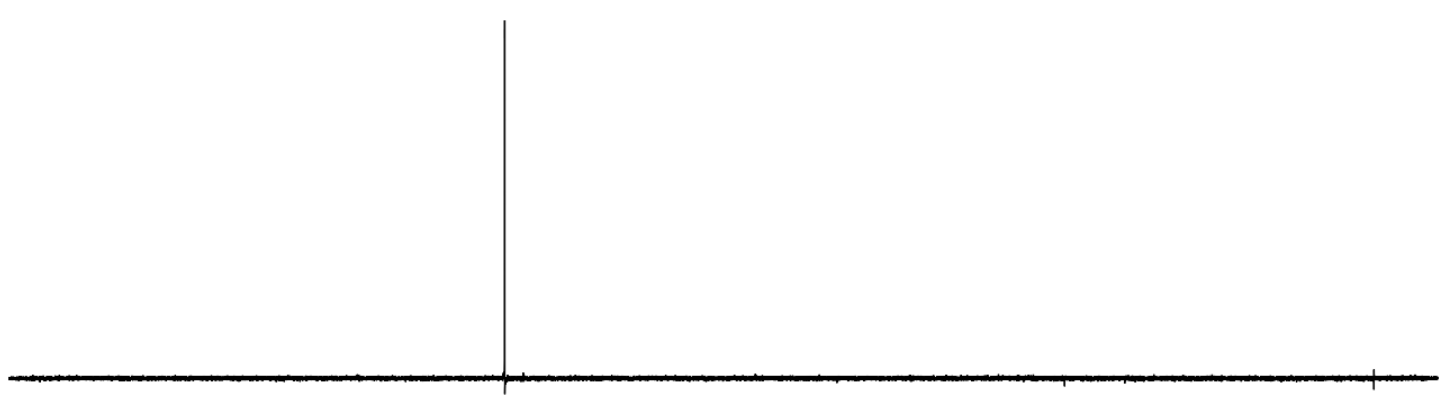

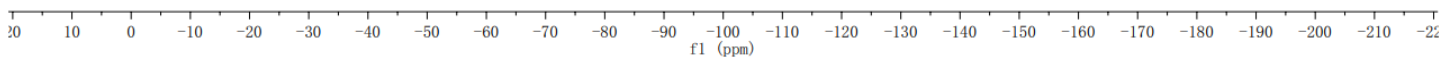


06102020-ch-s-6.1.1.1r -

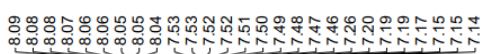<smiles>O=C(Sc1ccccc1)c1ccc(F)cc1</smiles>

$1 f$

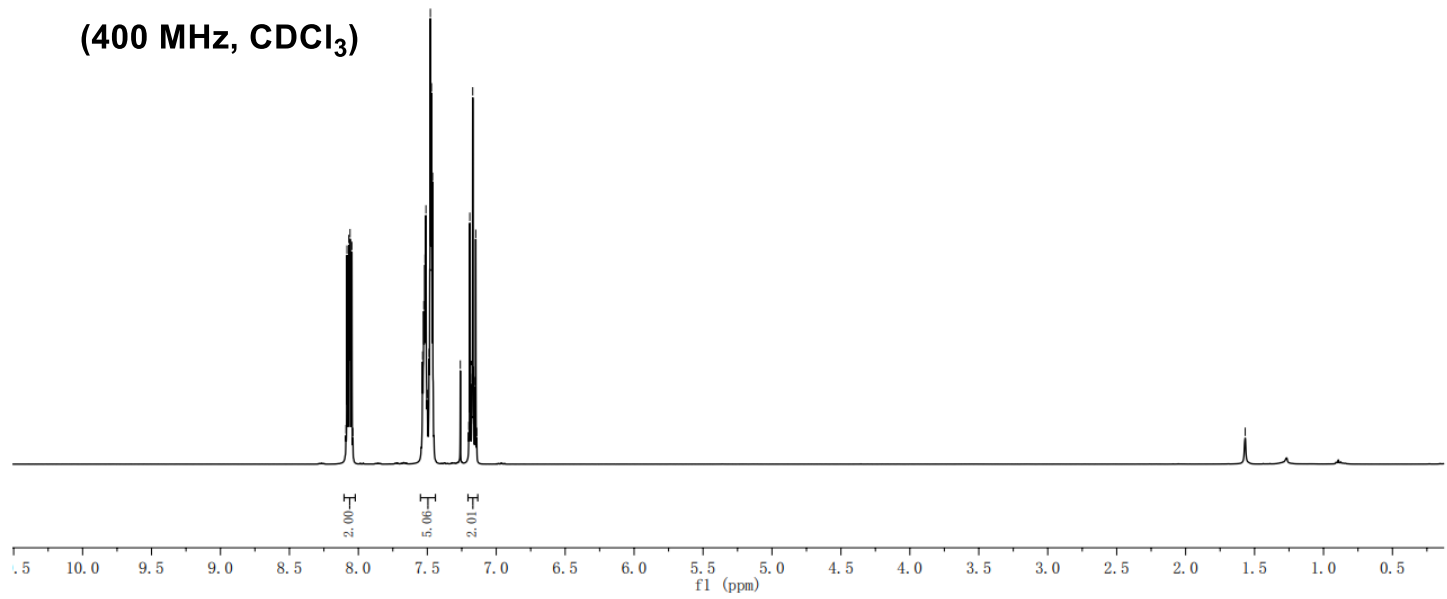

06102020-ch-s-6.2.1.1r -
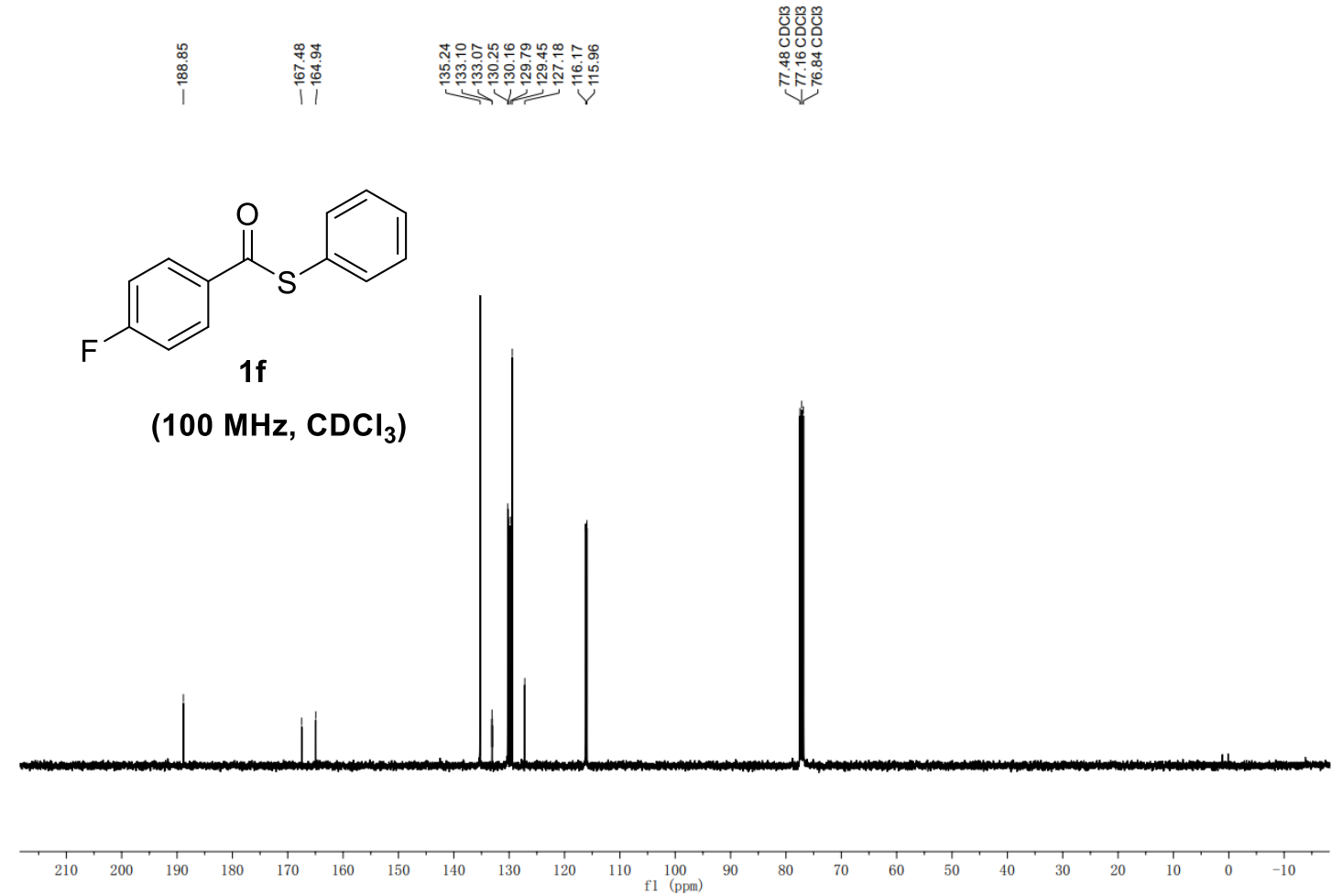
07232020-ch-s-6.1.1.1r -

$$
\frac{E}{i}
$$<smiles>O=C(Sc1ccccc1)c1ccc(F)cc1</smiles>

(376 MHz, $\mathrm{CDCl}_{3}$ )

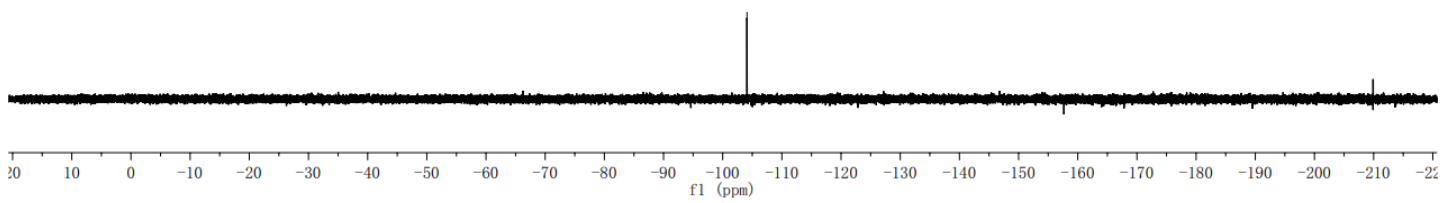




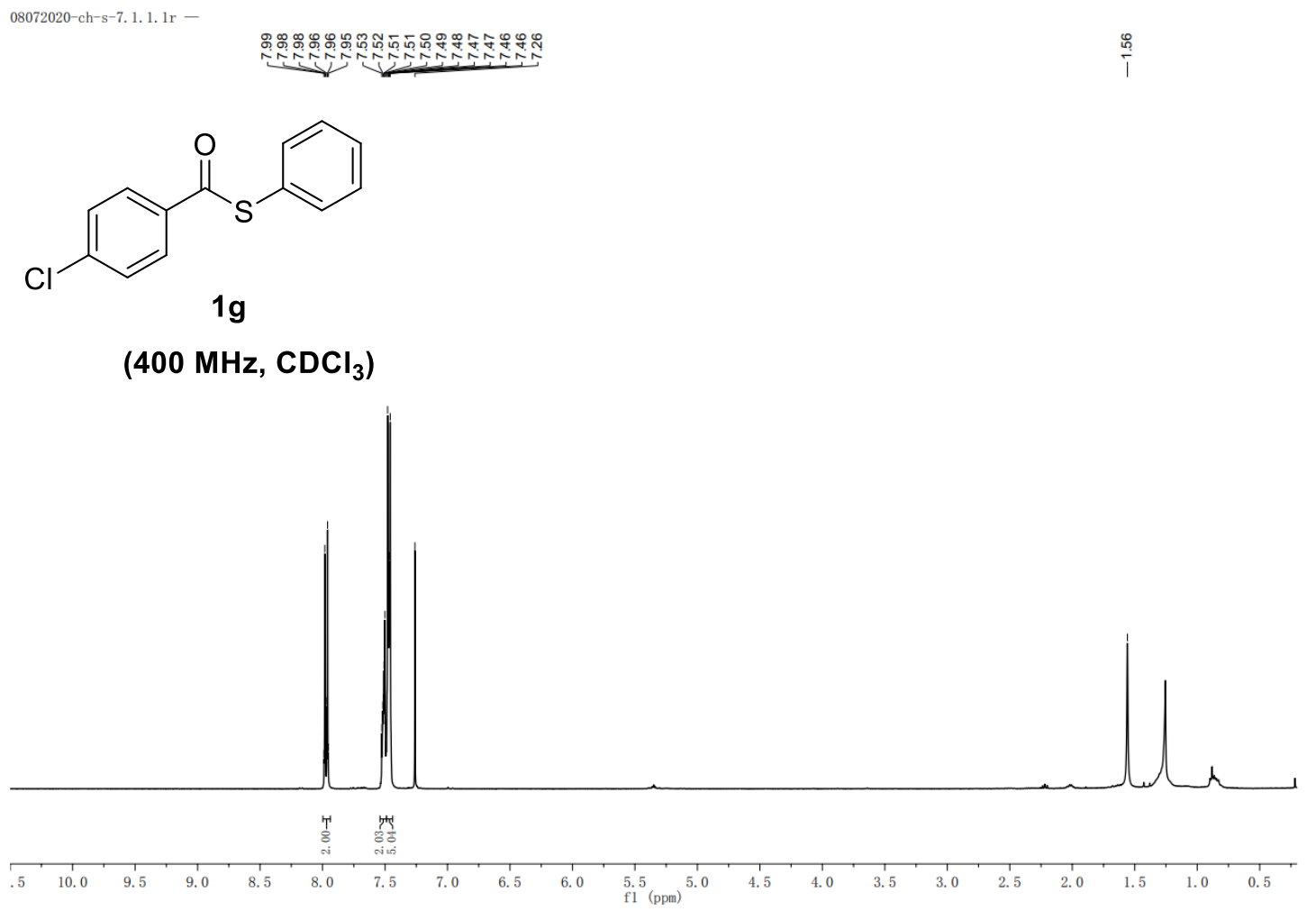

08072020-ch-s-7.6.1.1r -

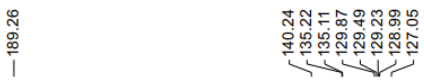<smiles>O=C(Sc1ccccc1)c1ccc(Cl)cc1</smiles>

19

(100 $\left.\mathrm{MHz} \mathrm{CDCl}_{3}\right)$

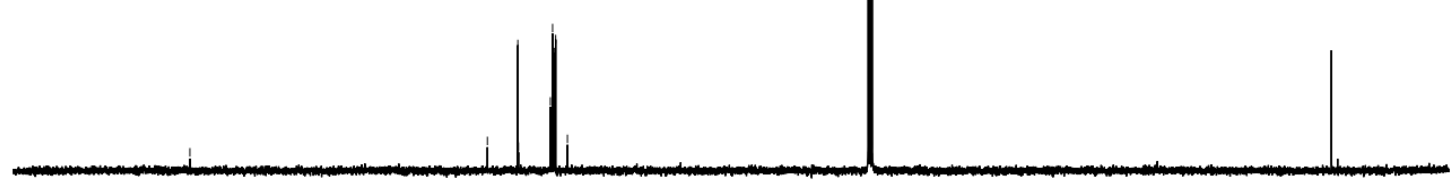


<smiles>N#Cc1ccc(C(=O)Sc2ccccc2)cc1</smiles>

$1 \mathrm{~h}$

(400 MHz, $\mathrm{CDCl}_{3}$ )
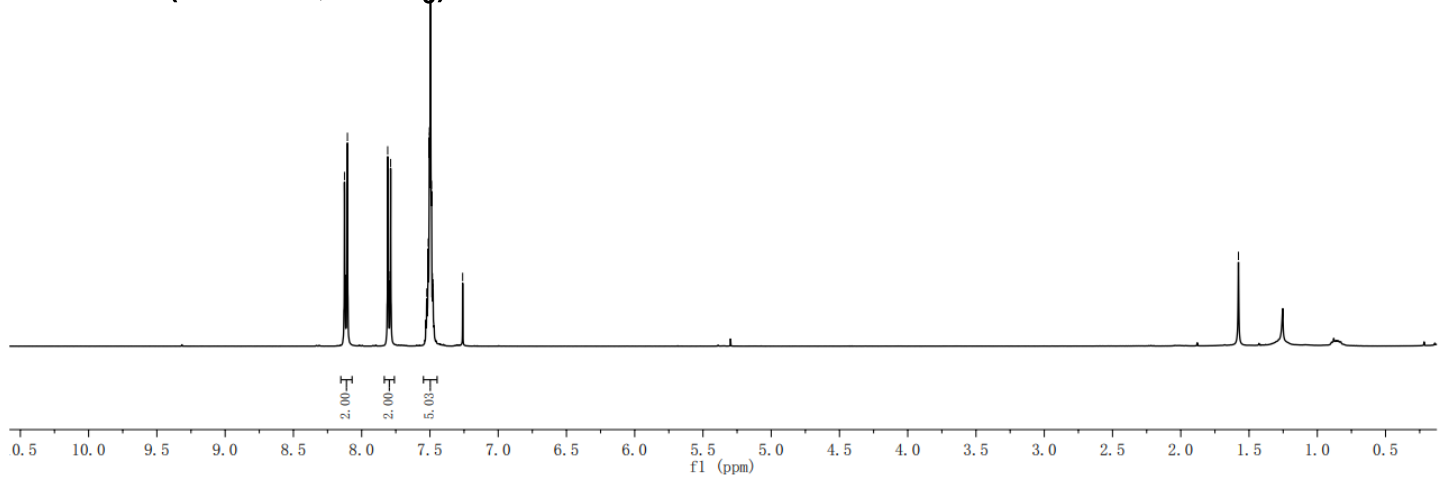

07292020-ch-STM-101. 2. 1. 1r -

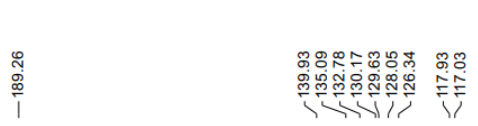<smiles>N#Cc1ccc(C(=O)Sc2ccccc2)cc1</smiles>

(100 MHz, $\left.\mathrm{CDCl}_{3}\right)$
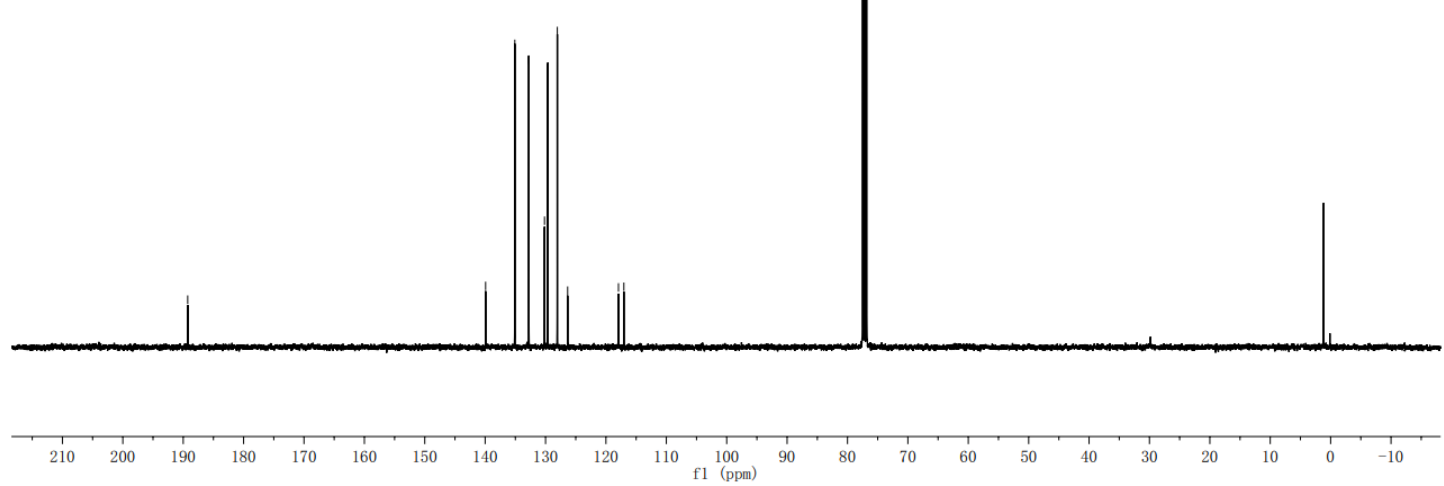


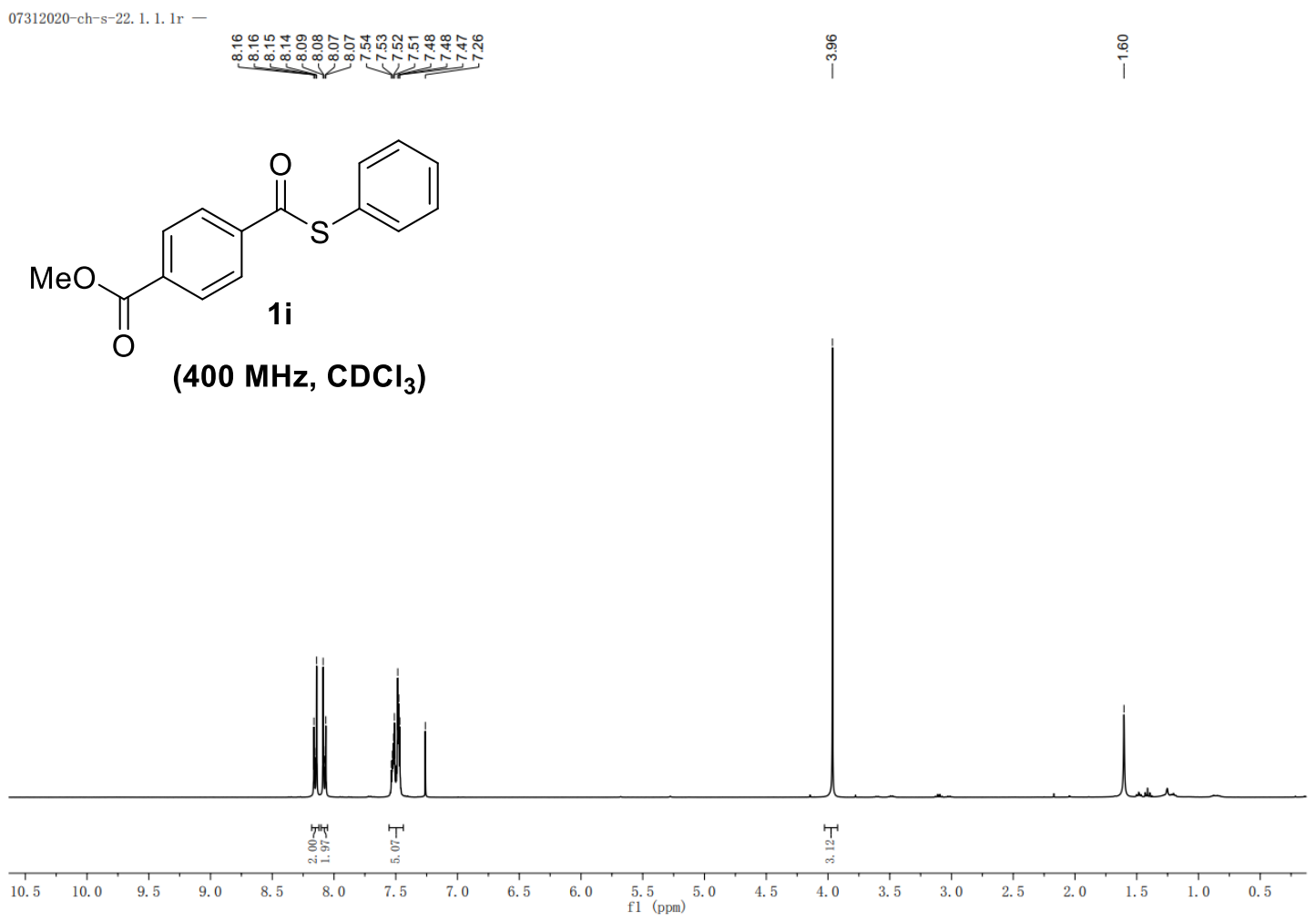

07312020-ch-s-22. 3.1.1r -

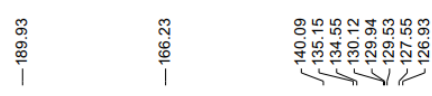<smiles>COC(=O)c1ccc(C(=O)Sc2ccccc2)cc1</smiles>

$\left(100 \mathrm{MHz}^{\left.\mathrm{CDCl}_{3}\right)}\right.$

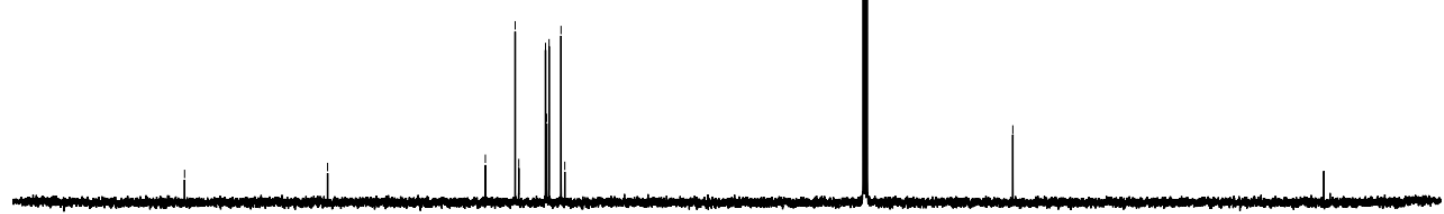

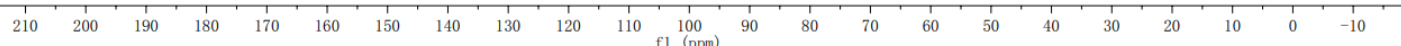


07292020-ch-STM-102. 1. 1. 1r-<smiles>CC(=O)c1ccc(C(=O)Sc2ccccc2)cc1</smiles>

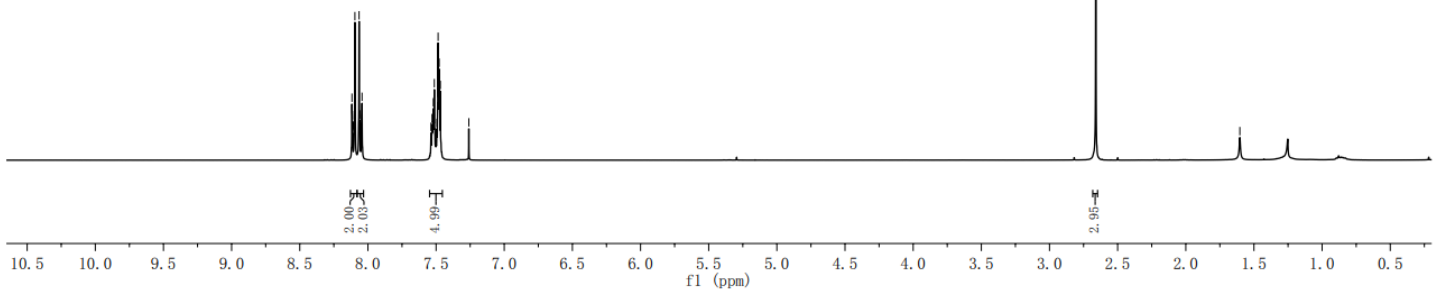

07292020-ch-STM-102.2.1.1r -

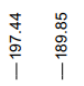

우음ำ

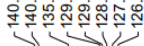<smiles>CC(=O)c1ccc(C(=O)Sc2ccccc2)cc1</smiles>

$\left(100 \mathrm{MHz}, \mathrm{CDCl}_{3}\right)$

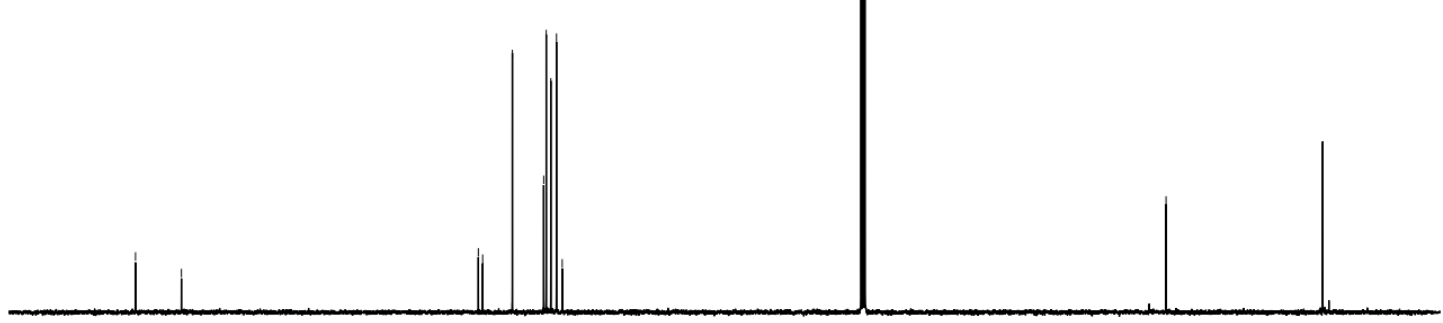

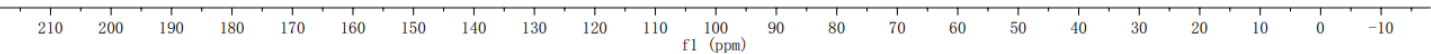


<smiles>Cc1ccccc1C(=O)Sc1ccccc1</smiles>

(400 MHz, $\mathrm{CDCl}_{3}$ )

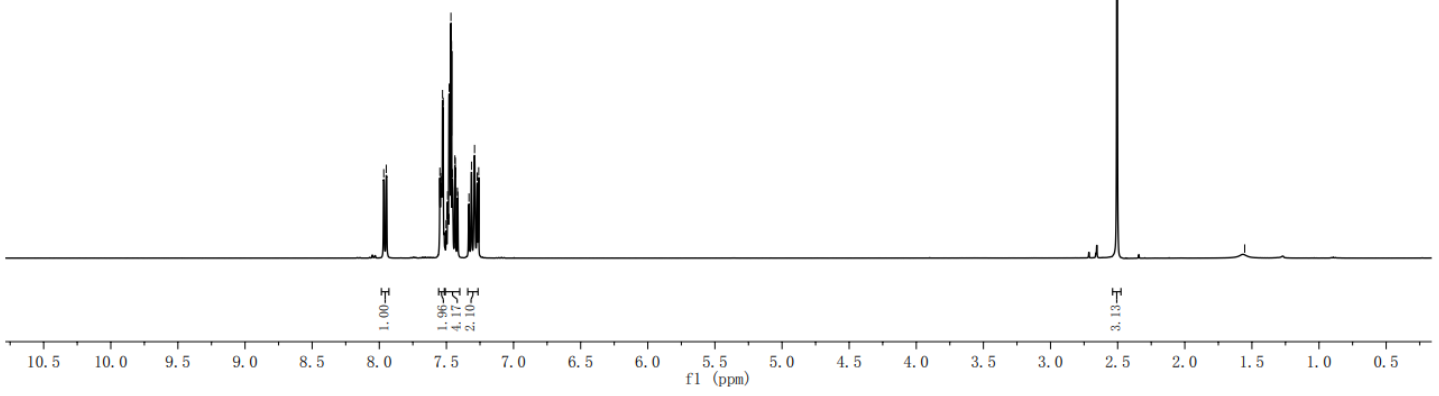

06152020-ch-s-2.2.1.1r -
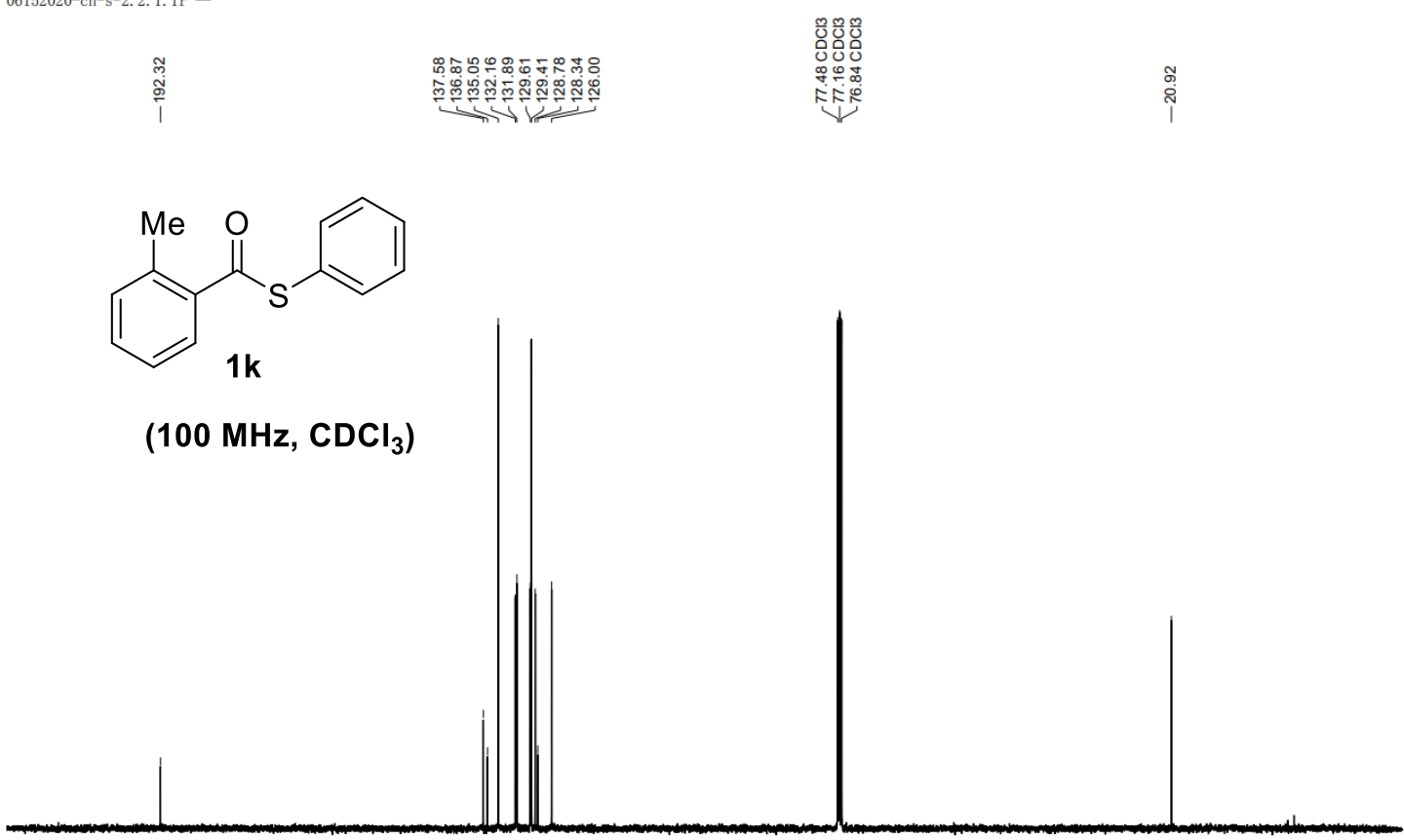
06152020-ch-s-8.1.1.1r -

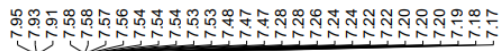<smiles>O=C(Sc1ccccc1)c1ccccc1F</smiles>

11

$\left(400 \mathrm{MHz}, \mathrm{CDCl}_{3}\right)$
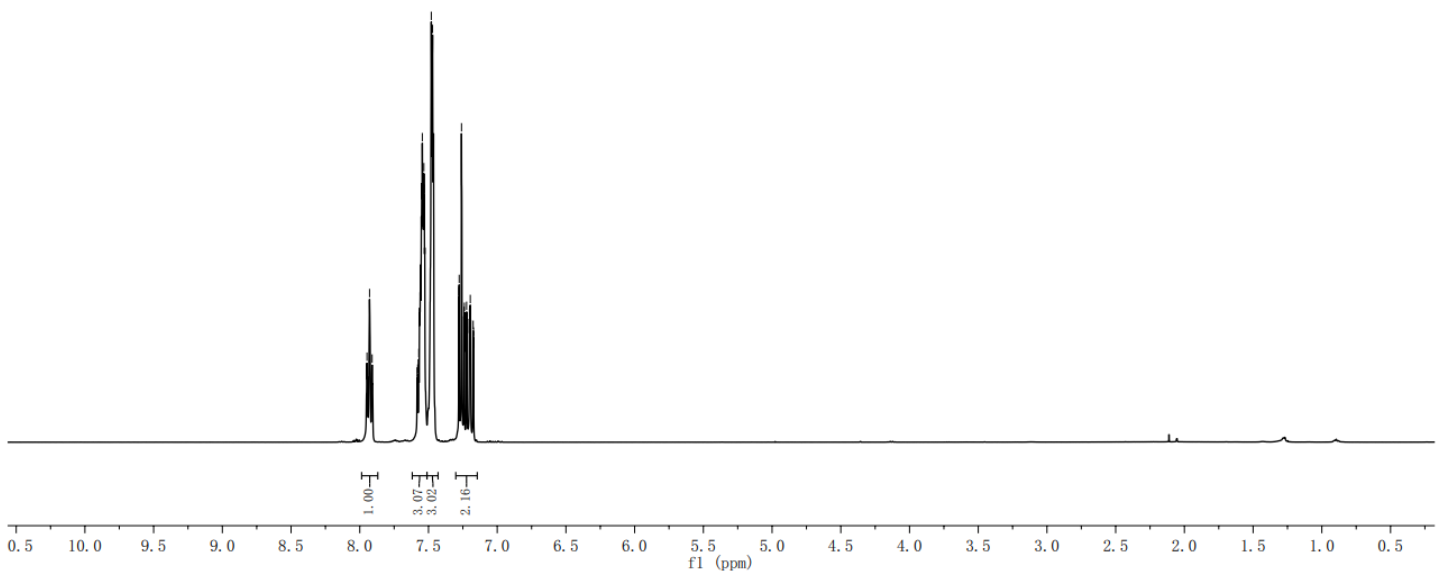

06152020-ch-s-8.2.1.1r -

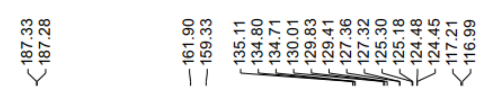

(N)

11

$\left(100 \mathrm{MHz} \mathrm{CDCl}_{3}\right)$

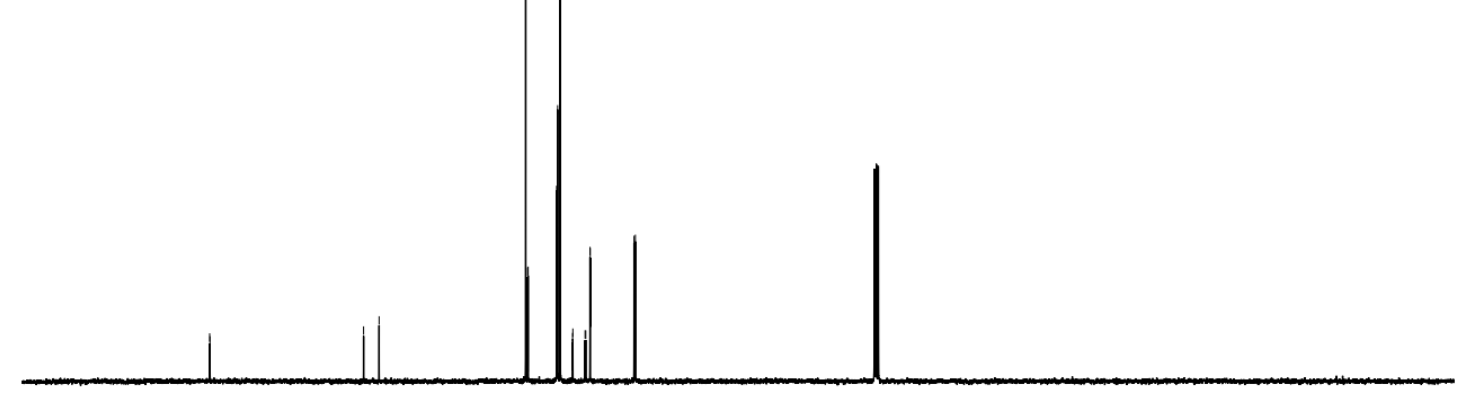

SI-15 
07232020-ch-s-8.1.1.1r -<smiles>O=C(Sc1ccccc1)c1ccccc1F</smiles>

(376 MHz, $\mathrm{CDCl}_{3}$ )

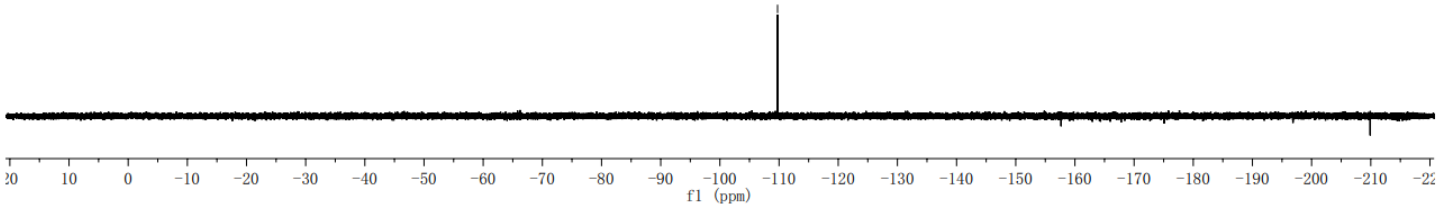


06152020-ch-s-9.1.1.1r -

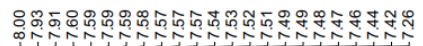

$\underbrace{\mathrm{O}}_{1 \mathrm{~m}}$

(400 MHz, $\mathrm{CDCl}_{3}$ )

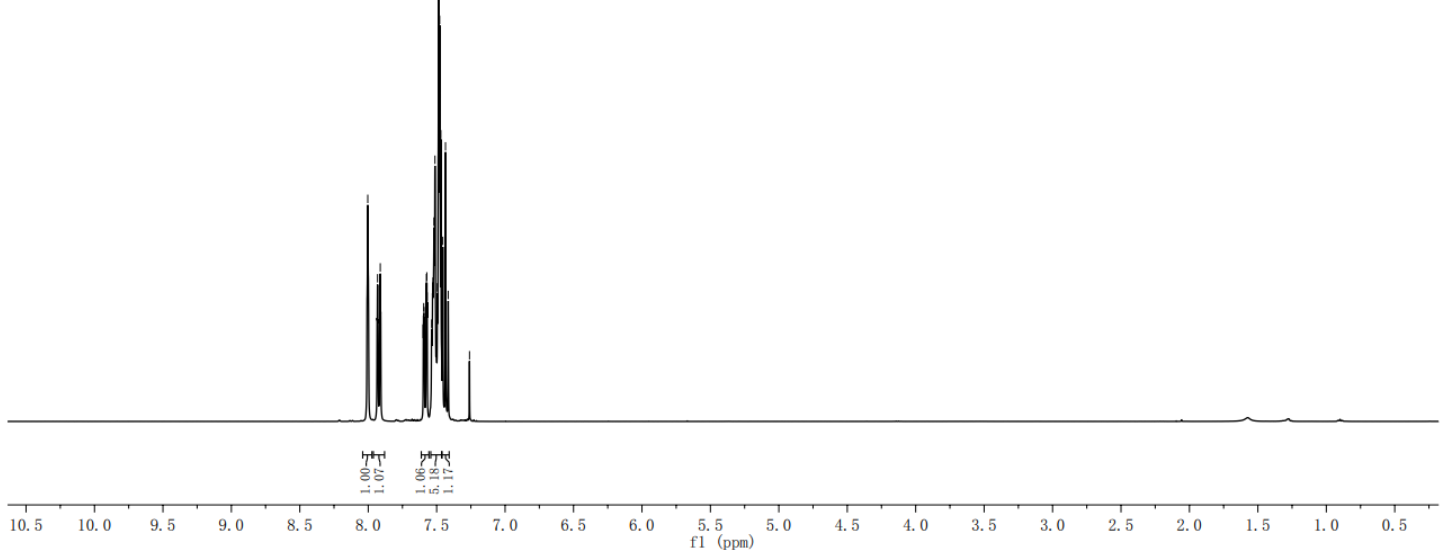

06152020-ch-s-9.2.1.1r -
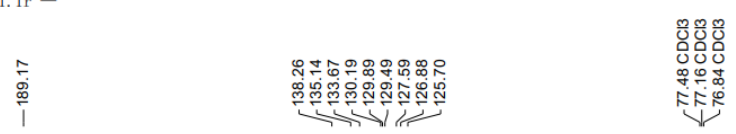<smiles>O=C(Sc1ccccc1)c1cccc(Cl)c1</smiles>

$1 \mathrm{~m}$

(100 MHz, $\mathrm{CDCl}_{3}$ )
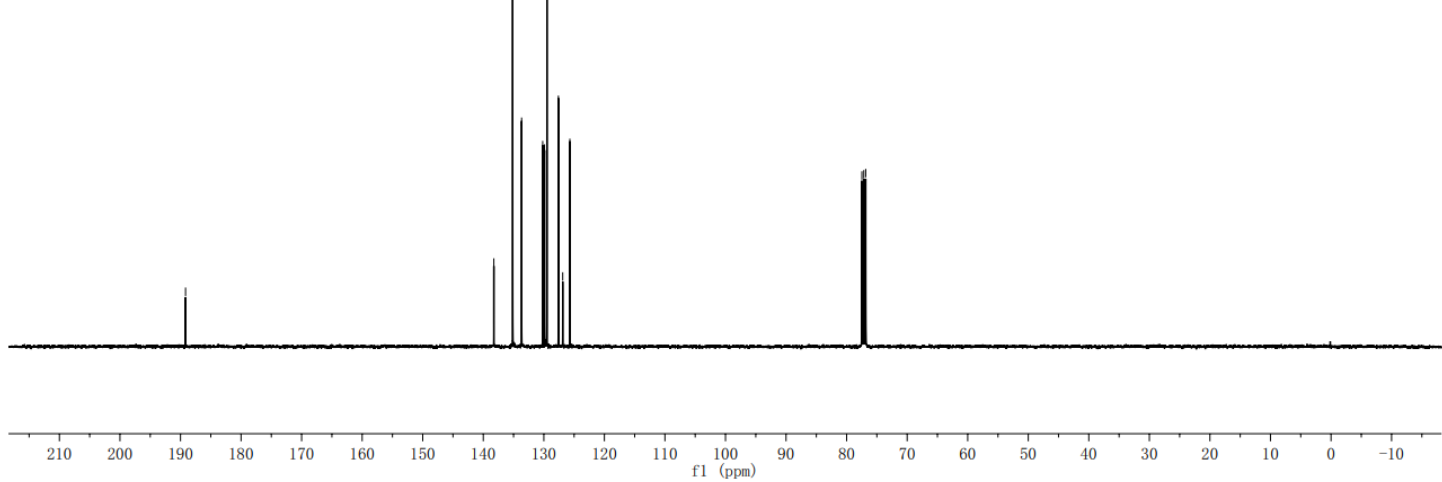
06152020-ch-s-10.1.1. 1r -

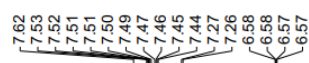

$\underbrace{1 n}_{0}$

(400 MHz, $\mathrm{CDCl}_{3}$ )

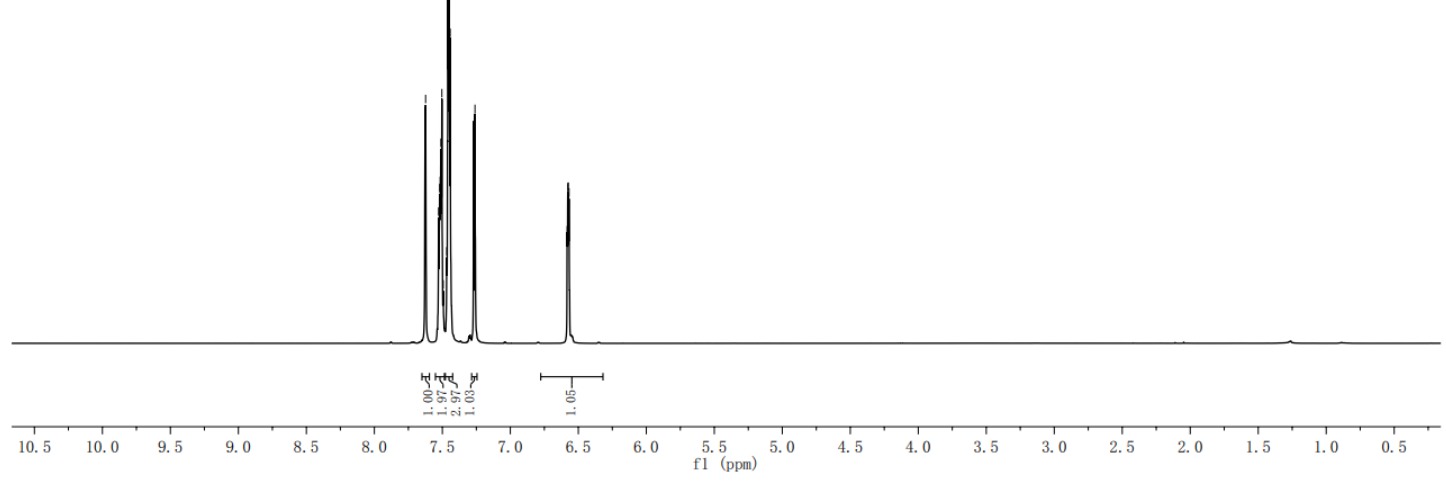

06152020-ch-s-10. 2.1. 1r -

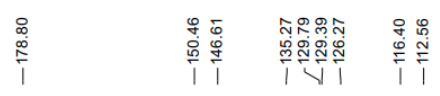<smiles>O=C(Sc1ccccc1)c1ccco1</smiles>

$\left(100 \mathrm{MHz}, \mathrm{CDCl}_{3}\right)$
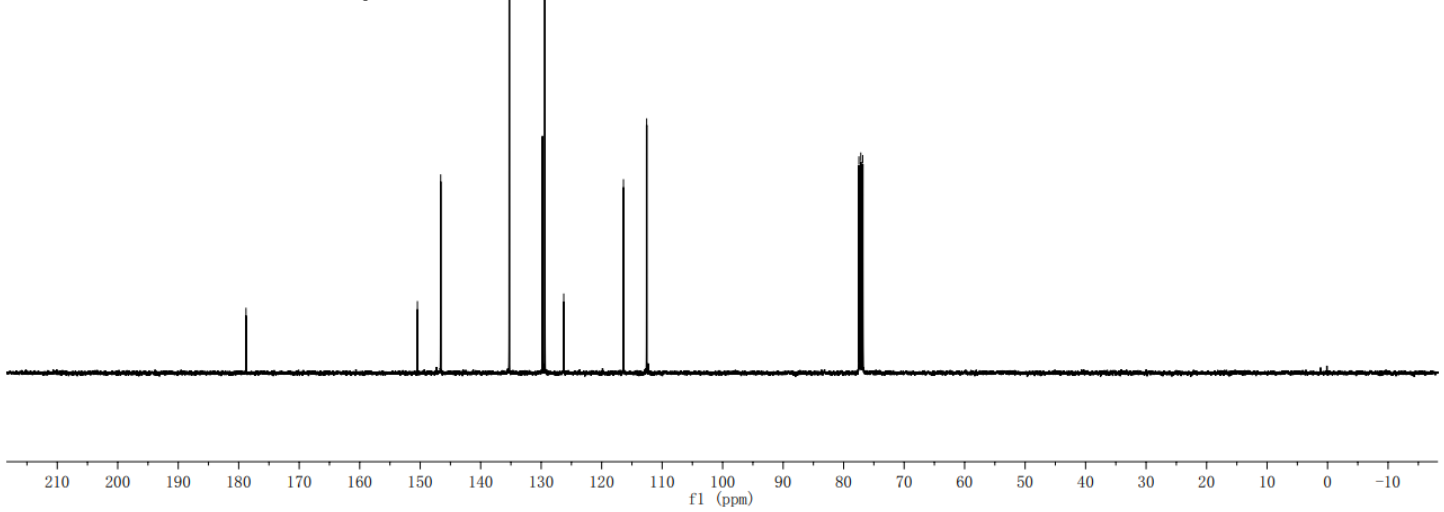


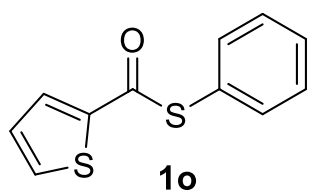

(400 $\mathrm{MHz}, \mathrm{CDCl}_{3}$ )

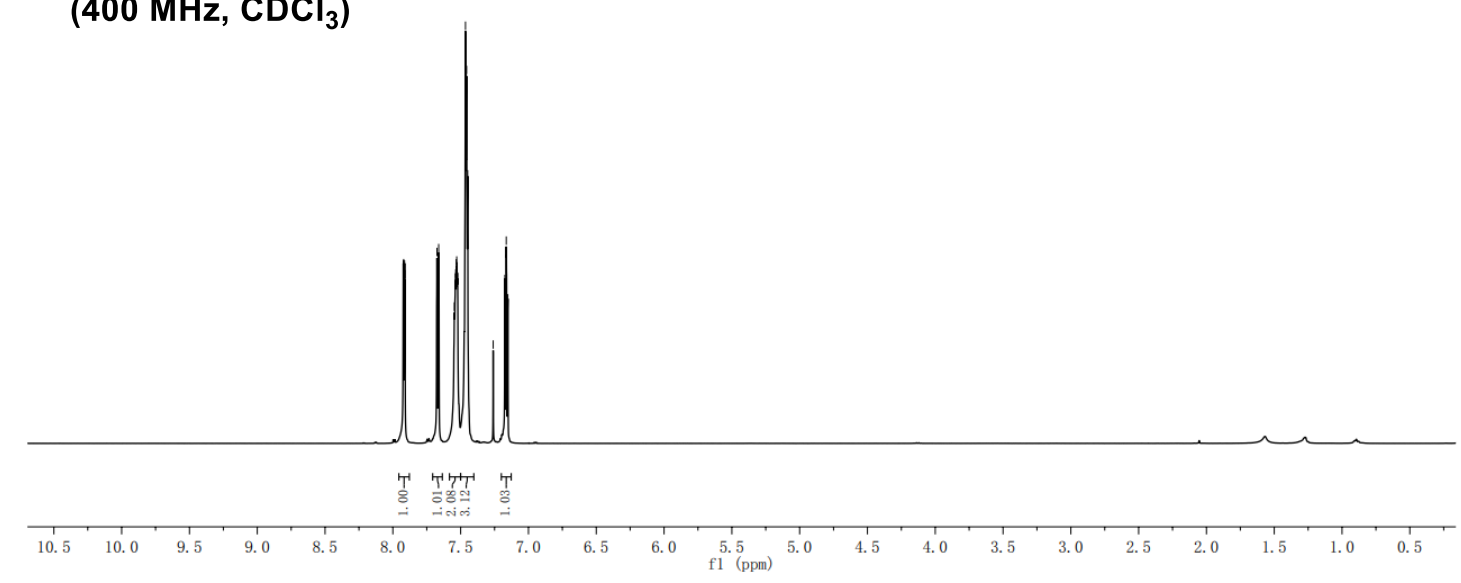

06152020-ch-s-11. 2.1.1r -
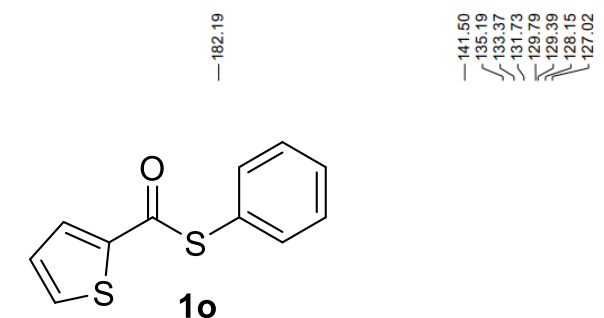

$\left(100 \mathrm{MHz}, \mathrm{CDCl}_{3}\right)$
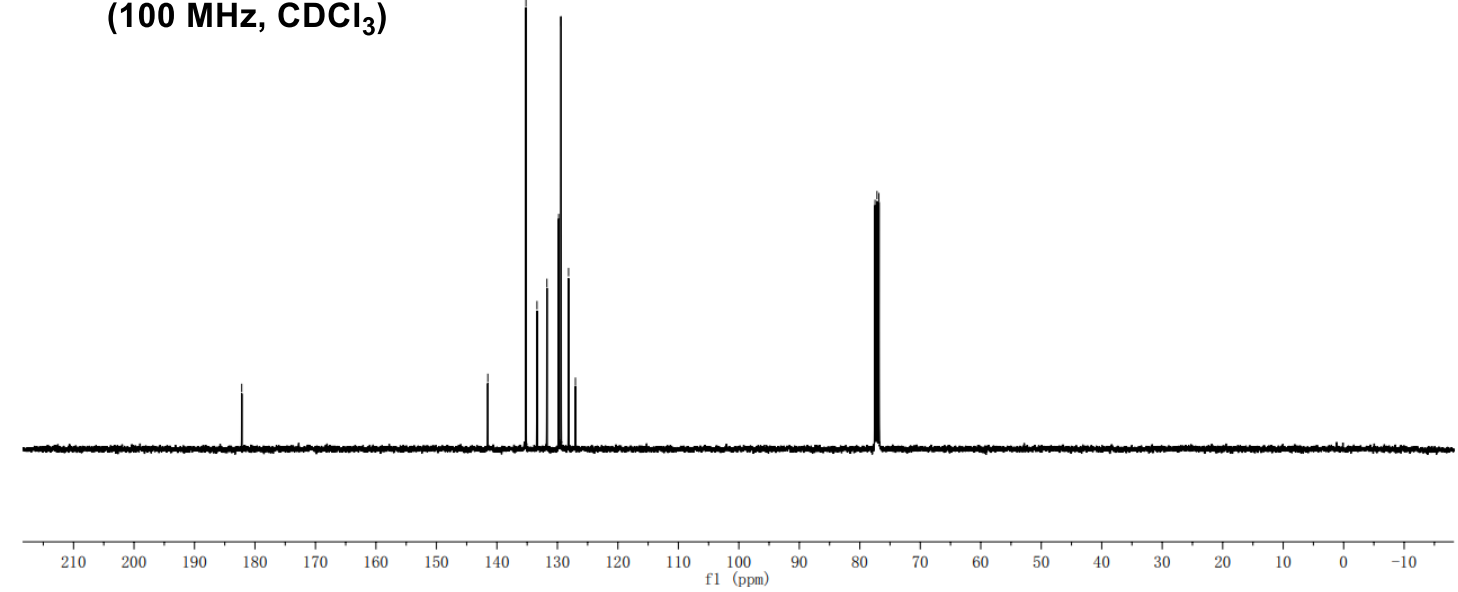
07312020-ch-s-24. 1.1. 1r -

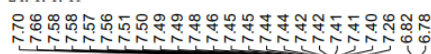<smiles>O=C(/C=C/c1ccccc1)Sc1ccccc1</smiles>

(400 $\mathrm{MHz}, \mathrm{CDCl}_{3}$ )

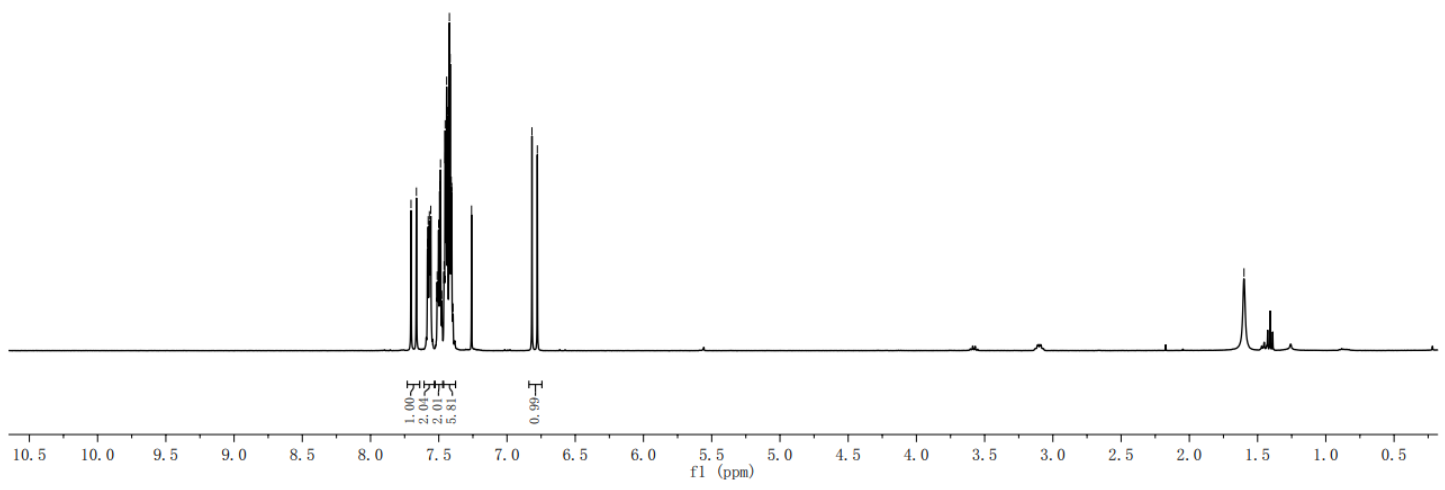

07312020-ch-s-24. 3. 1. 1r -
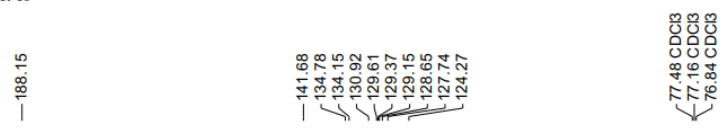<smiles>O=C(/C=C/c1ccccc1)Sc1ccccc1</smiles>

(100 $\left.\mathrm{MHz}, \mathrm{CDCl}_{3}\right)$
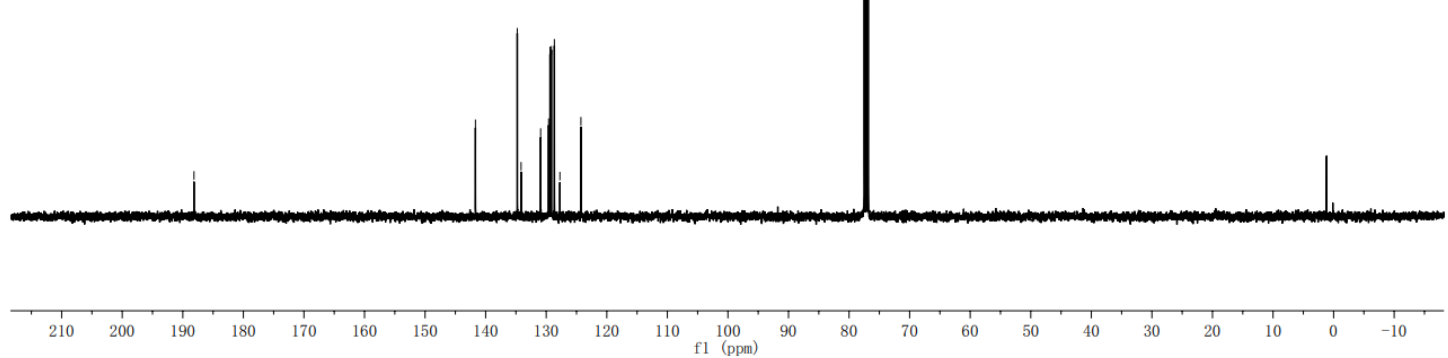
<smiles>Cc1ccc(SC(=O)c2ccccc2)cc1</smiles>

(400 $\mathrm{MHz} \mathrm{CDCl}_{3}$ )

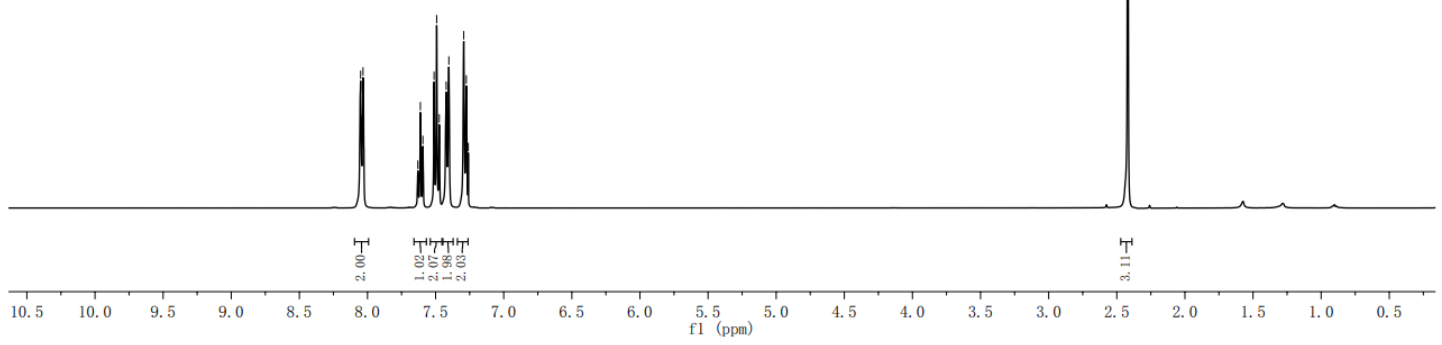

06152020-ch-s-12.2.1. 1r -

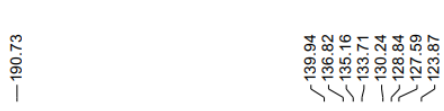<smiles>Cc1ccc(SC(=O)c2ccccc2)cc1</smiles>
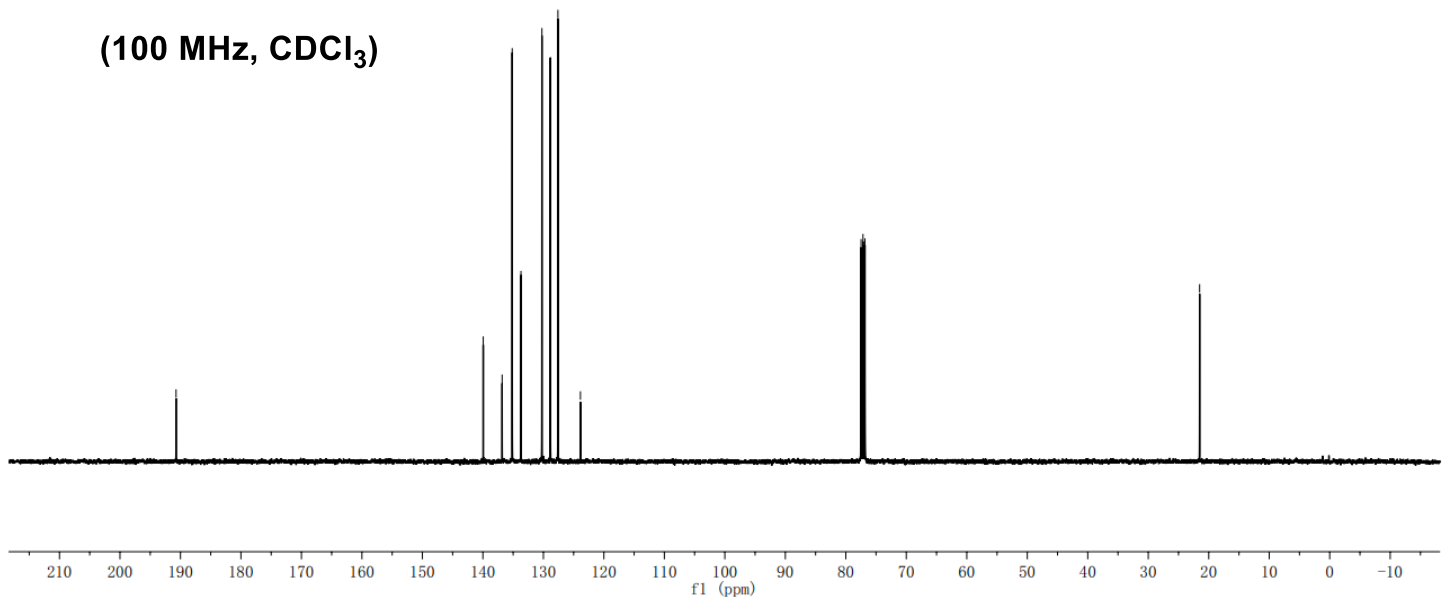
<smiles>COc1ccc(SC(=O)c2ccccc2)cc1</smiles>

(400 MHz, $\mathrm{CDCl}_{3}$ )

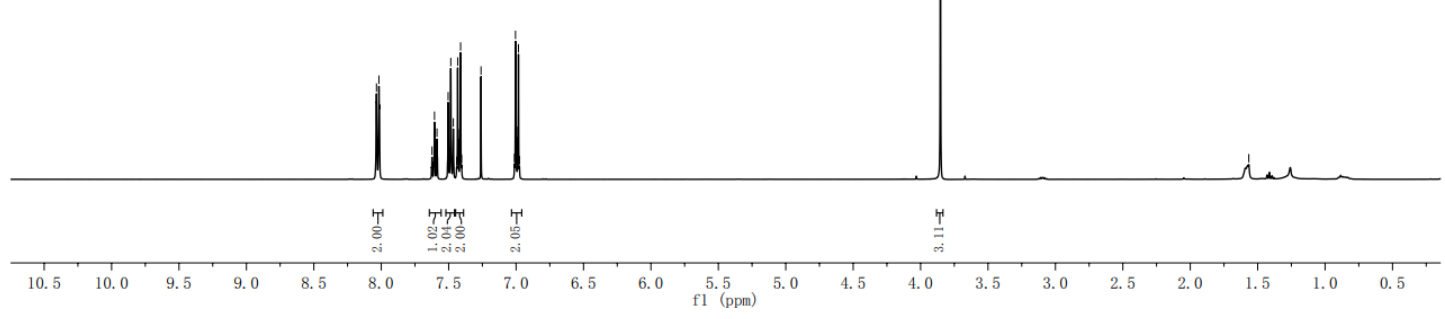

06152020-ch-s-13. 2.1.1r -

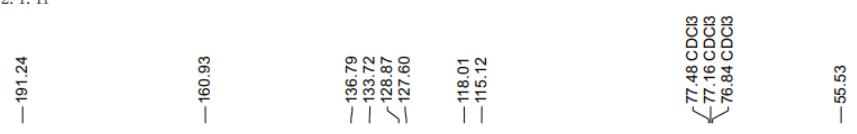<smiles>COc1ccc(SC(=O)c2ccccc2)cc1</smiles>

$\left(100 \mathrm{MHz}, \mathrm{CDCl}_{3}\right)$
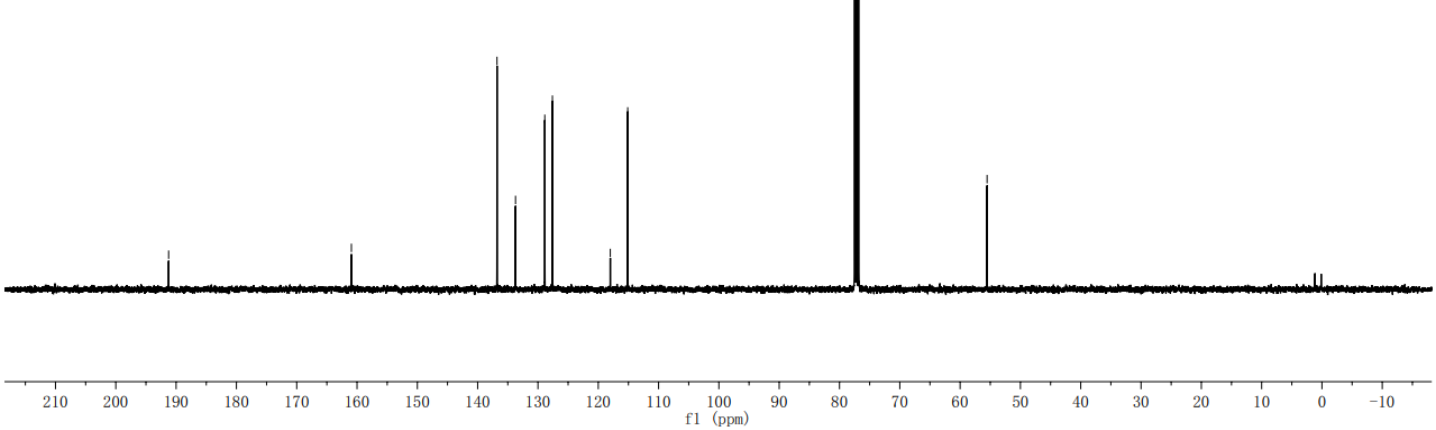
<smiles>O=C(Sc1ccc(C(F)(F)F)cc1)c1ccccc1</smiles>

(400 MHz, $\mathrm{CDCl}_{3}$ )

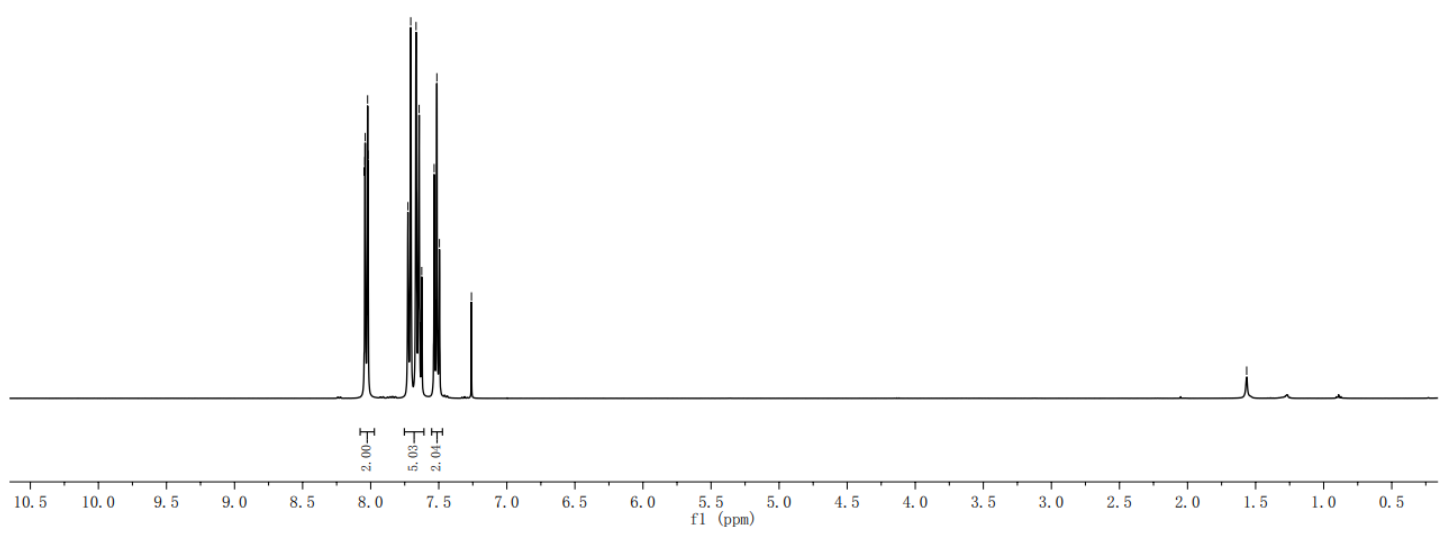

06152020-ch-s-14. 2.1.1r -

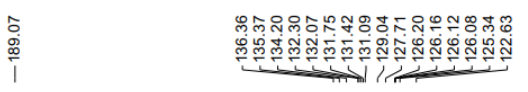<smiles>O=C(Sc1ccc(C(F)(F)F)cc1)c1ccccc1</smiles>

$\left(100 \mathrm{MHz}, \mathrm{CDCl}_{3}\right)$
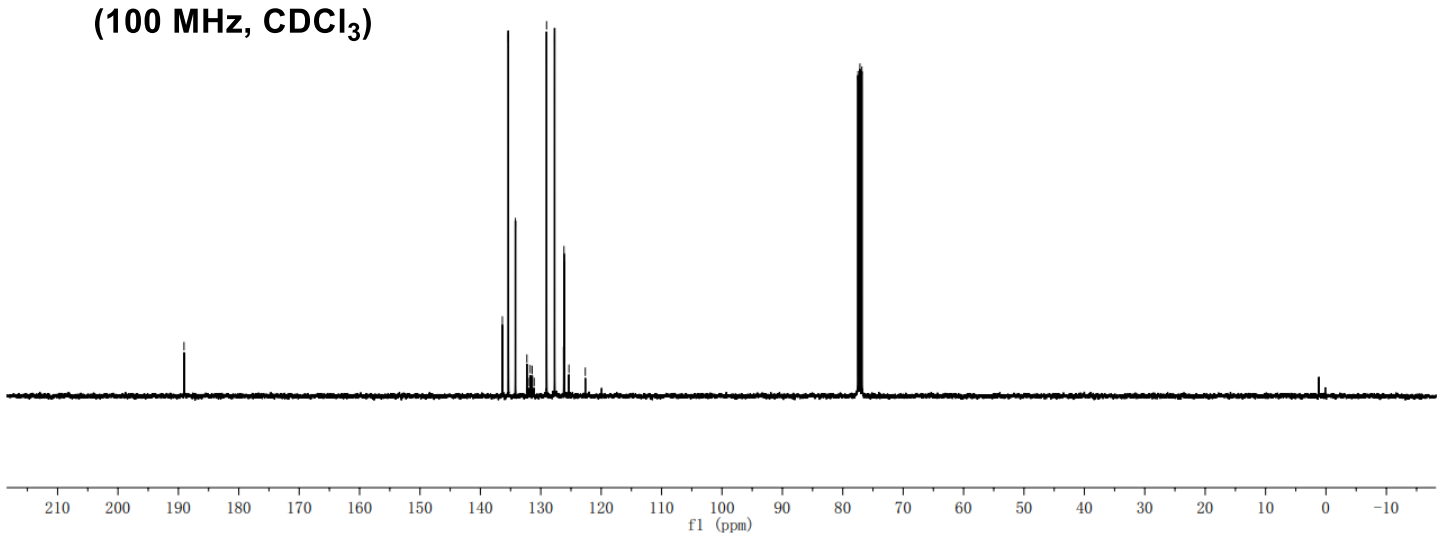


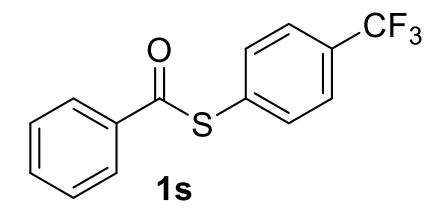

(376 MHz, $\mathrm{CDCl}_{3}$ )

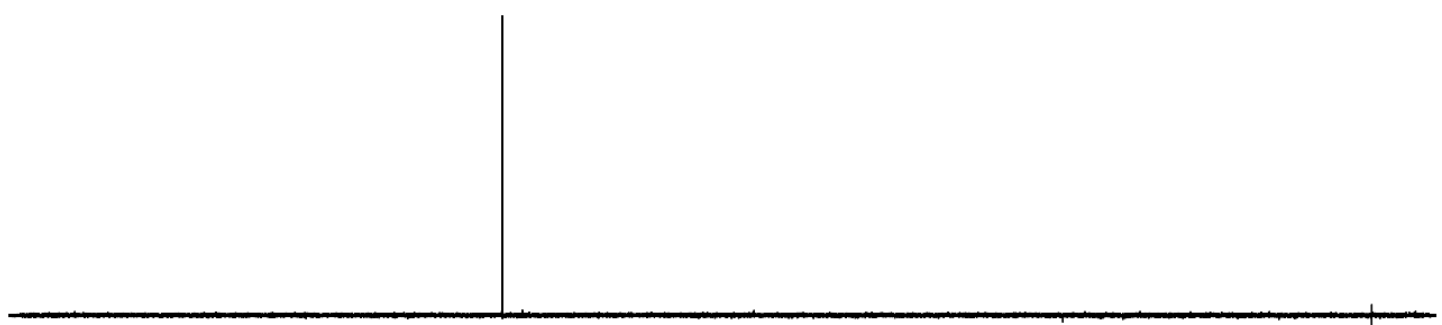

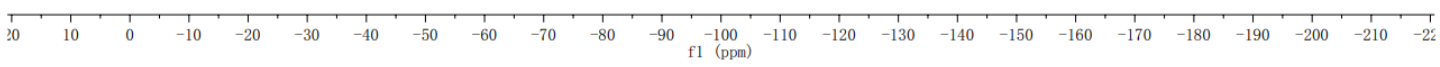


<smiles>O=C(Sc1ccc(F)cc1)c1ccccc1</smiles>

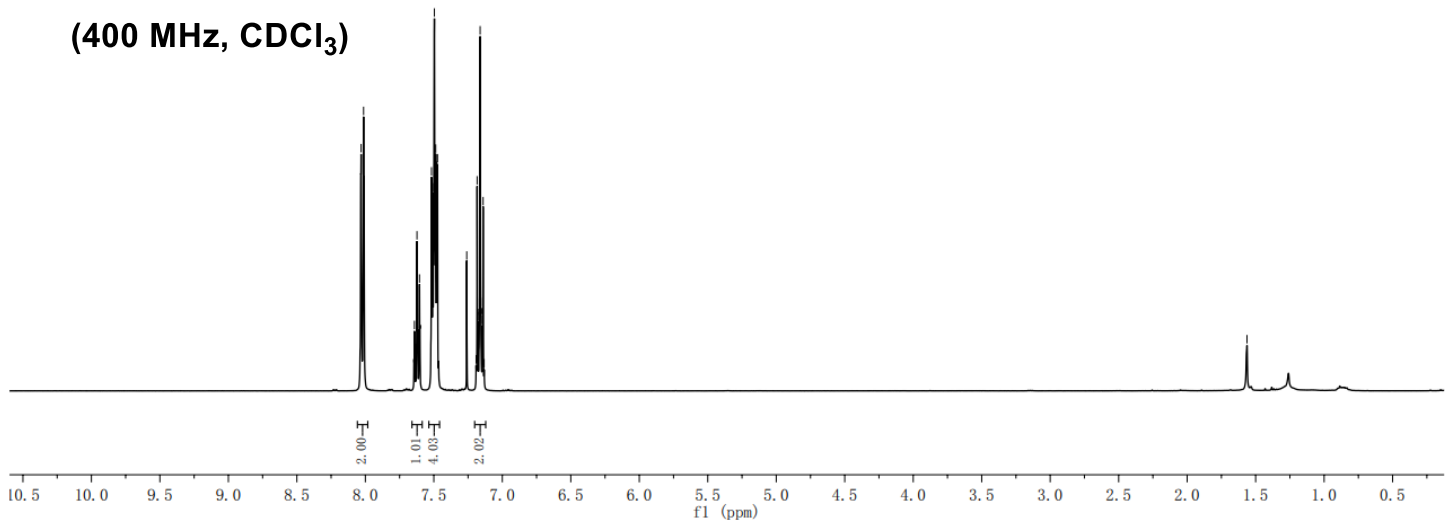

06152020-ch-s-15. 2.1. 1r -

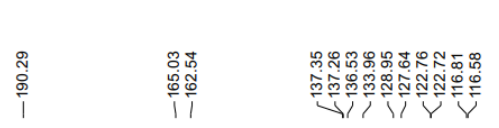<smiles>O=C(Sc1ccc(F)cc1)c1ccccc1</smiles>

$1 \mathrm{t}$

(100 $\mathrm{MHz}, \mathrm{CDCl}_{3}$ )

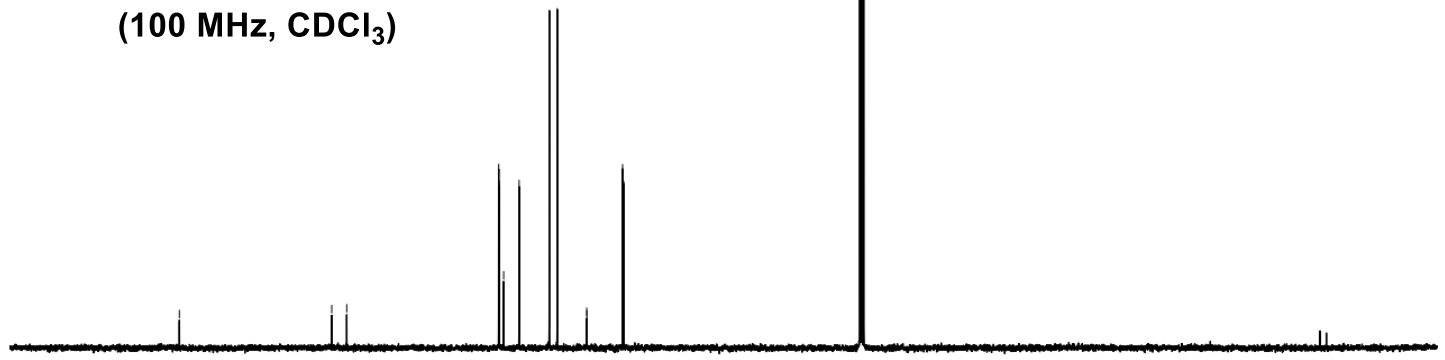

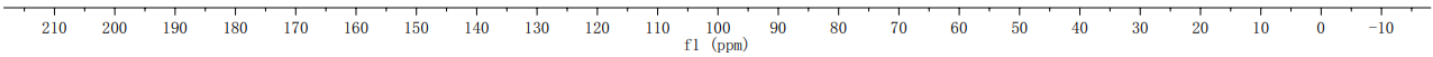




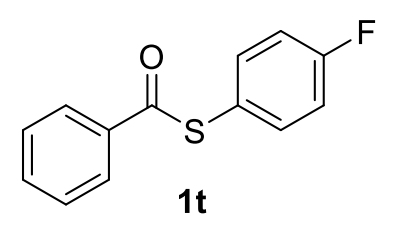

(376 MHz, $\mathrm{CDCl}_{3}$ )

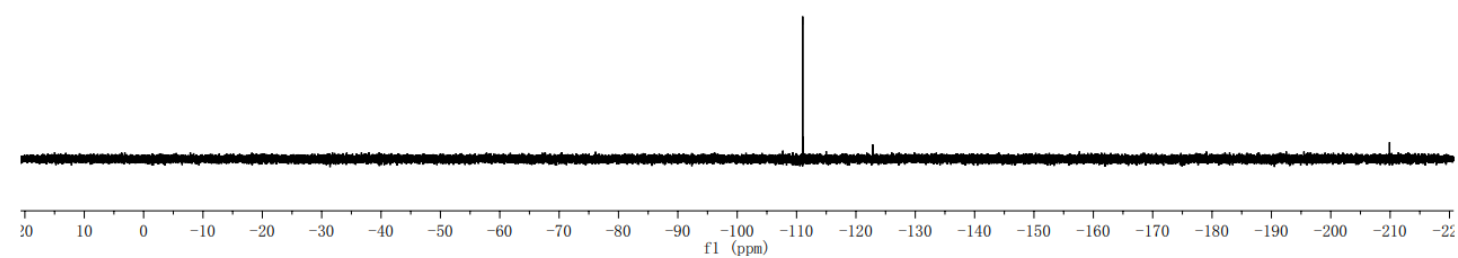




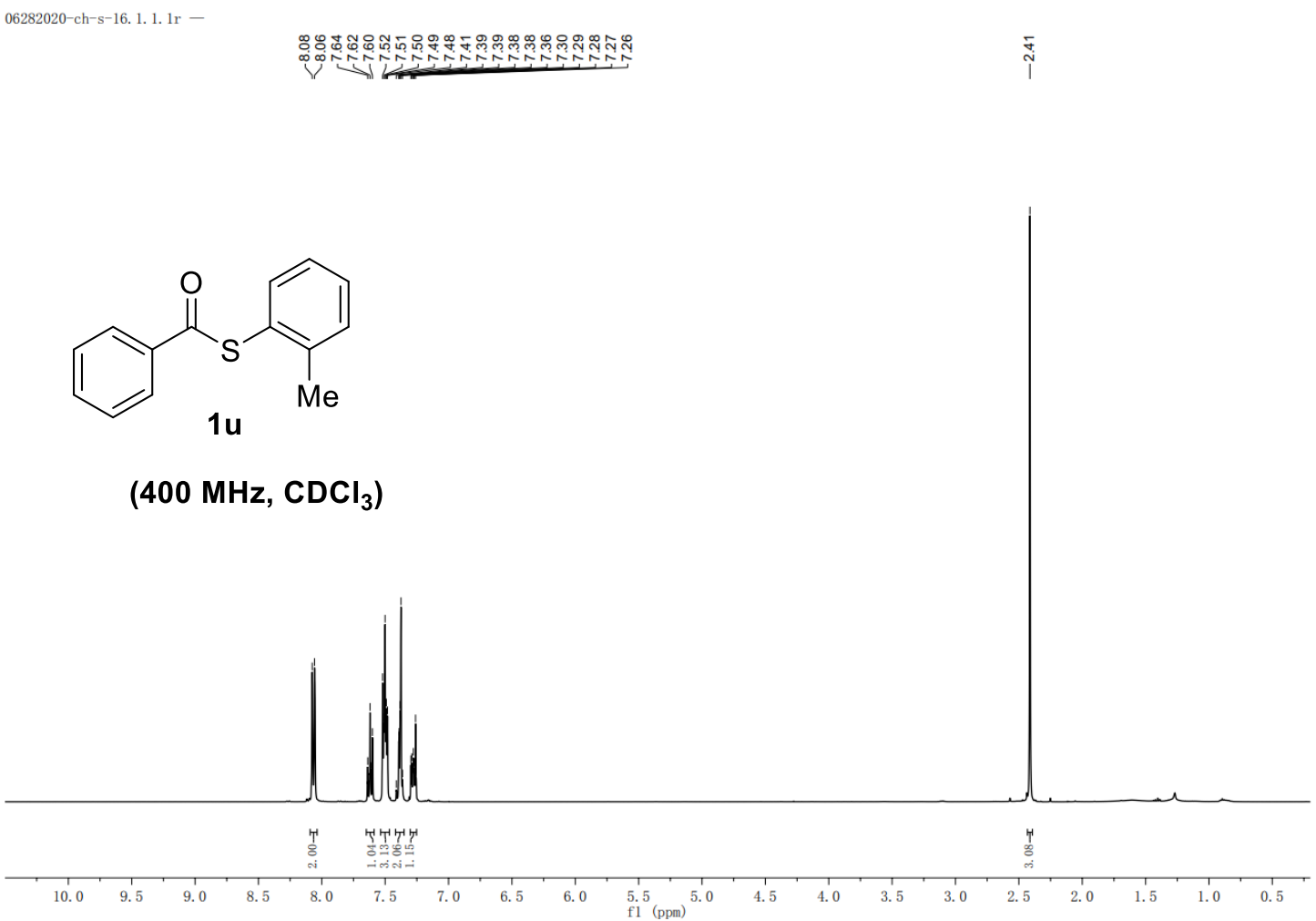

06282020-ch-s-16. 2.1.1r -
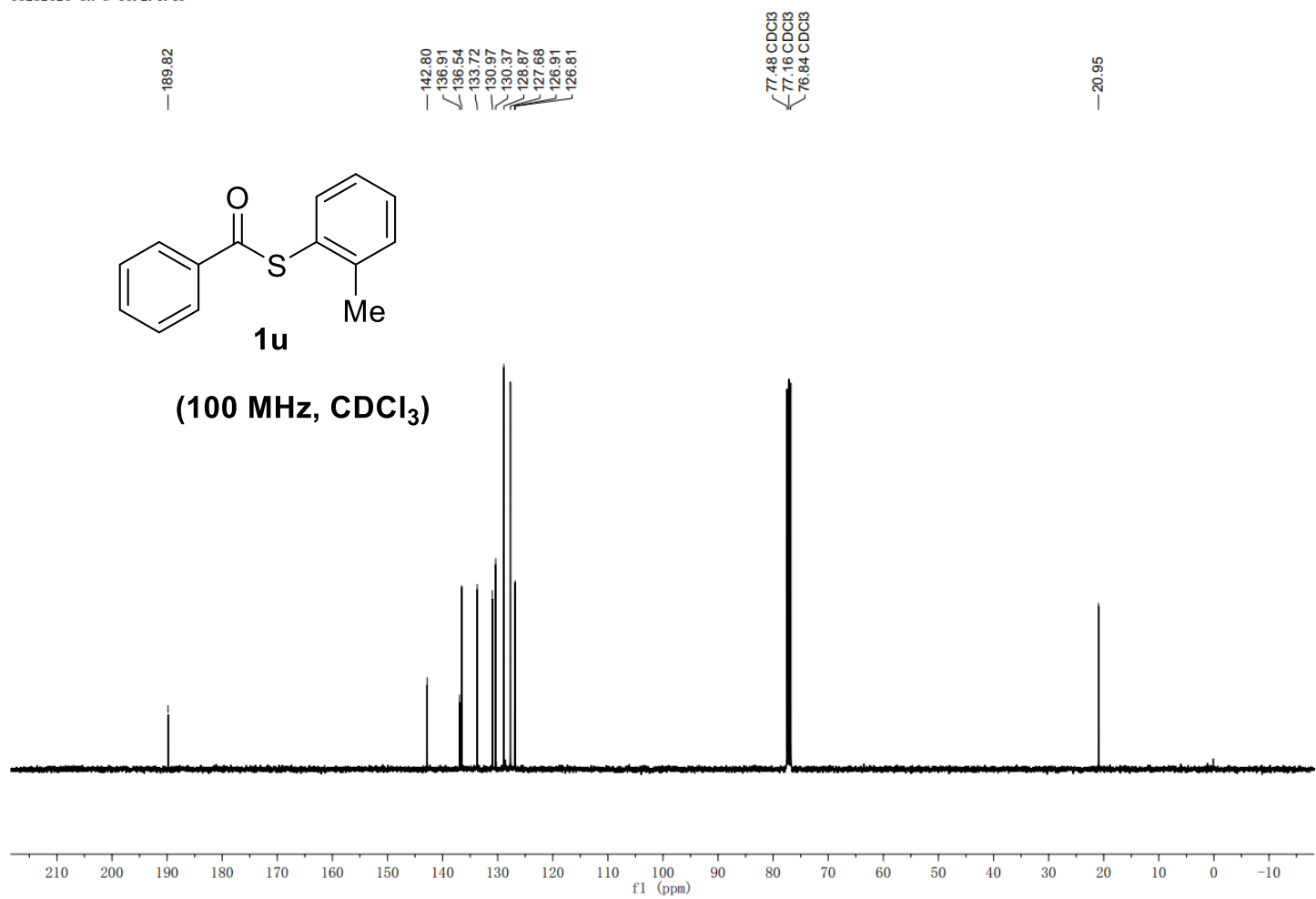
06282020-ch-s-17. 1. 1.1r -

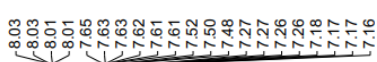

$\overbrace{1 v}^{O}$

(400 MHz, $\mathrm{CDCl}_{3}$ )

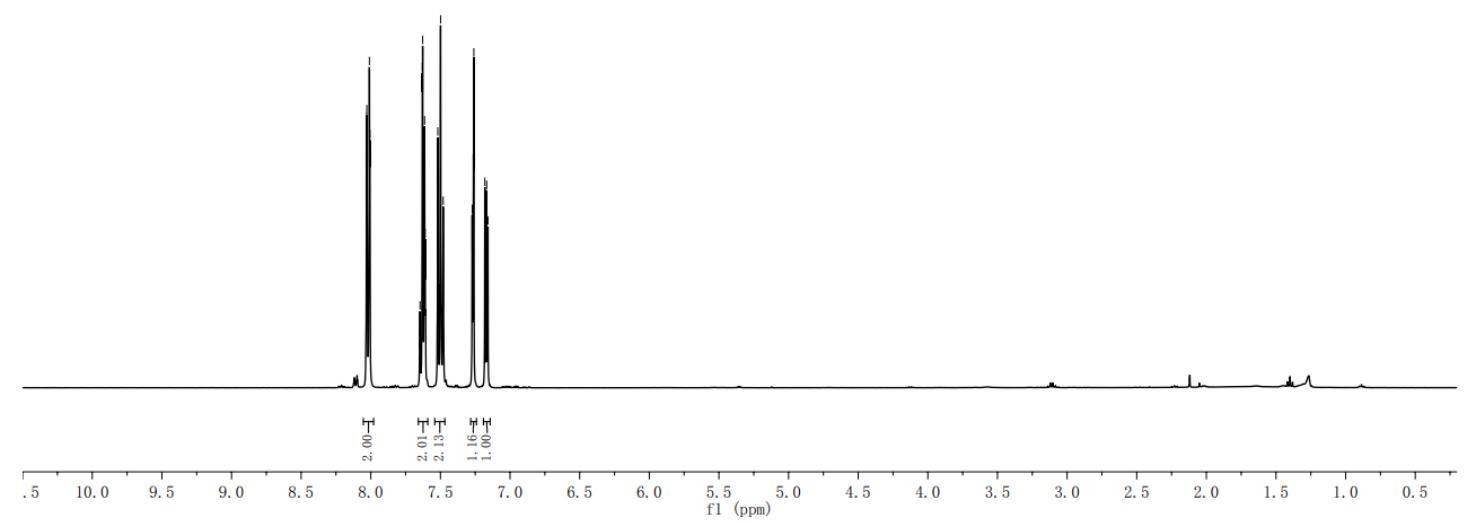

06282020-ch-s-17.2.1.1r -

$\stackrel{\substack{\circ \\ \infty}}{\stackrel{\infty}{+}}$

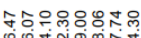

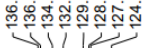<smiles>O=C(Sc1cccs1)c1ccccc1</smiles>

$\left(100 \mathrm{MHz}, \mathrm{CDCl}_{3}\right)$
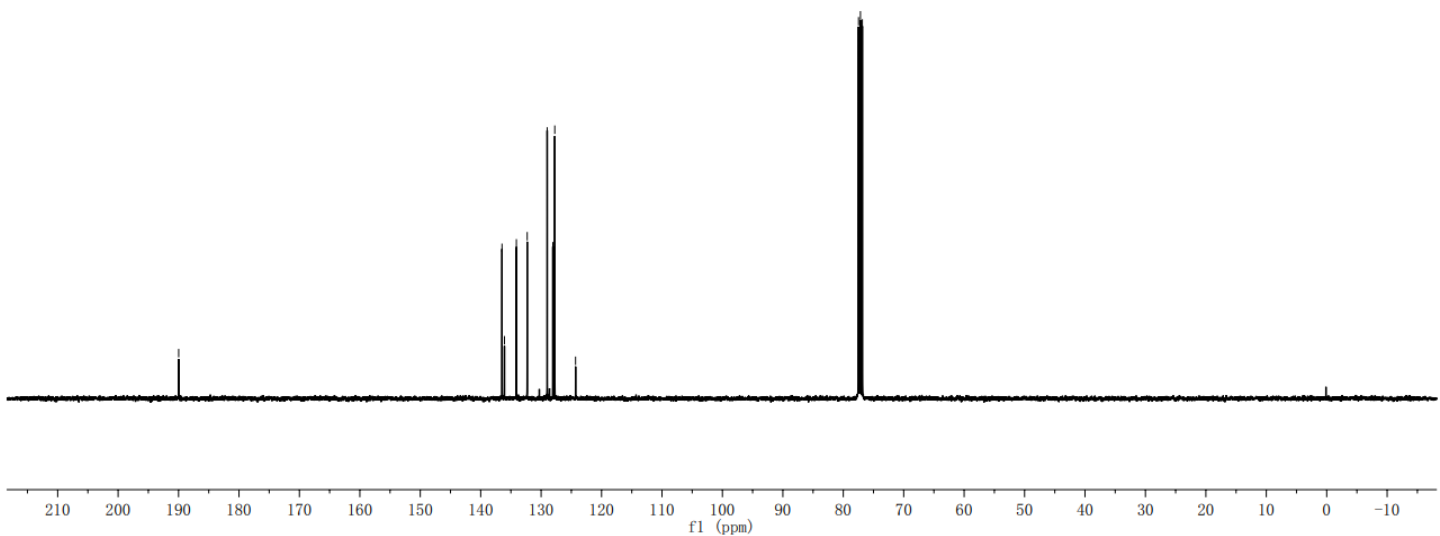
06282020-ch-s-18. 1. 1. 1r -

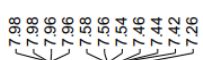

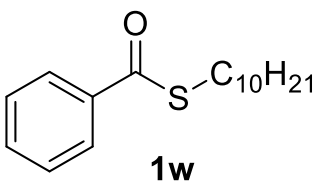

(400 MHz, $\mathrm{CDCl}_{3}$ )

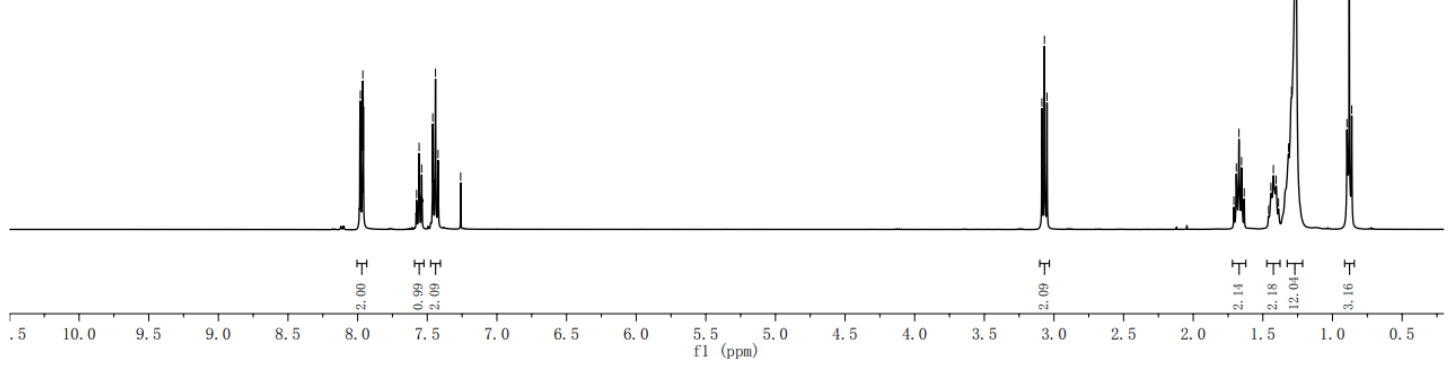

06282020-ch-s-18. 2.1.1r -

$$
\text { ঙ্లু }
$$

$$
\begin{aligned}
& \text { चल ल⿸户 }
\end{aligned}
$$

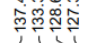

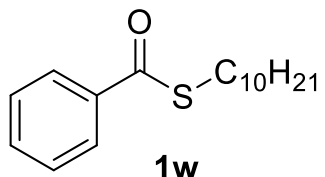

(100 $\mathrm{MHz} \mathrm{CDCl}_{3}$ )
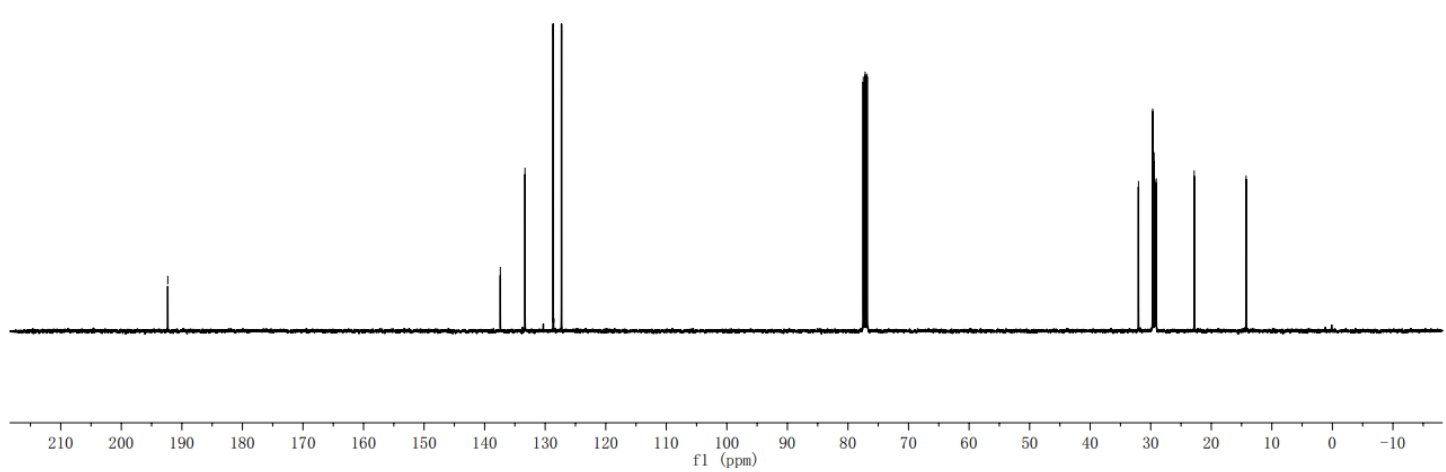


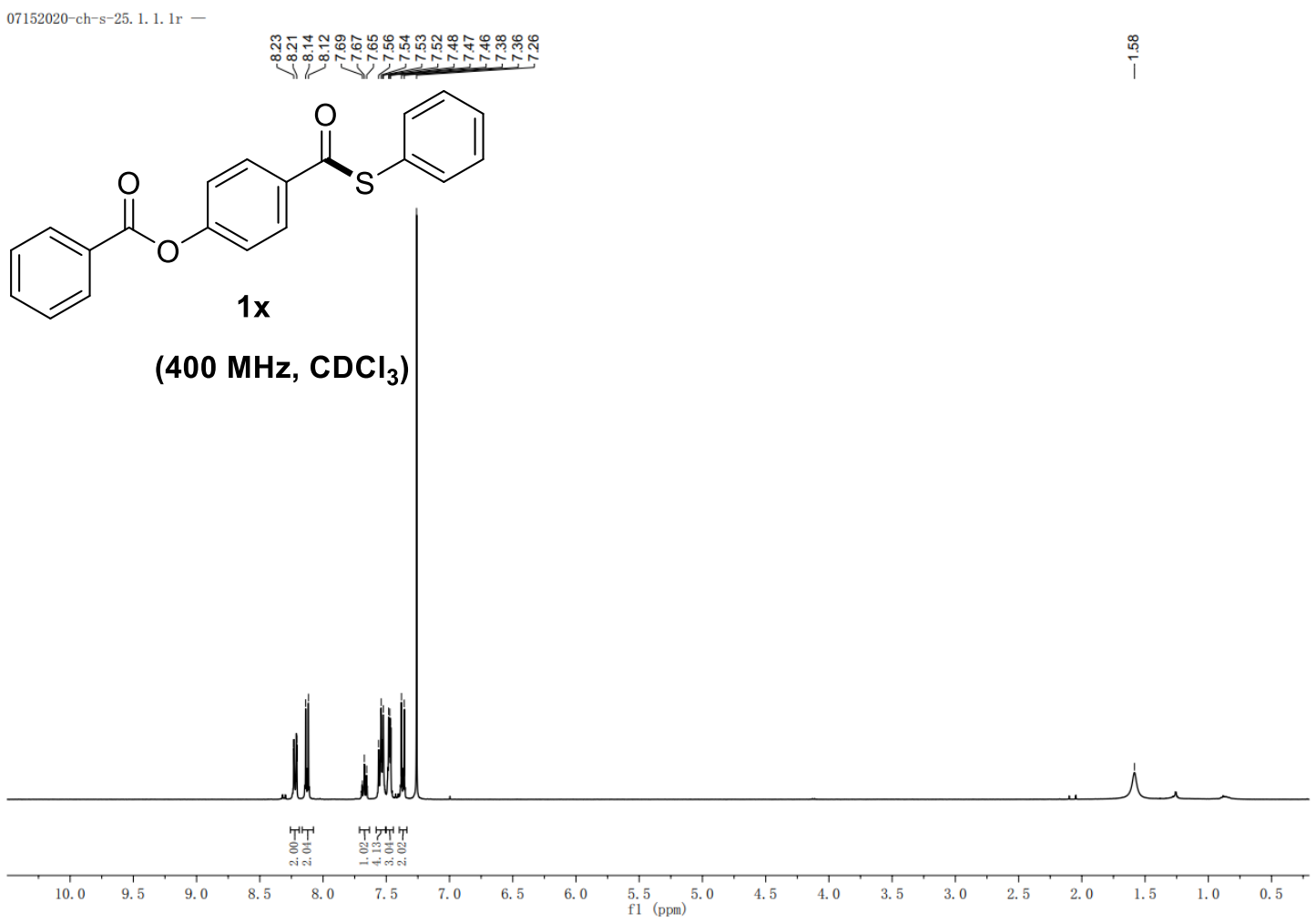

07152020-ch-s-25. 3.1.1r -

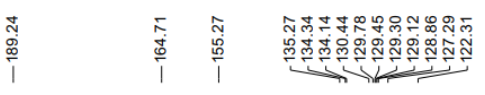<smiles>[X]c1ccc(C(=O)Sc2ccccc2)cc1</smiles>

(100 MHz, $\left.\mathrm{CDCl}_{3}\right)$
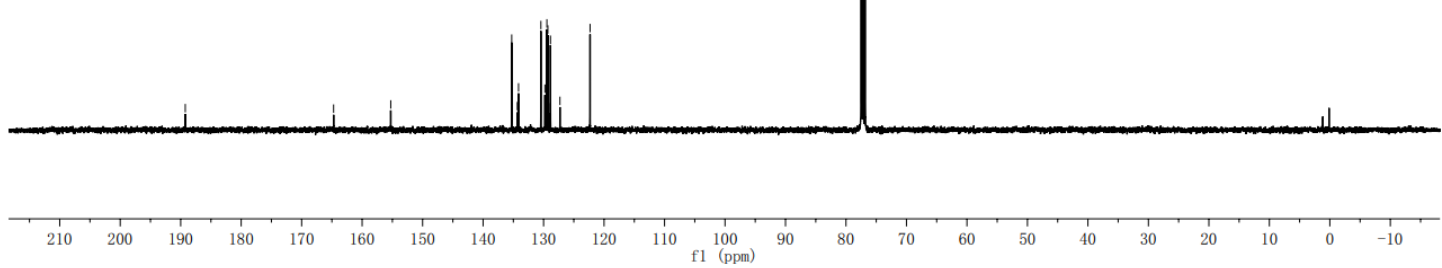
07232020-ch-s-28. 1. 1. 1r -<smiles>O=C(Sc1ccccc1)c1ccc(Br)cc1</smiles>

$\left(400 \mathrm{MHz}, \mathrm{CDCl}_{3}\right)$

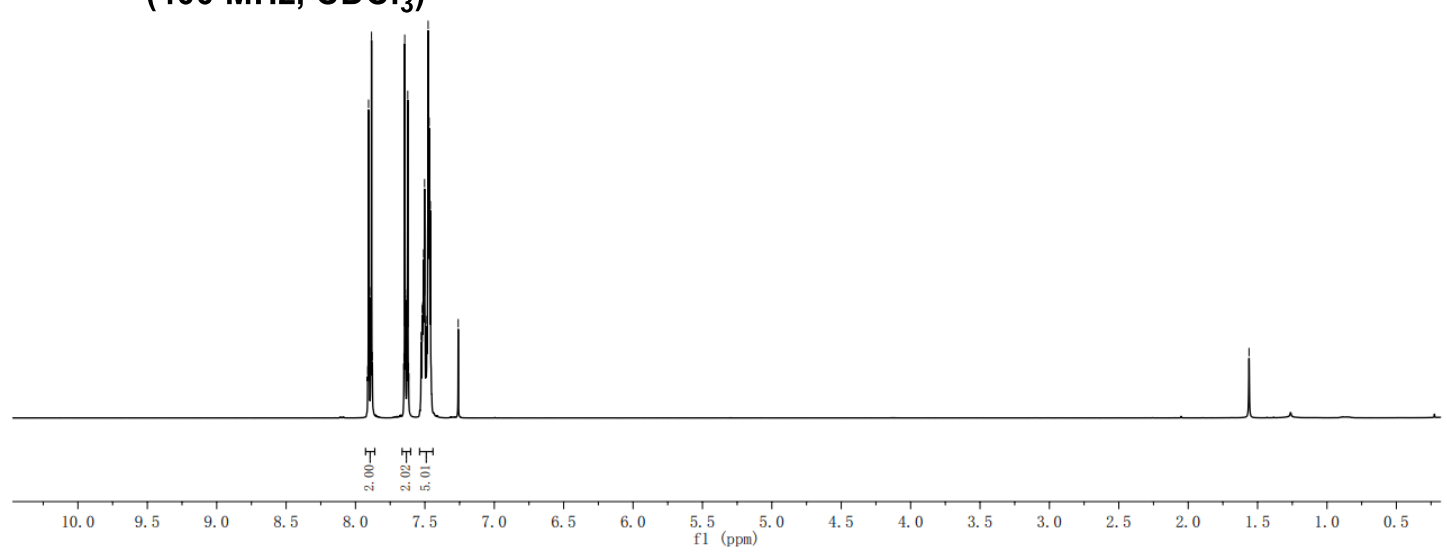

07312020-ch-s-28. 1. 1. 1r -

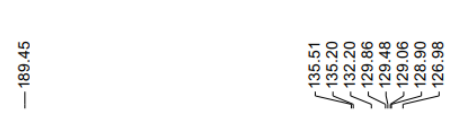

$\overbrace{1 y}^{c}$

(100 MHz, $\mathrm{CDCl}_{3}$ )
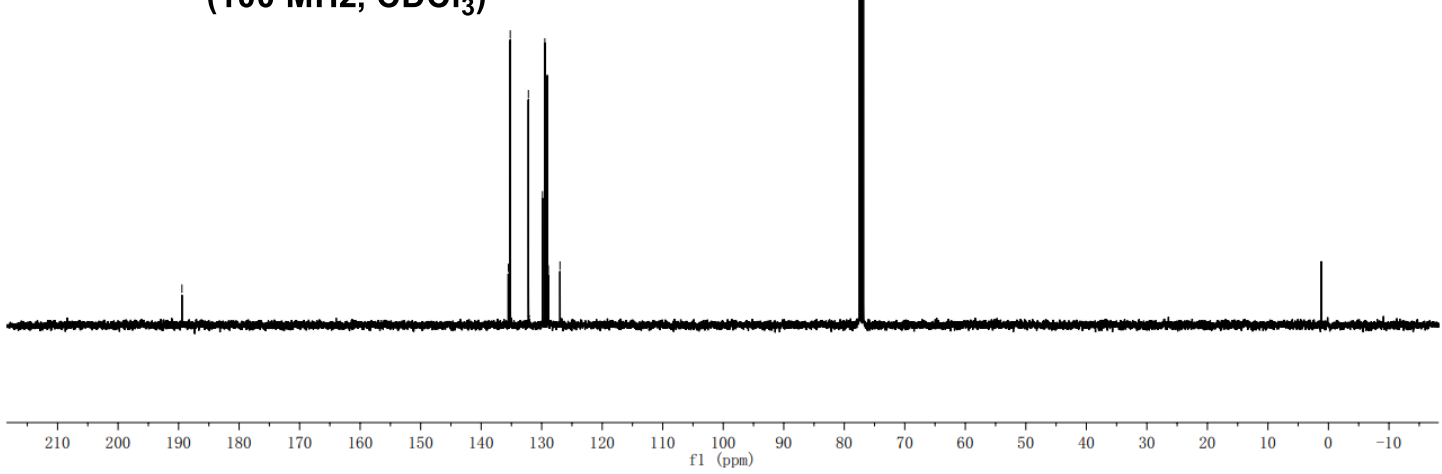
08122020-ch-s-27. 1. 1. 1r -

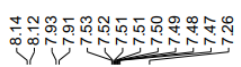

(400 MHz, CDCl 3$)$
ल다요

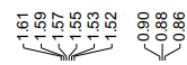

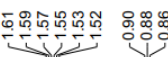
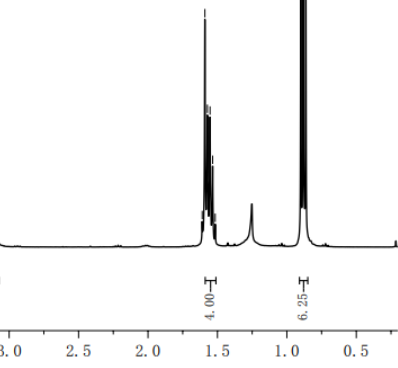

08122020-ch-s-27. 2.1.1r -

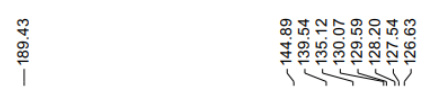<smiles>CCCN(CCC)S(=O)(=O)c1ccc(C(=O)Sc2ccccc2)cc1</smiles>
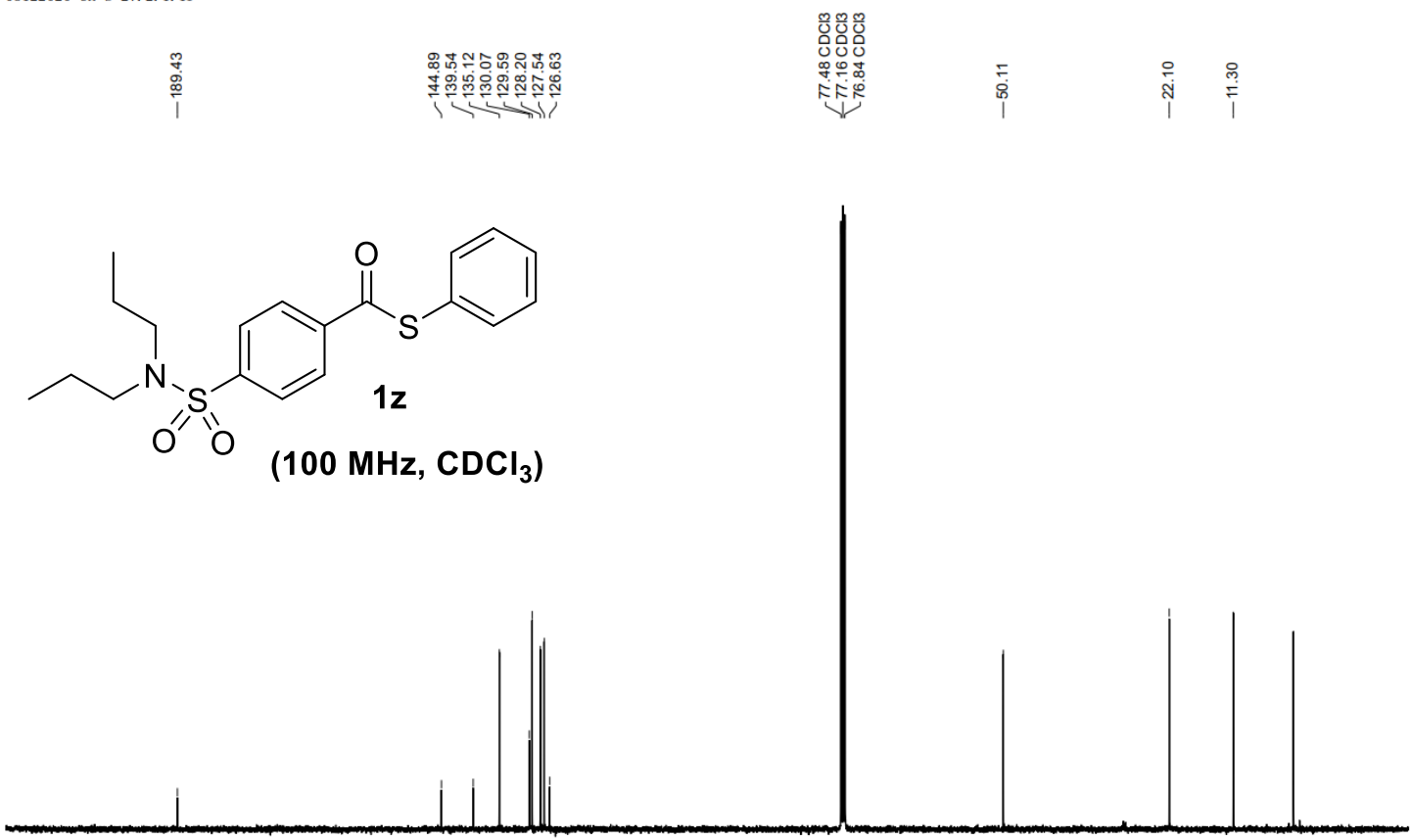


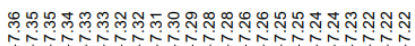<smiles>c1ccc(Sc2ccccc2)cc1</smiles>

2a

(400 MHz, $\mathrm{CDCl}_{3}$ )

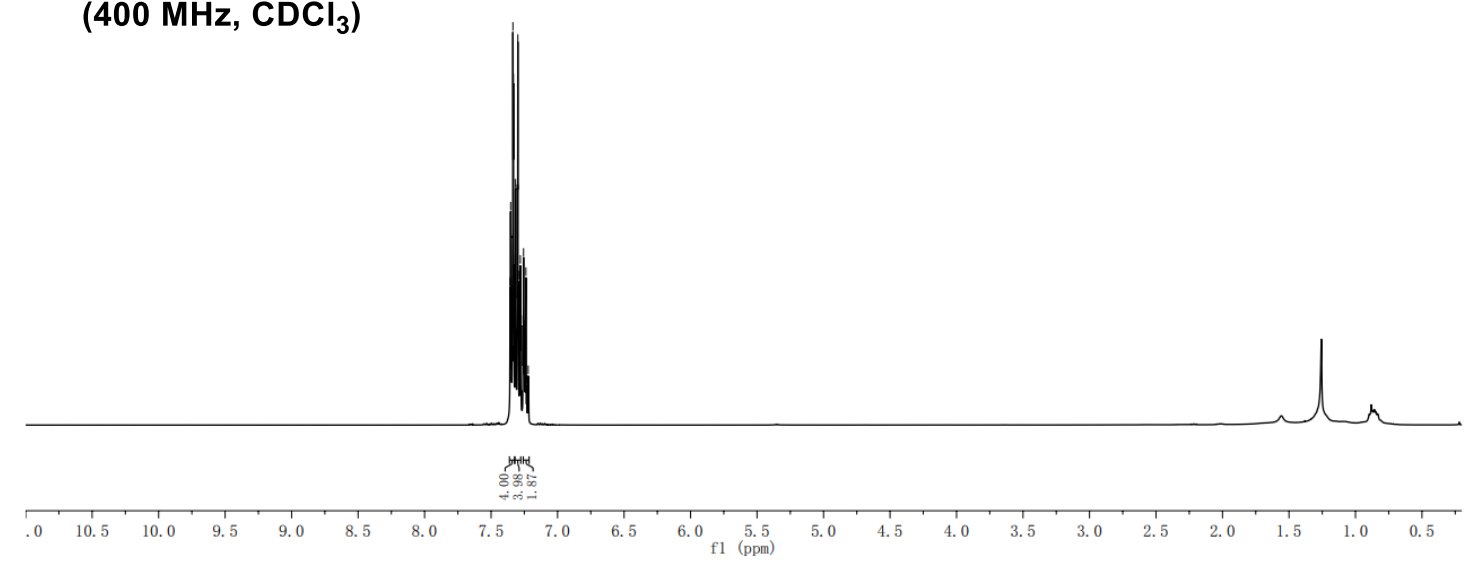<smiles>c1ccc(Sc2ccccc2)cc1</smiles>

2a

$\left(100 \mathrm{MHz} \mathrm{CDCl}_{3}\right.$ )
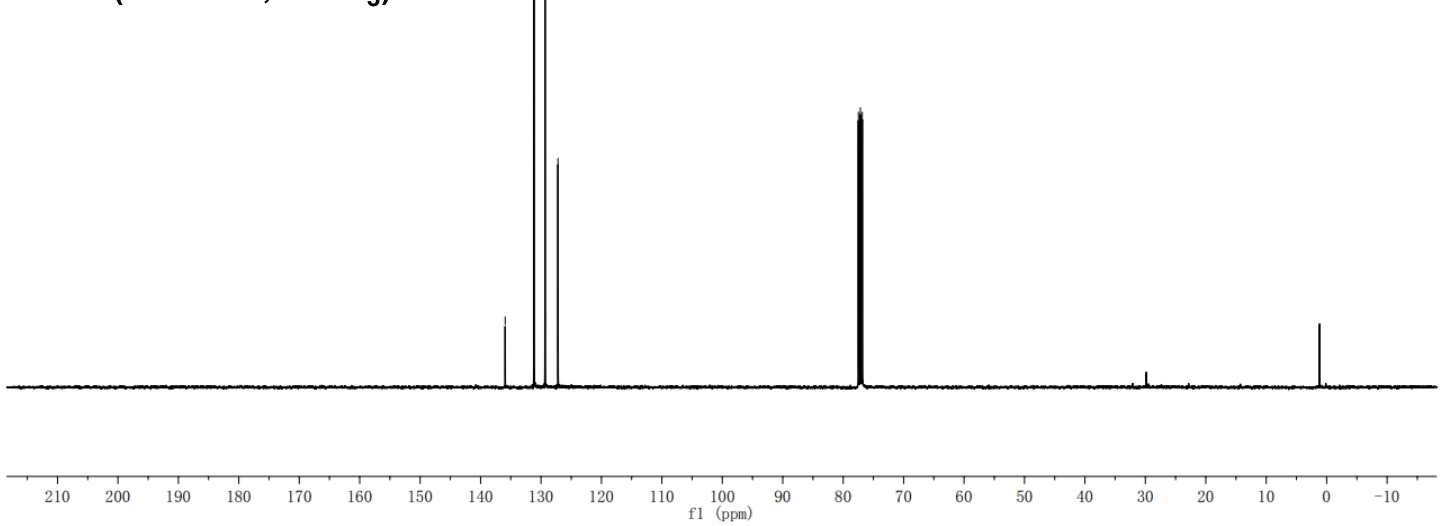


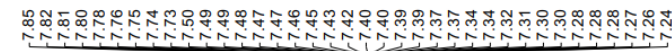<smiles>c1ccc(Sc2ccc3ccccc3c2)cc1</smiles>

2 b

$400 \mathrm{MHz}, \mathrm{CDCl} 3$

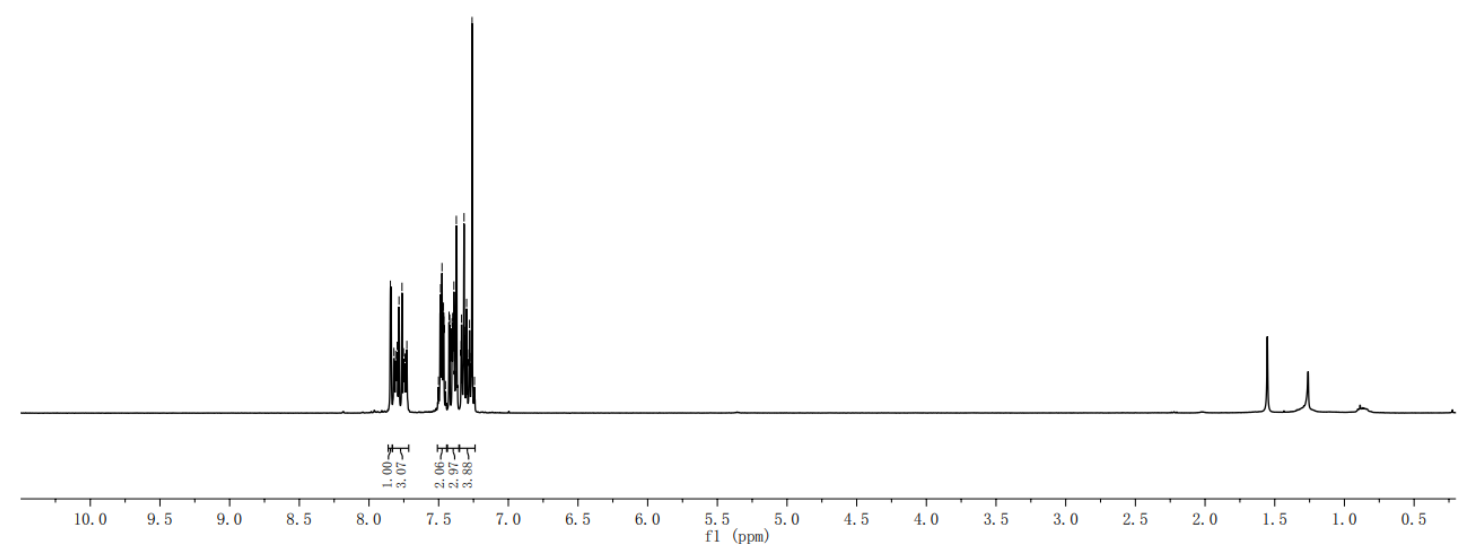

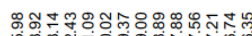

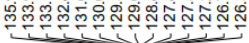<smiles>c1ccc(Sc2ccc3ccccc3c2)cc1</smiles>

$2 b$

$100 \mathrm{MHz}, \mathrm{CDCl} 3$

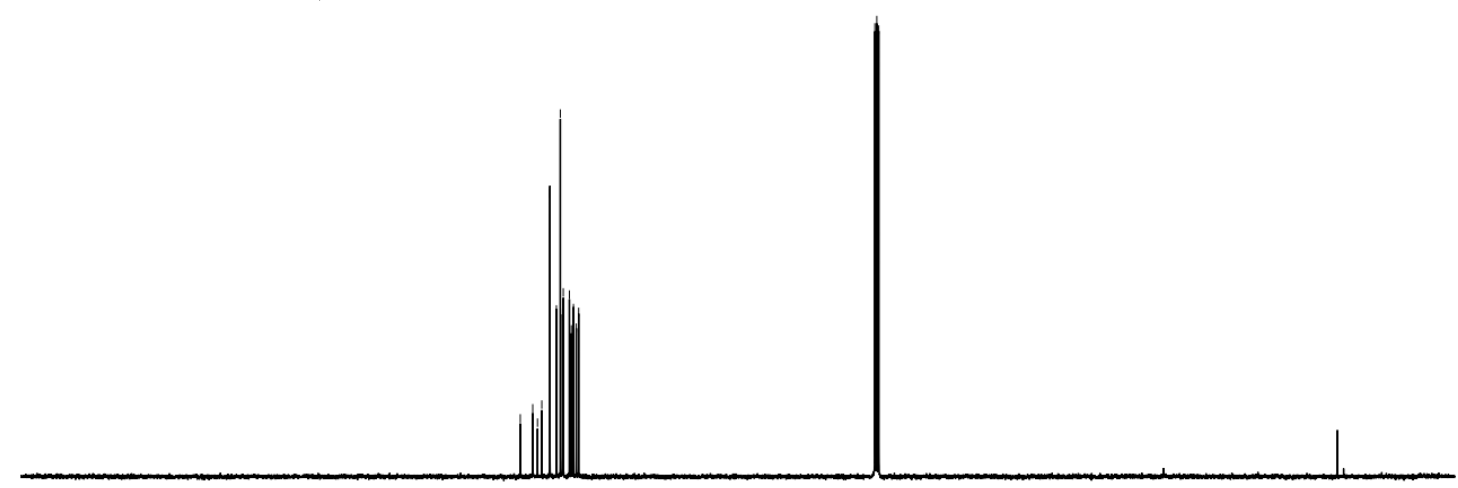

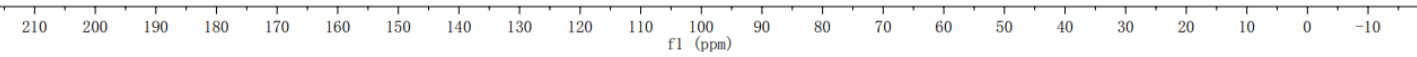


<smiles>Cc1ccc(Sc2ccccc2)cc1</smiles>

(400 MHz, $\mathrm{CDCl}_{3}$ )
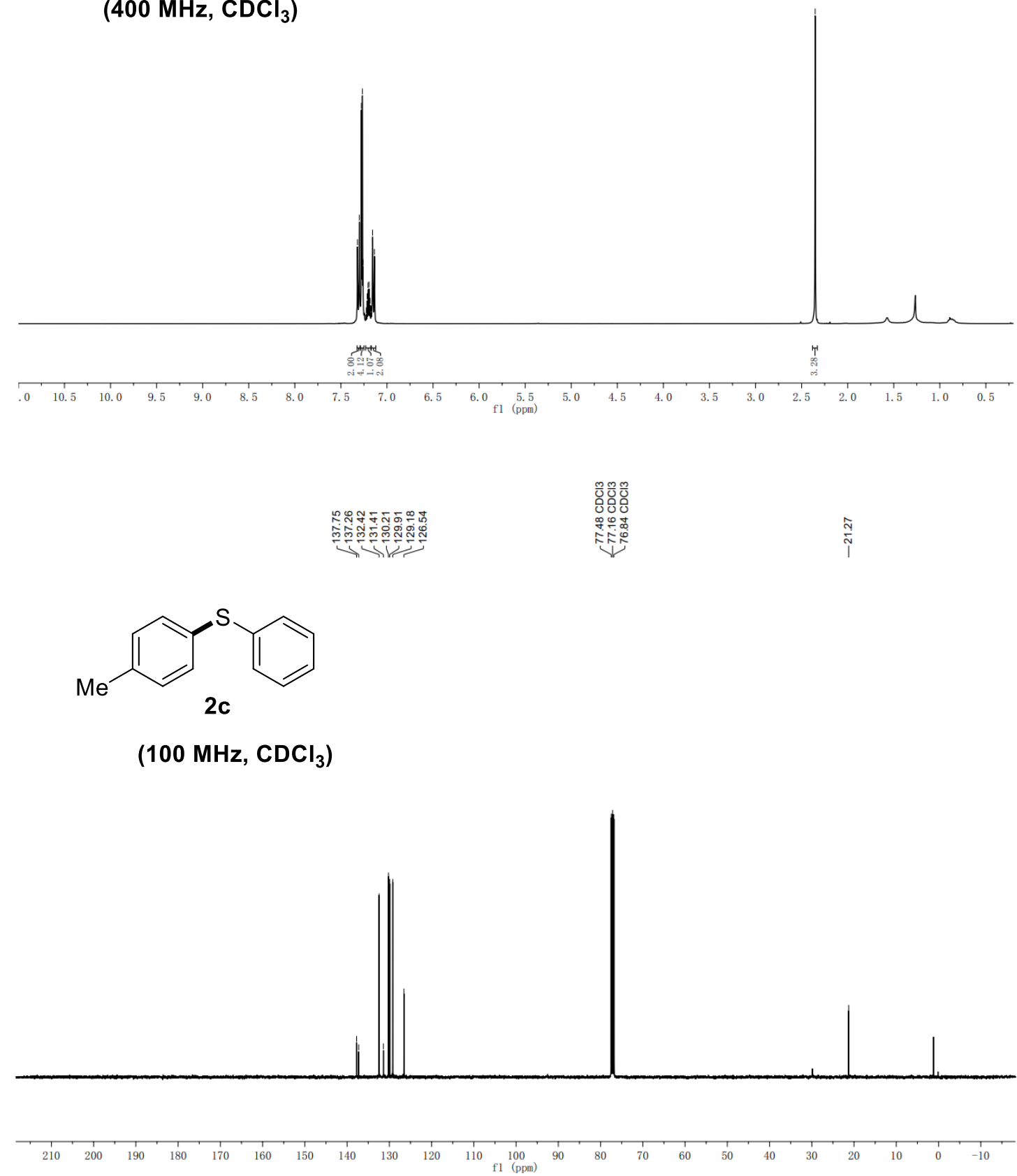
<smiles>COc1ccc(Sc2ccccc2)cc1</smiles>

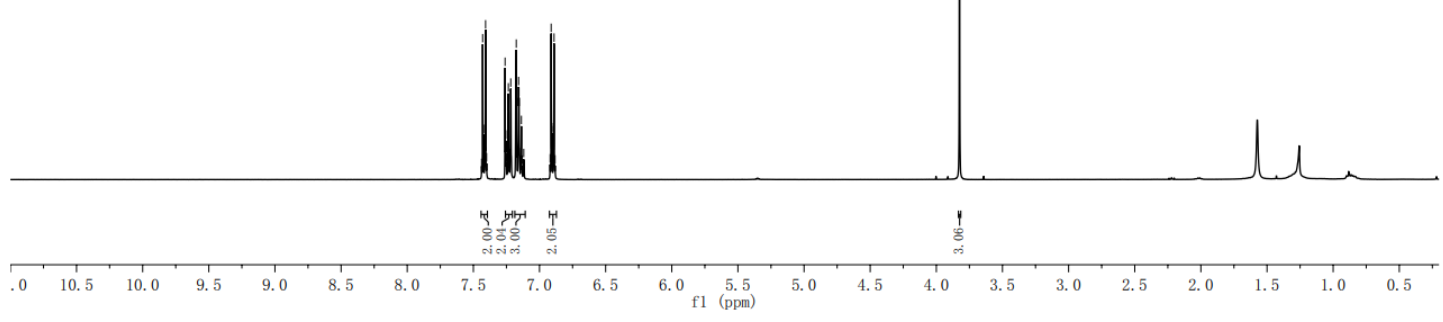<smiles>COc1ccc(Sc2ccccc2)cc1</smiles>

(100 $\mathrm{MHz}, \mathrm{CDCl}_{3}$ )
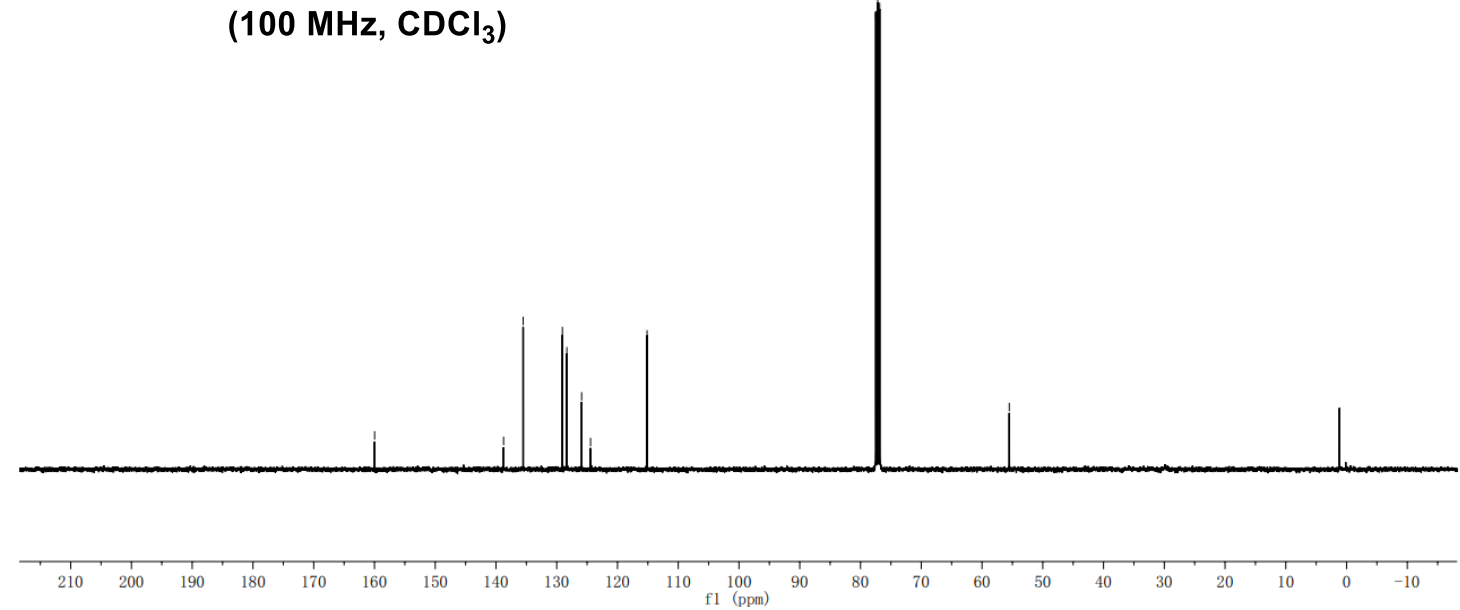


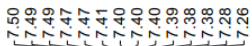<smiles>FC(F)(F)c1ccc(Sc2ccccc2)cc1</smiles>

(400 $\mathrm{MHz}, \mathrm{CDCl}_{3}$ )
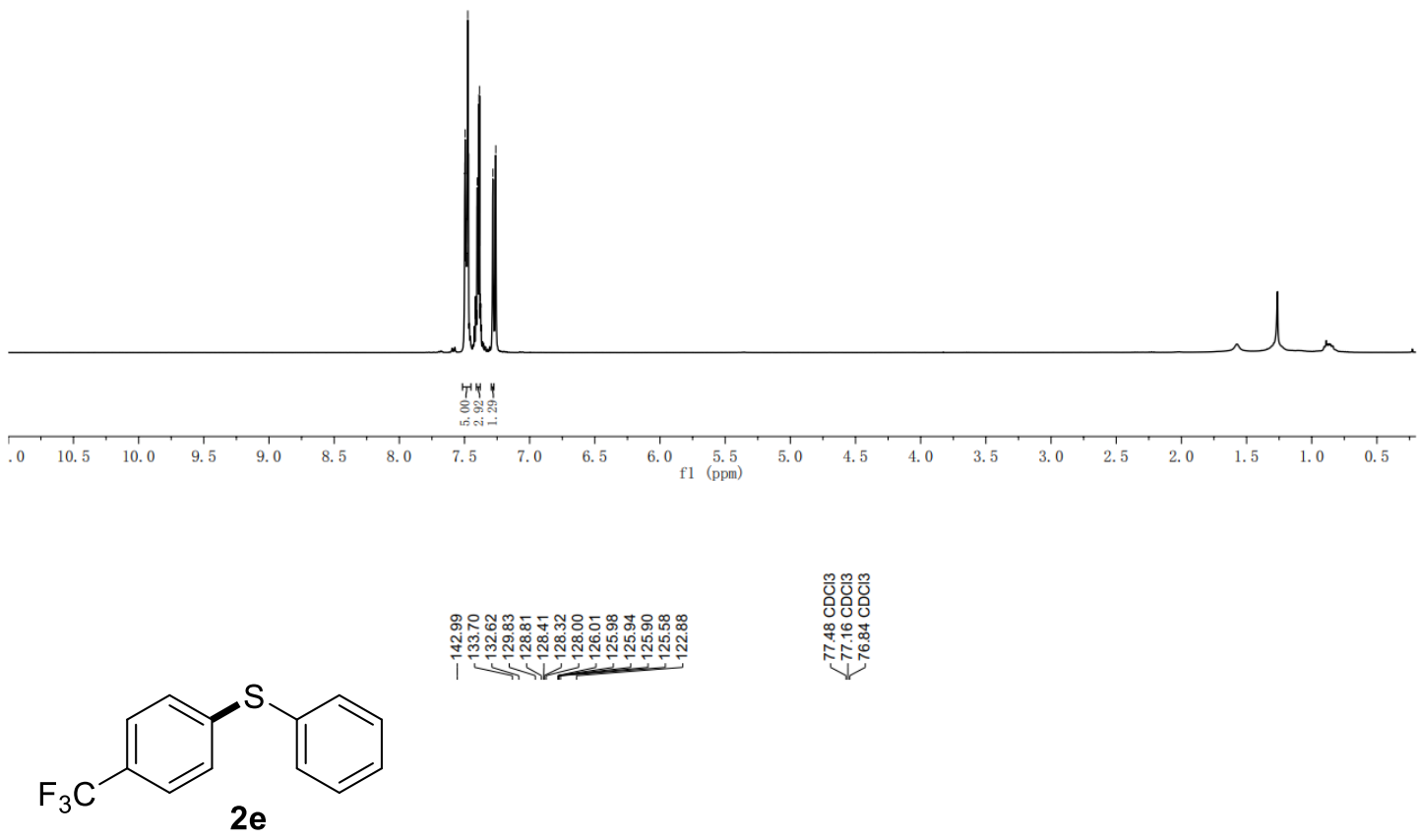

(100 $\mathrm{MHz}, \mathrm{CDCl}_{3}$ )
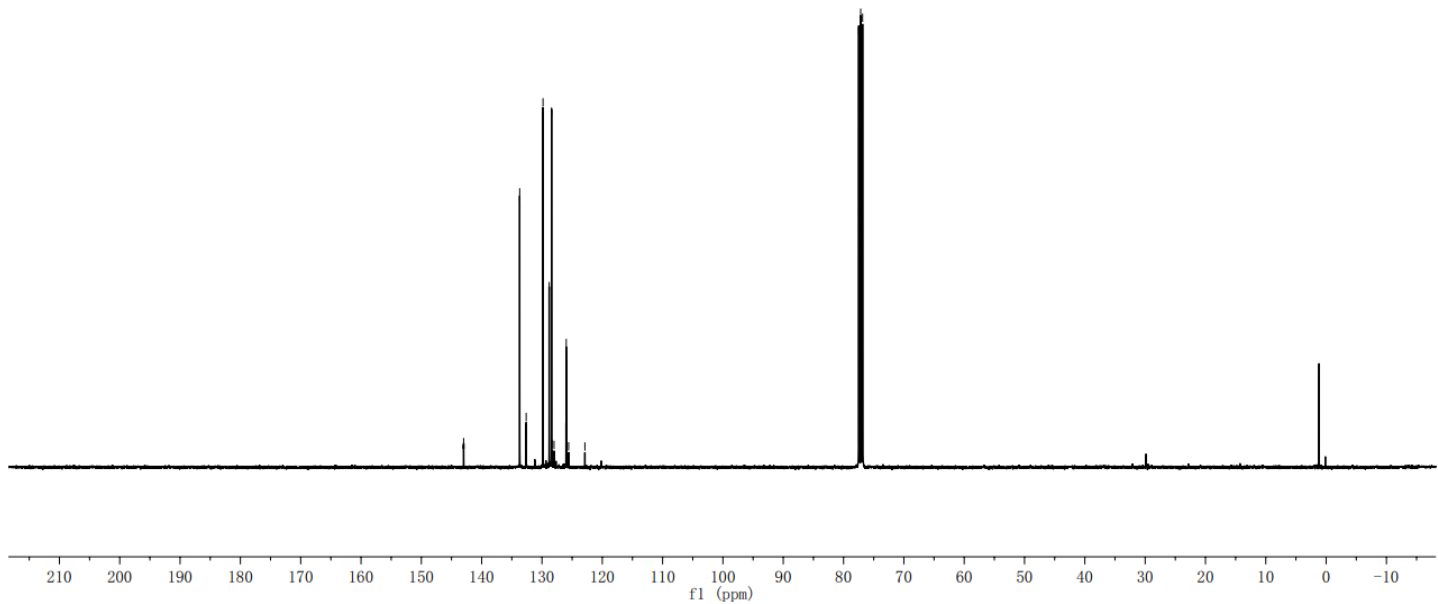


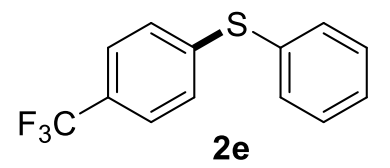

(376 $\mathrm{MHz}, \mathrm{CDCl}_{3}$ )

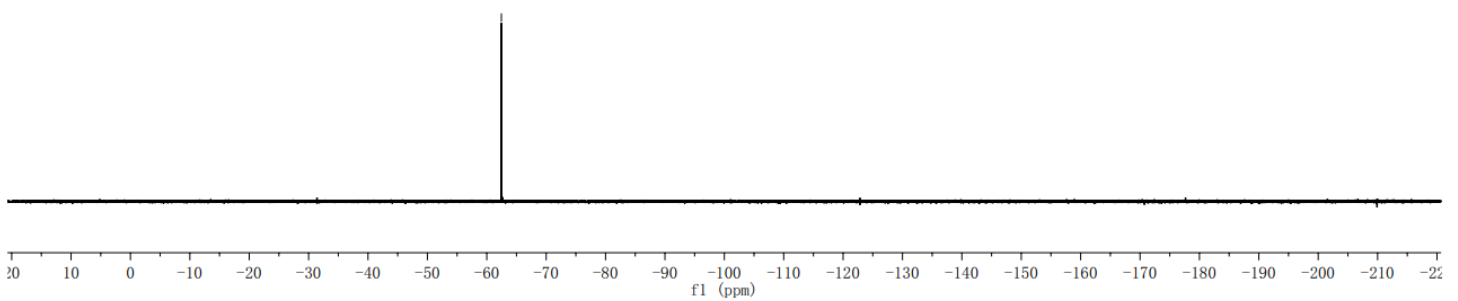




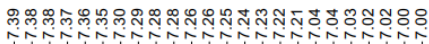

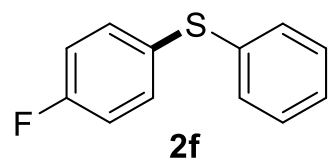

(400 MHz, $\mathrm{CDCl}_{3}$ )

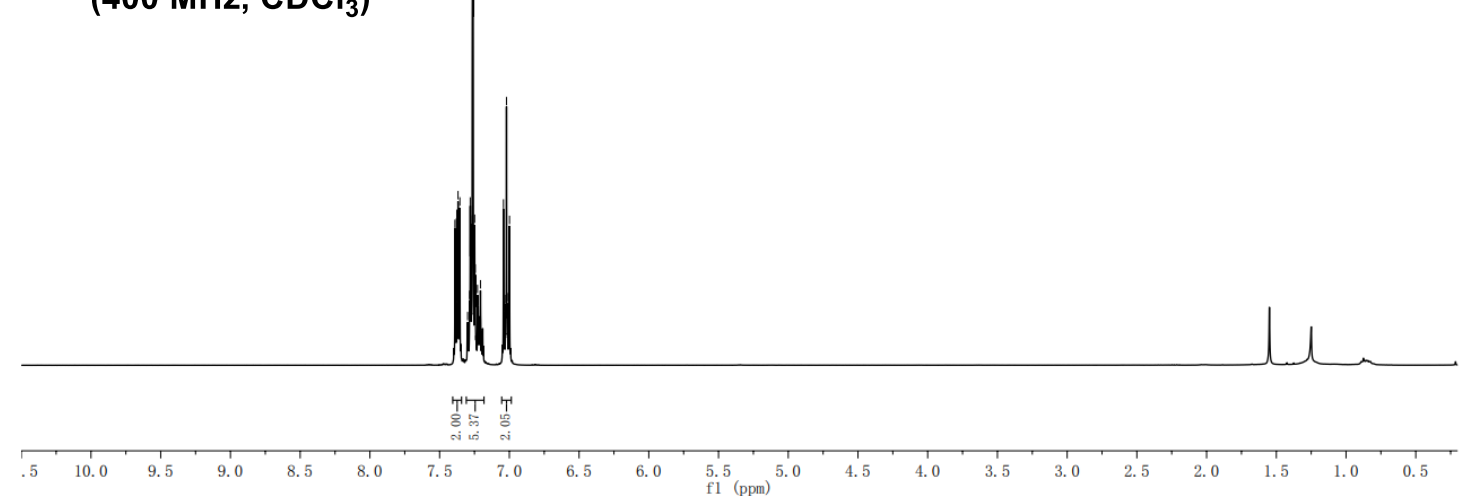<smiles>Fc1ccc(Sc2ccccc2)cc1</smiles>

(100 $\left.\mathrm{MHz}, \mathrm{CDCl}_{3}\right)$

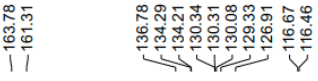

广

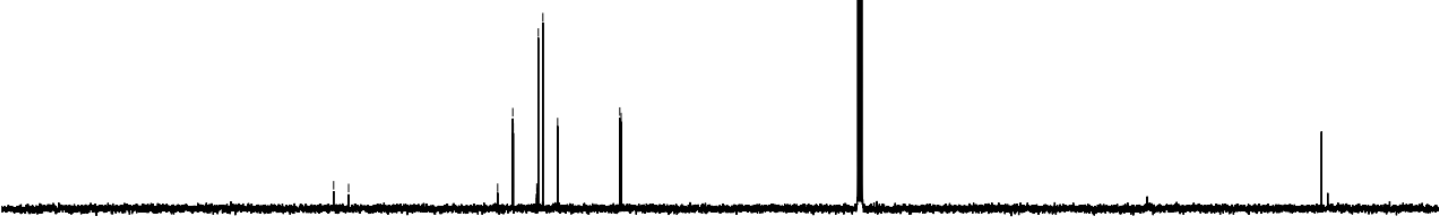




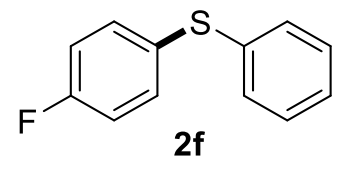

$376 \mathrm{MHz}^{\mathrm{CDCl}} \mathrm{CD}_{3}$

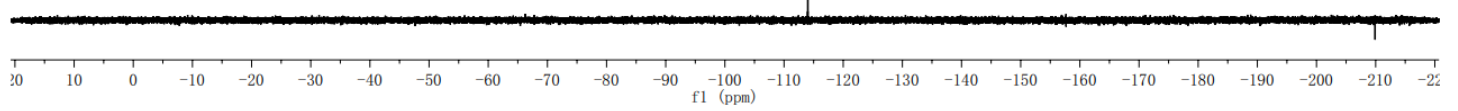




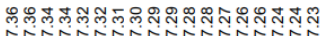<smiles>Clc1ccc(Sc2ccccc2)cc1</smiles>

(400 MHz, $\mathrm{CDCl}_{3}$ )

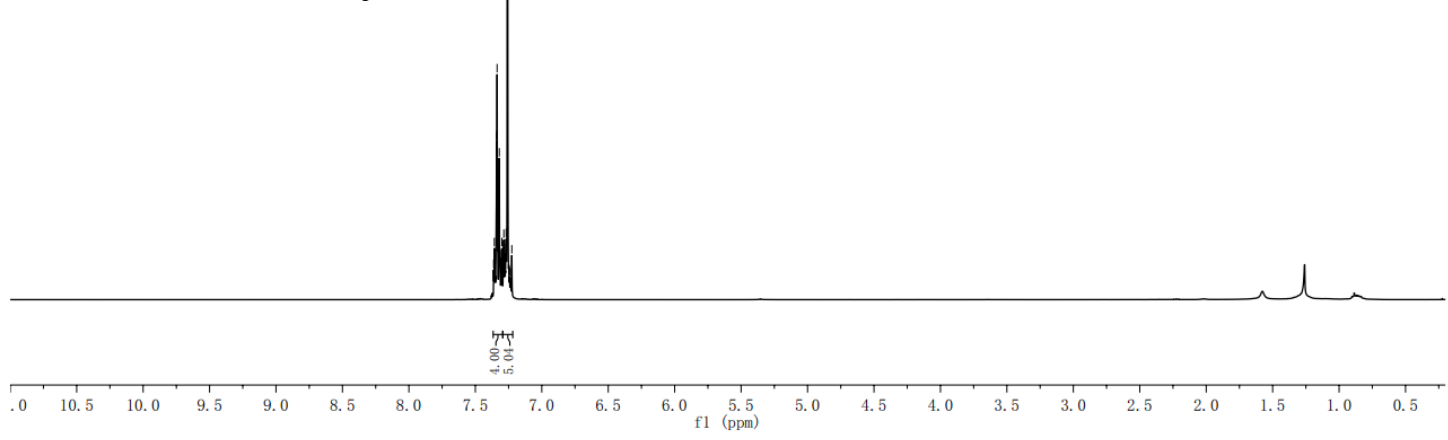<smiles>Clc1ccc(Sc2ccccc2)cc1</smiles>

$2 \mathrm{~g}$

$\left(100 \mathrm{MHz} \mathrm{CDCl}_{3}\right)$
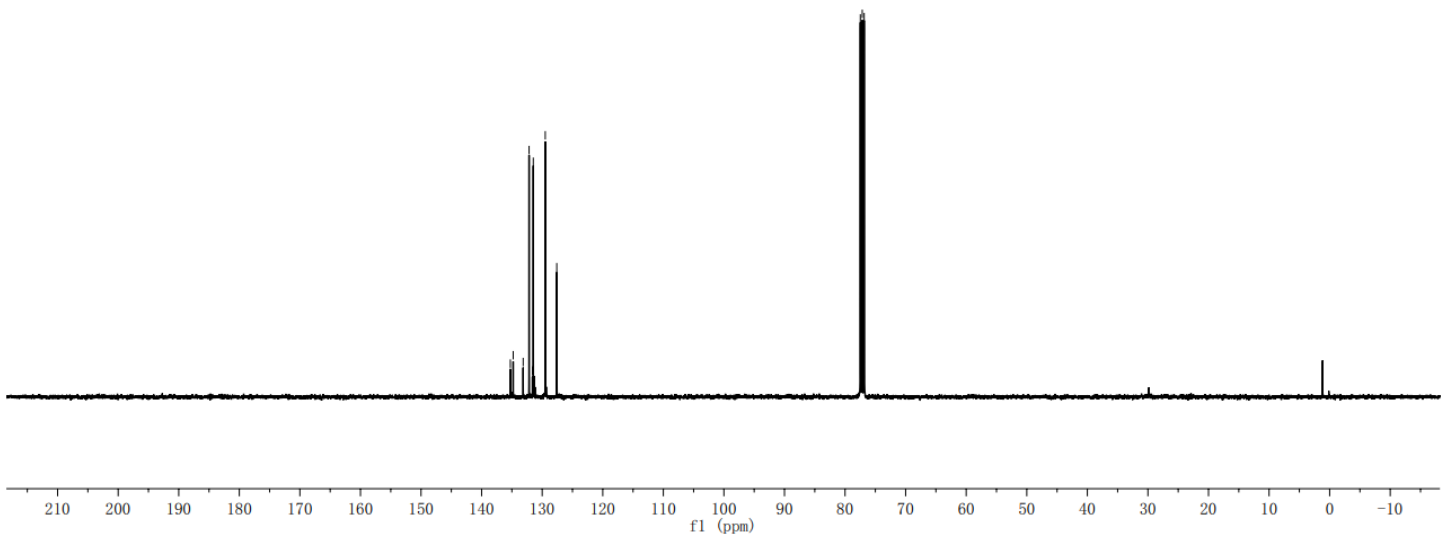


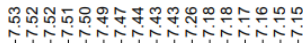<smiles>N#Cc1ccc(Sc2ccccc2)cc1</smiles>

$2 \mathrm{~h}$

(400 MHz, $\mathrm{CDCl}_{3}$ )
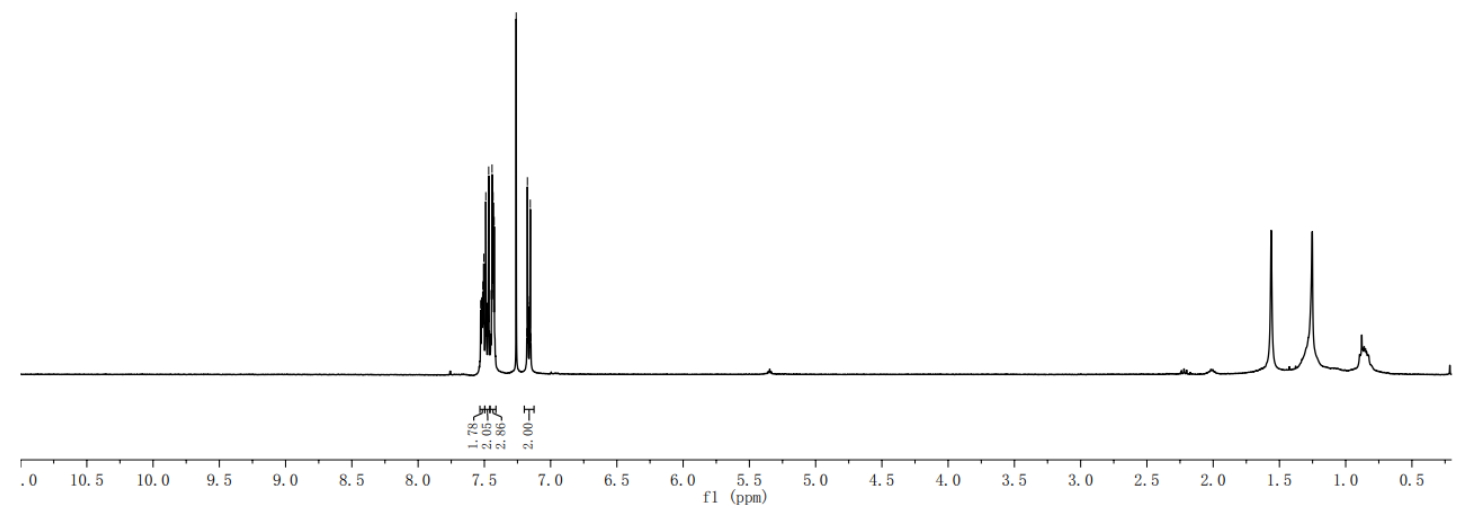<smiles>N#Cc1ccc(Sc2ccccc2)cc1</smiles>

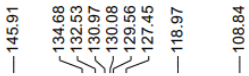

$2 \mathrm{~h}$

(100 MHz, $\mathrm{CDCl}_{3}$ )

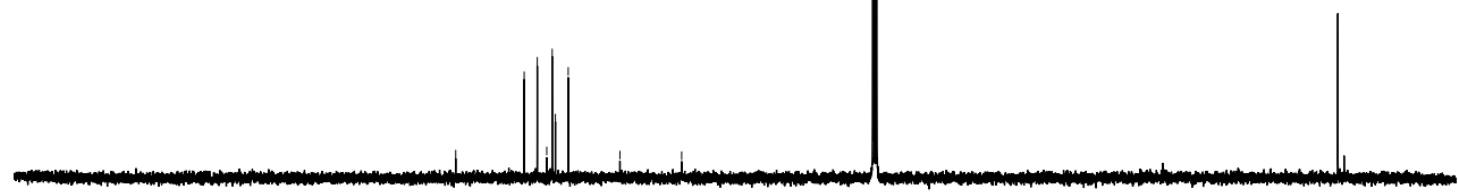



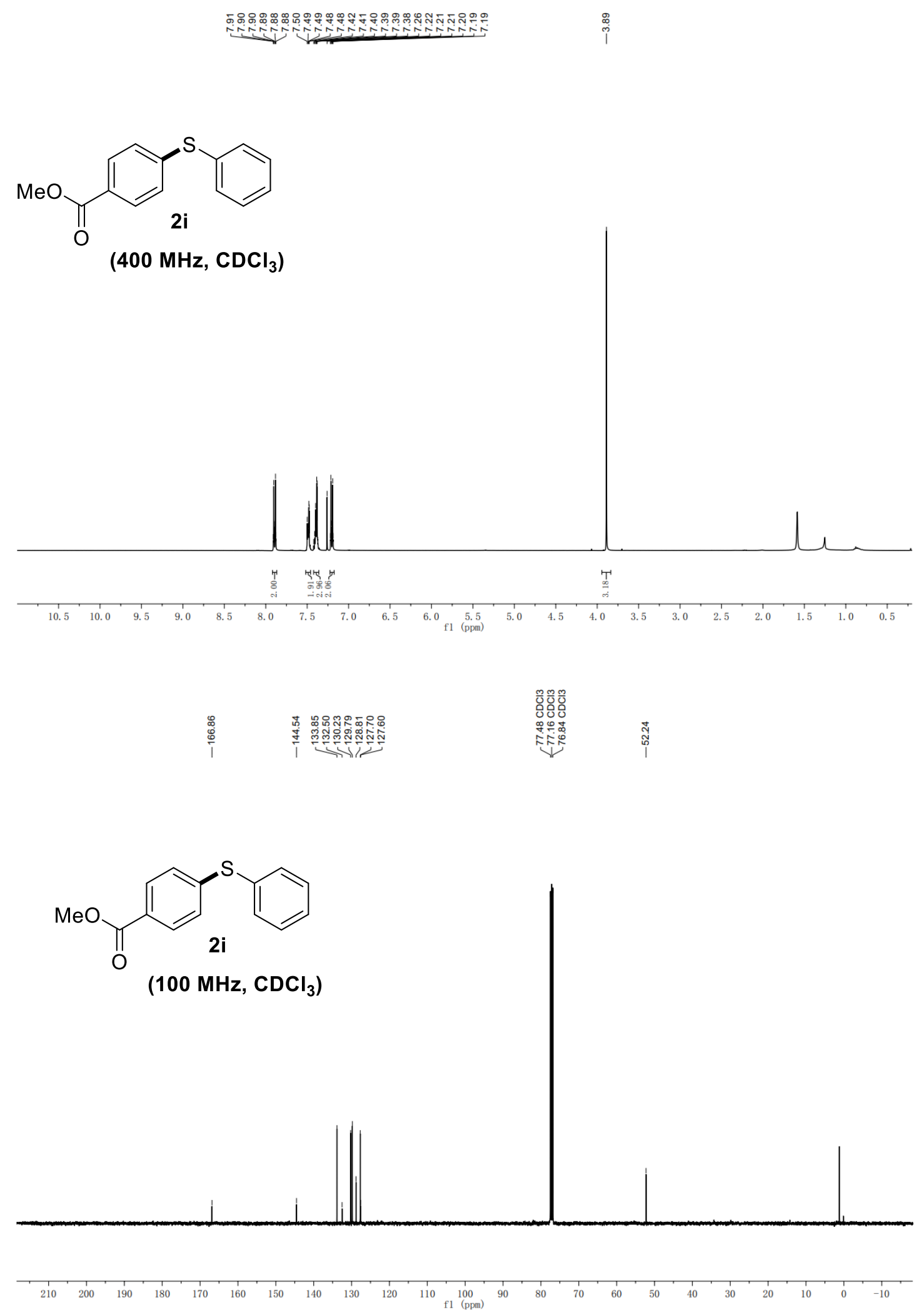
<smiles>CC(=O)c1ccc(Sc2ccccc2)cc1</smiles>
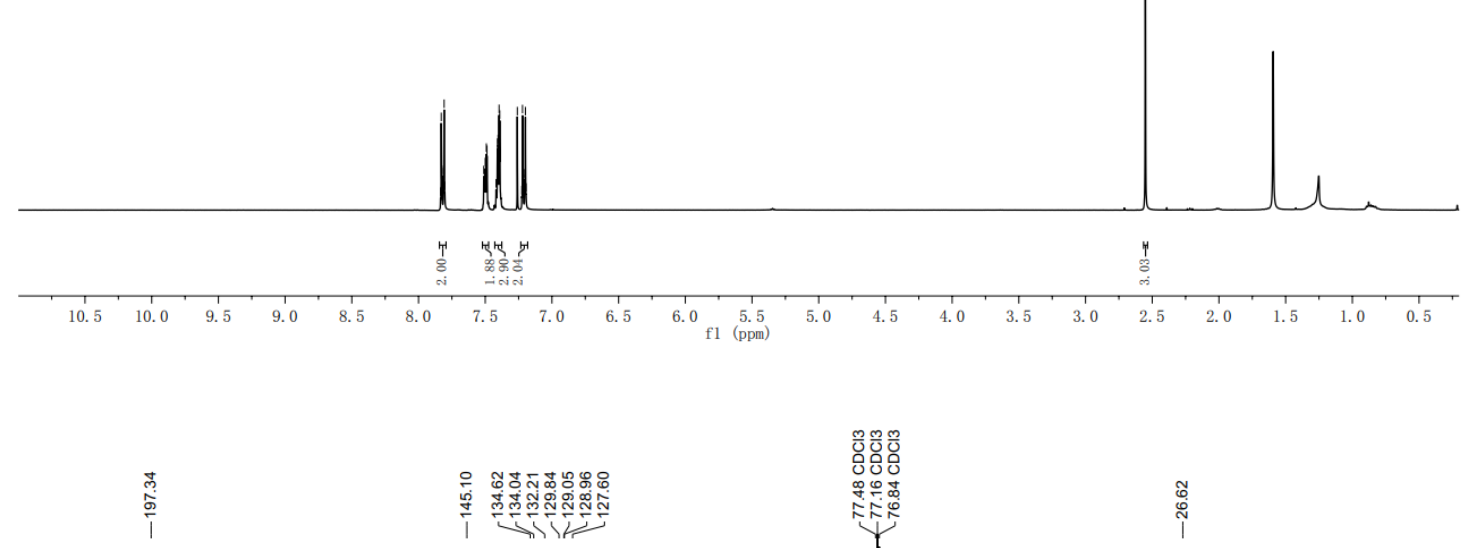<smiles>CC(=O)c1ccc(Sc2ccccc2)cc1</smiles>

$\left(100 \mathrm{MHz}, \mathrm{CDCl}_{3}\right)$
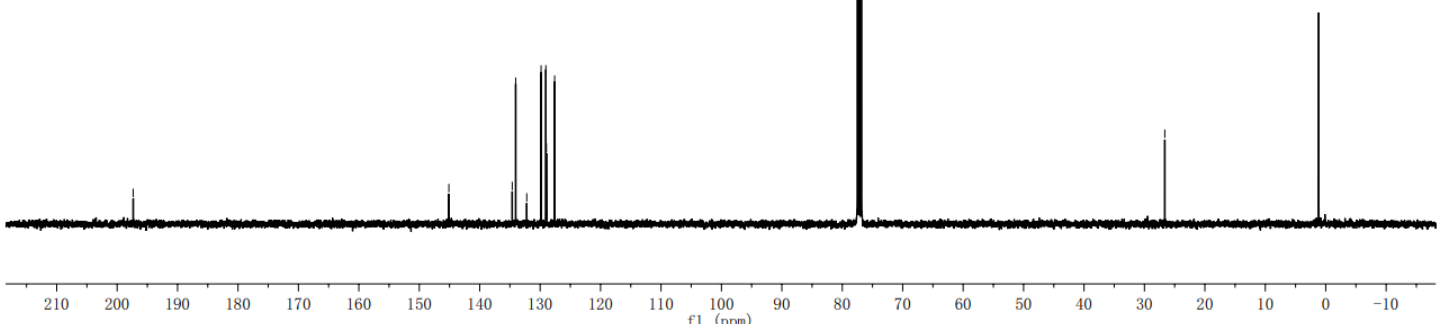

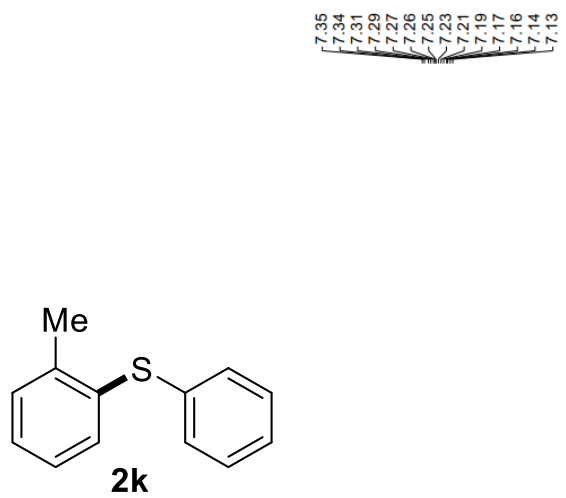

$\left(400 \mathrm{MHz}, \mathrm{CDCl}_{3}\right)$

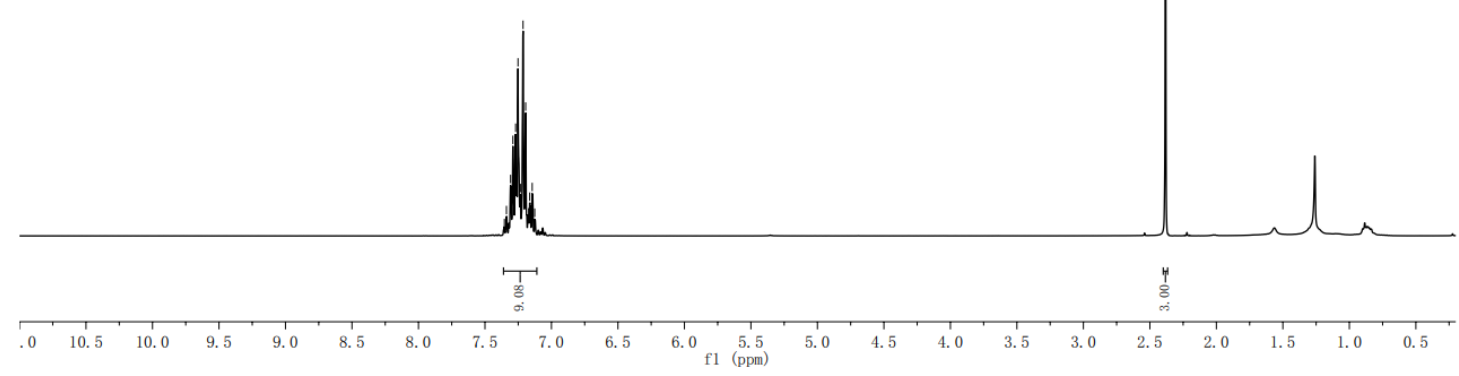

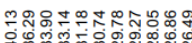

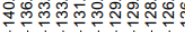

(n)

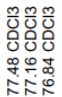

岤

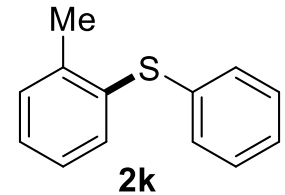

$\left(100 \mathrm{MHz} \mathrm{CDCl}_{3}\right)$
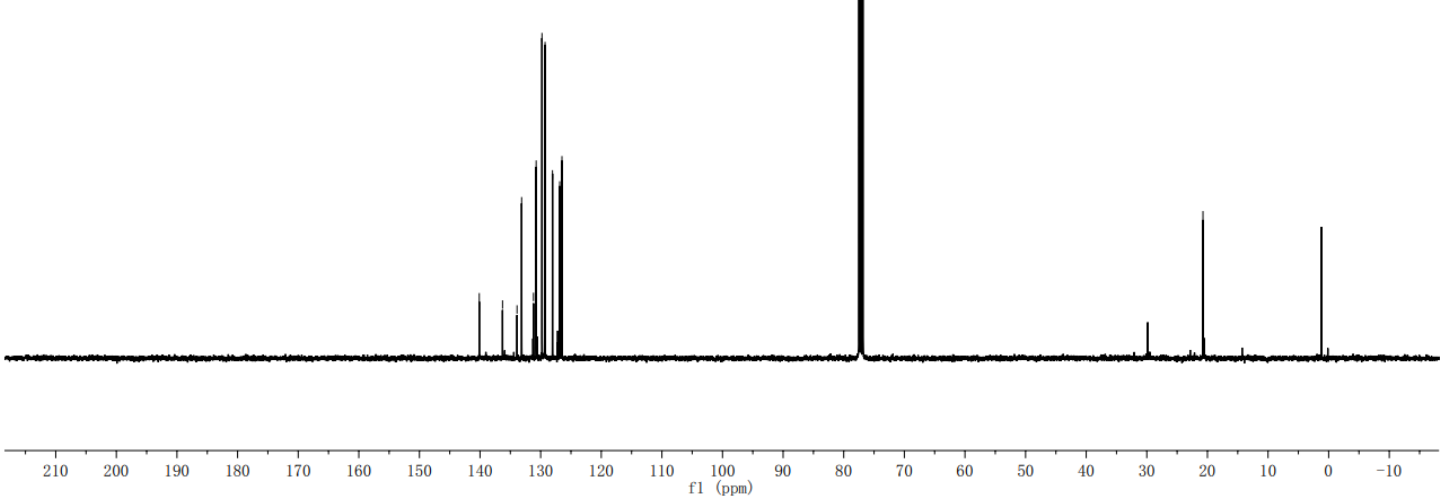
<smiles>Fc1ccccc1Sc1ccccc1</smiles>

2I

(400 $\mathrm{MHz}, \mathrm{CDCl}_{3}$ )
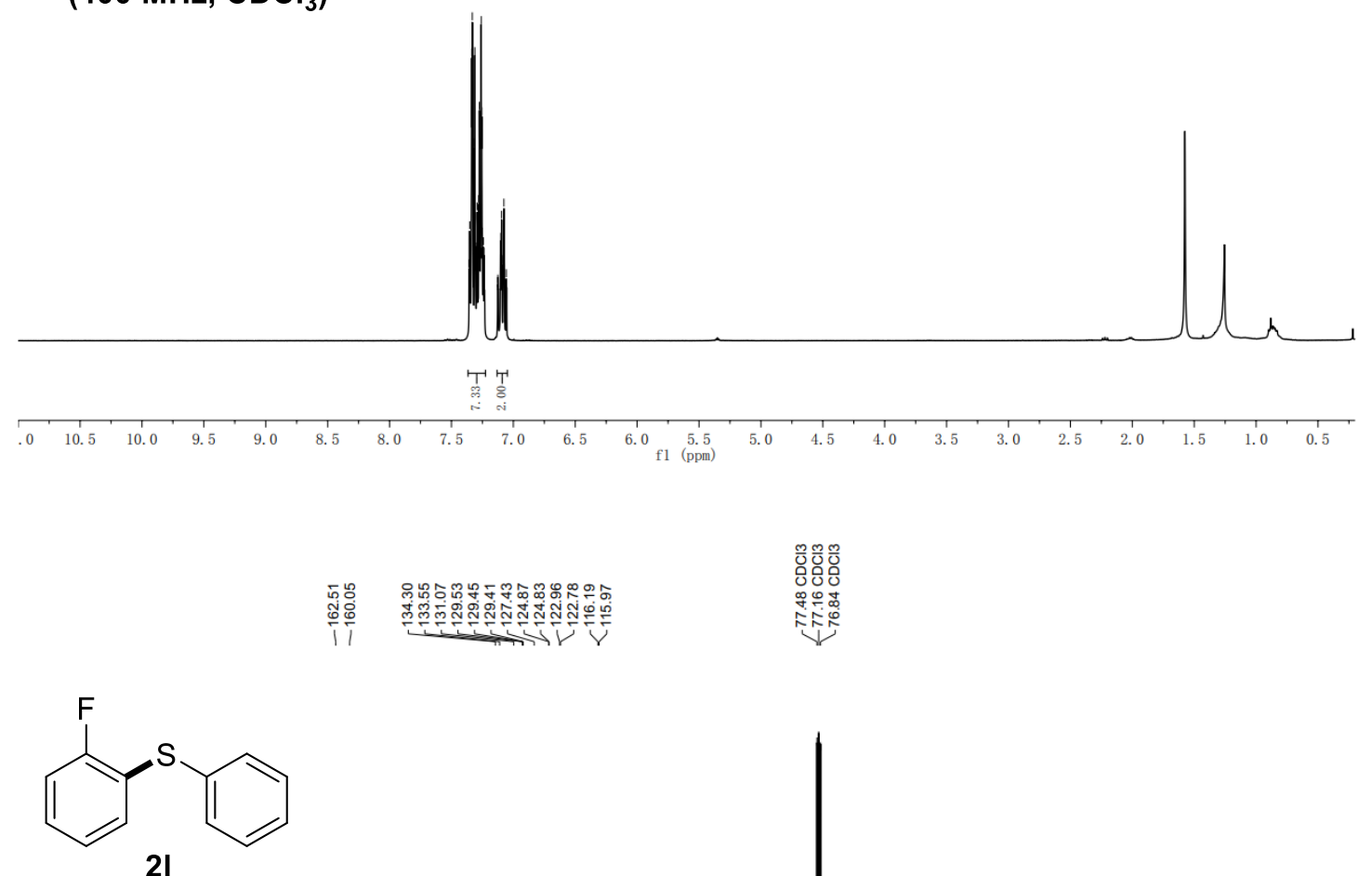

(100 MHz, $\left.\mathrm{CDCl}_{3}\right)$

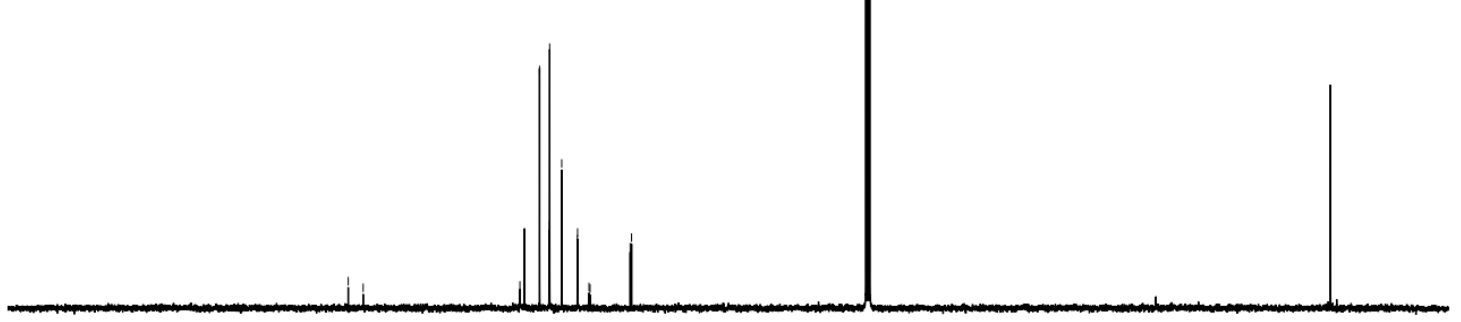




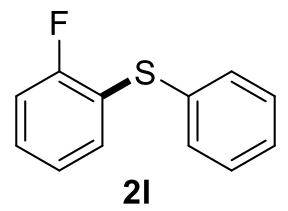

(376 MHz, $\mathrm{CDCl}_{3}$ )

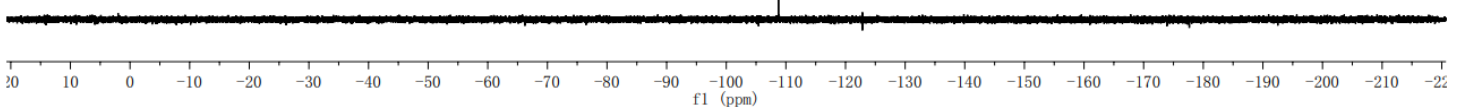




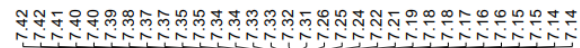<smiles>Clc1cccc(Sc2ccccc2)c1</smiles>
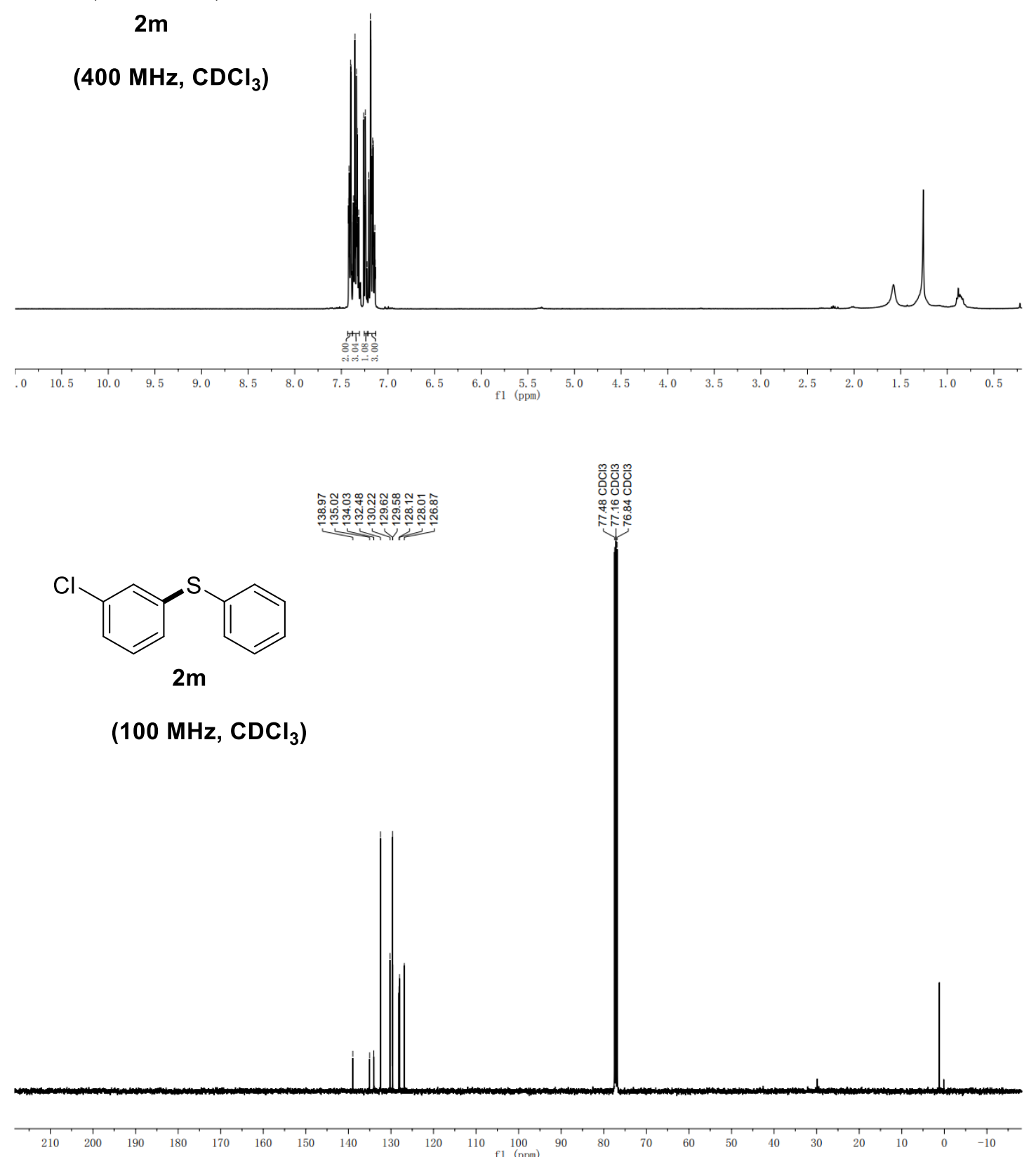


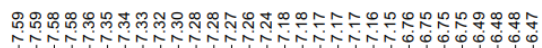<smiles>c1ccc(Sc2ccco2)cc1</smiles>

2n

(400 $\mathrm{MHz} \mathrm{CDCl}_{3}$ )
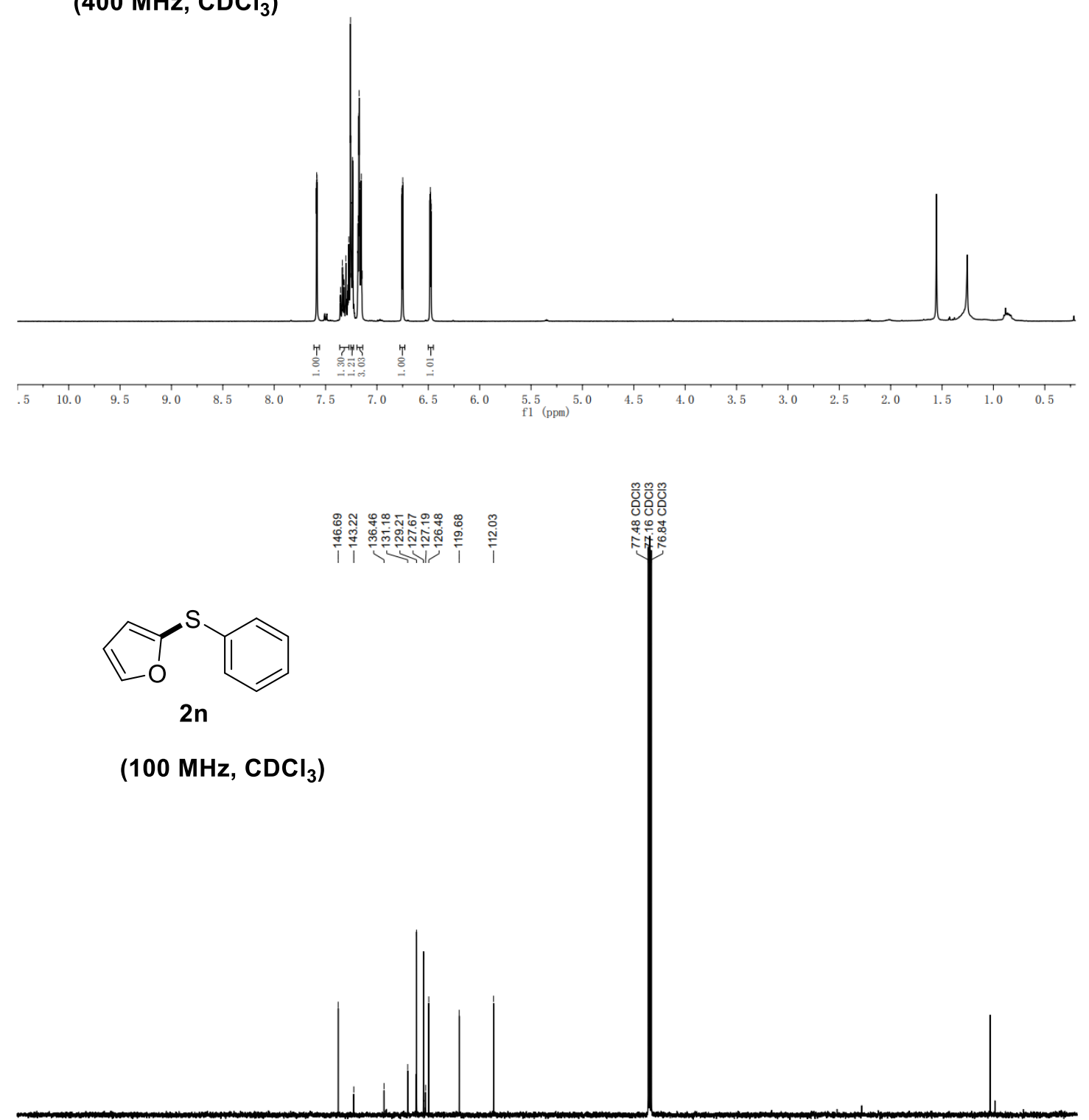


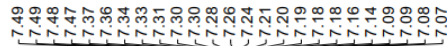

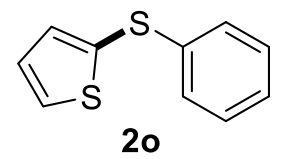

(400 MHz, $\mathrm{CDCl}_{3}$ )
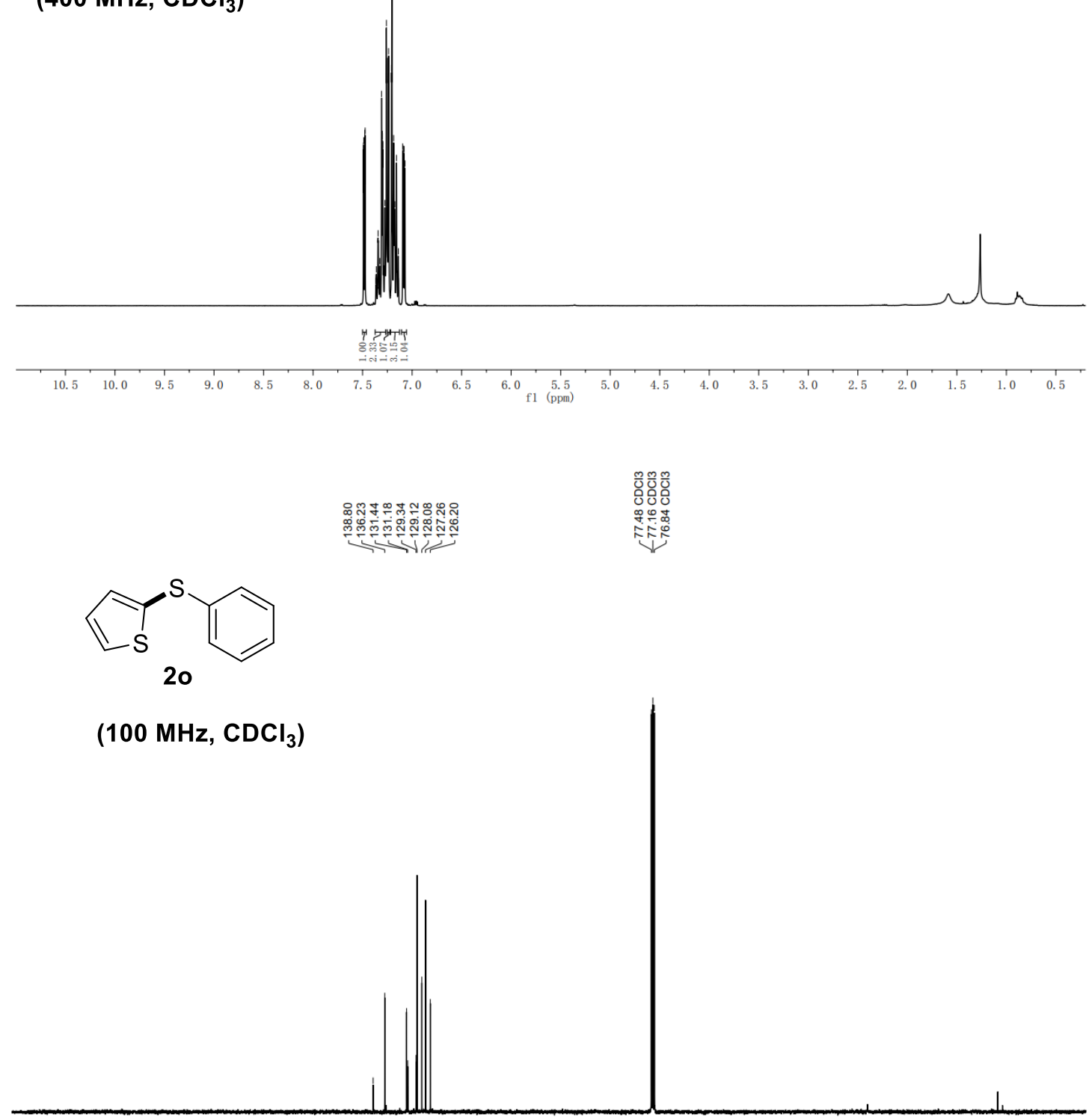

20

$\left(100 \mathrm{MHz}, \mathrm{CDCl}_{3}\right)$

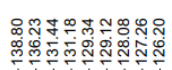

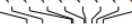

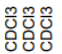

㿻

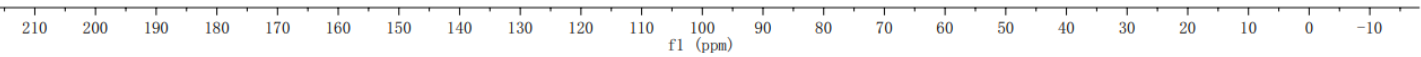



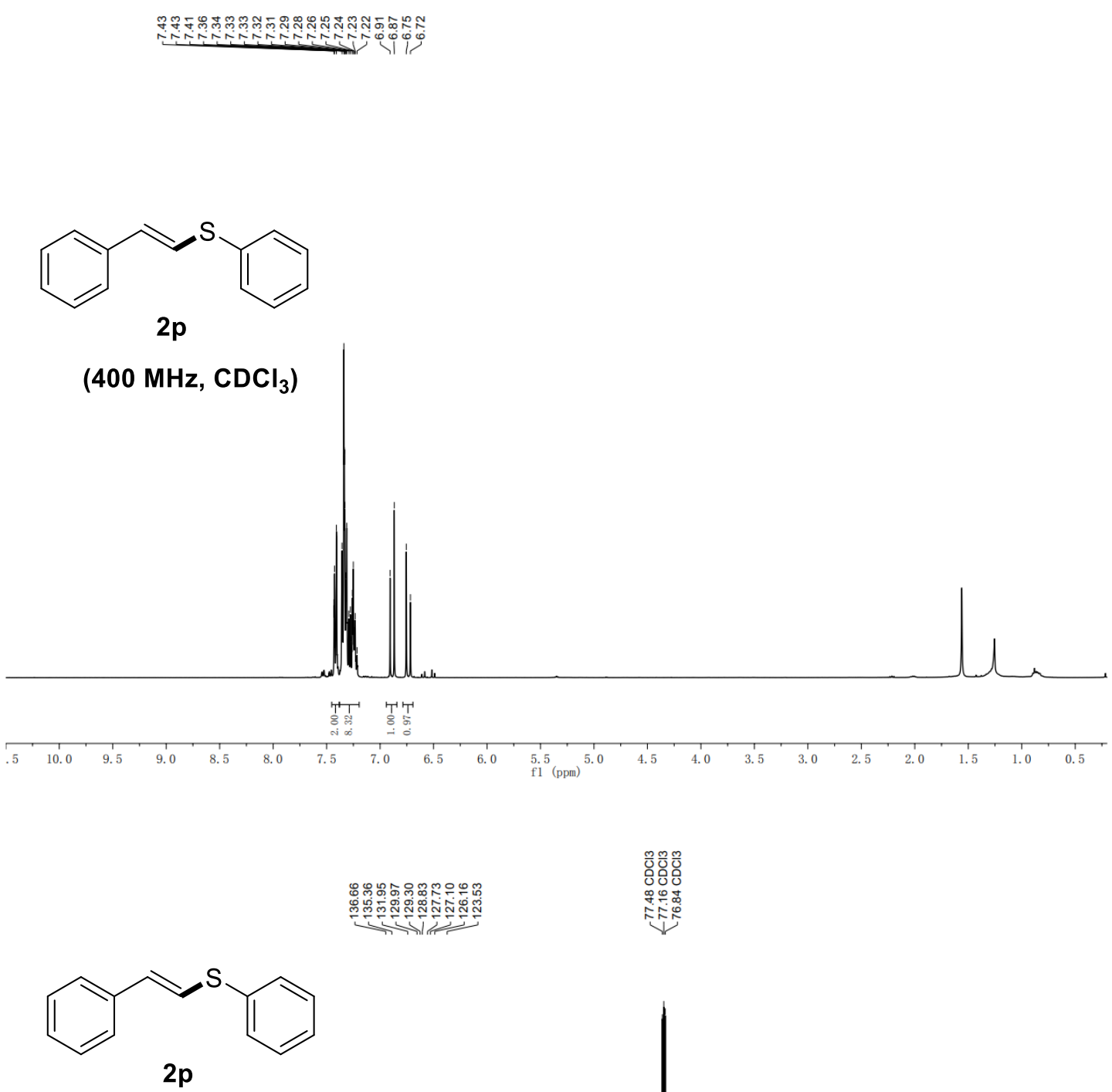

$\left(100 \mathrm{MHz}, \mathrm{CDCl}_{3}\right)$
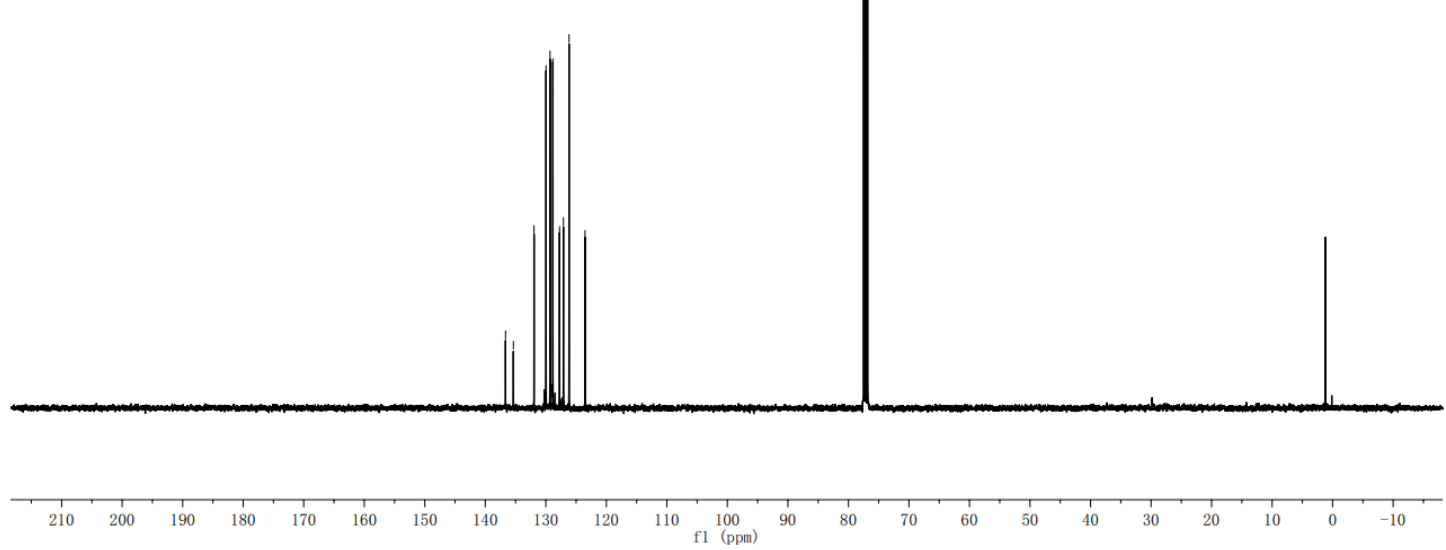
$\overbrace{\mathbf{2 q}}^{\mathrm{S}} \mathrm{C}_{10} \mathrm{H}_{21}$

(400 $\mathrm{MHz} \mathrm{CDCl}_{3}$ )

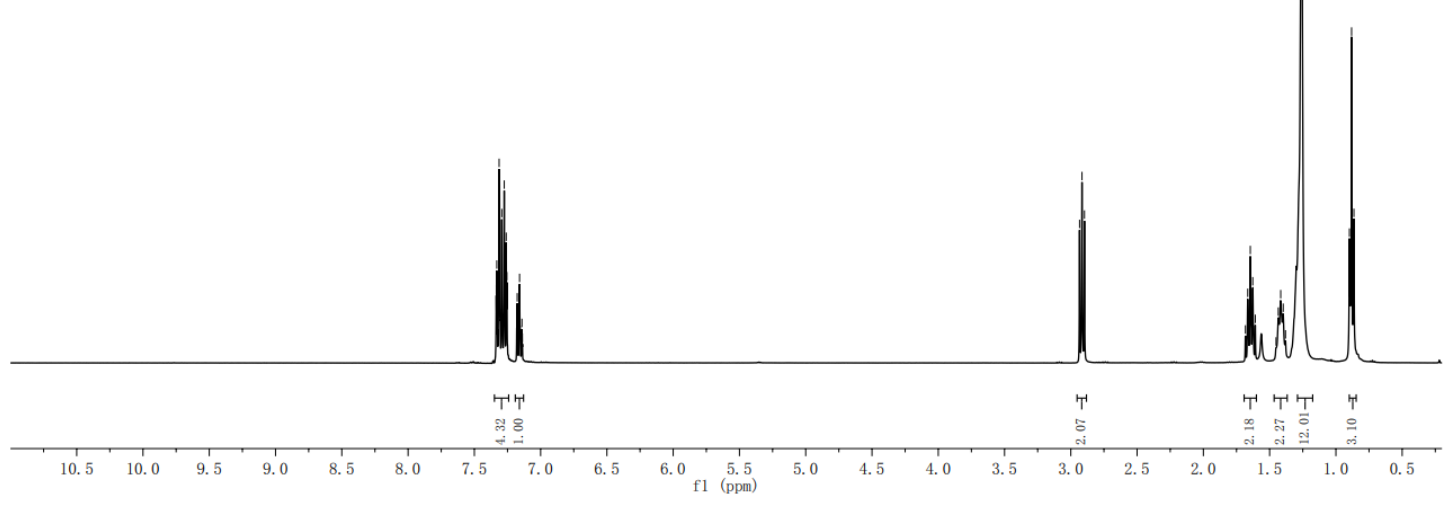<smiles></smiles>

(100 $\mathrm{MHz}, \mathrm{CDCl}_{3}$ )
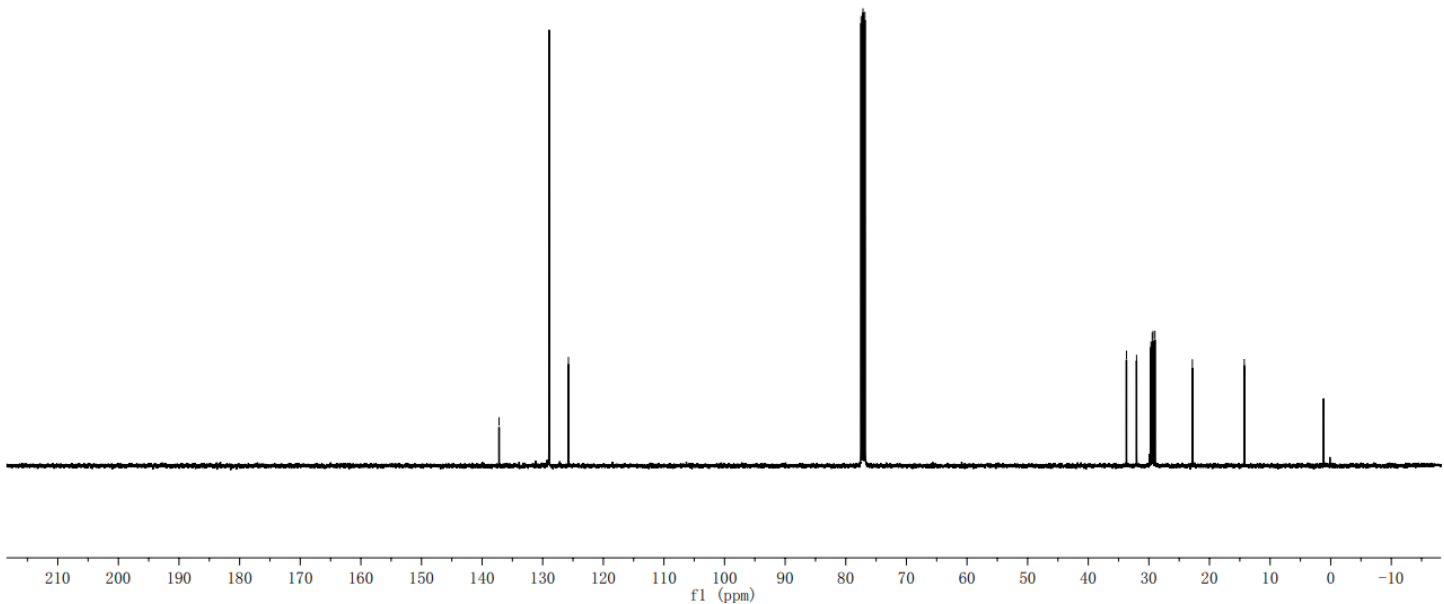


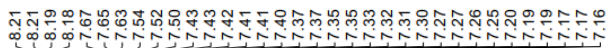<smiles>O=C(Oc1ccc(Sc2ccccc2)cc1)c1ccccc1</smiles>

(400 MHz, $\mathrm{CDCl}_{3}$ )

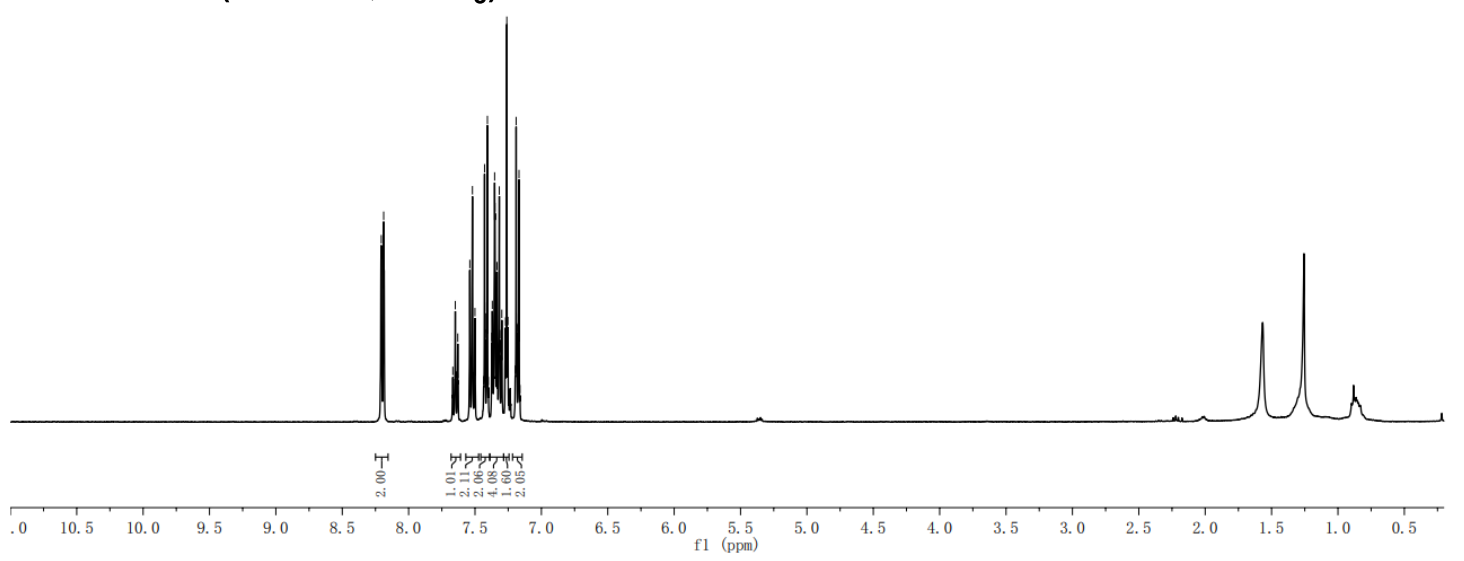

।<smiles>O=C(Oc1ccc(Sc2ccccc2)cc1)c1ccccc1</smiles>

$\left(100 \mathrm{MHz}, \mathrm{CDCl}_{3}\right)$

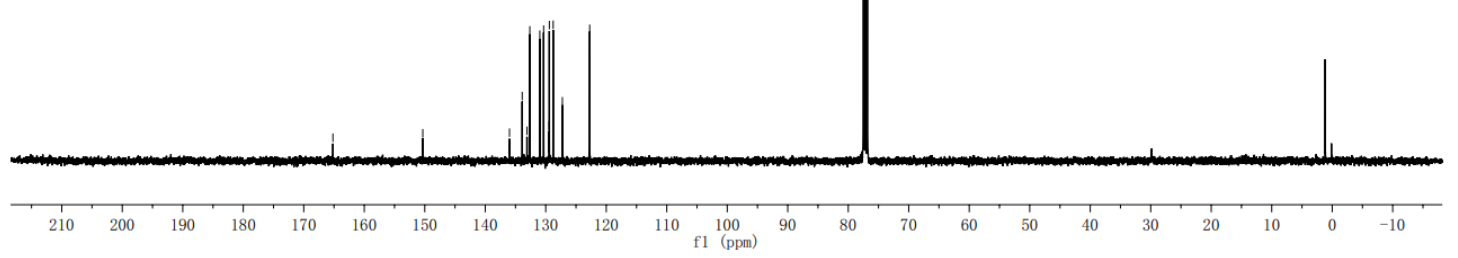




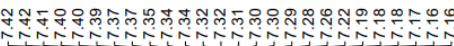<smiles>Brc1ccc(Sc2ccccc2)cc1</smiles>

(400 $\mathrm{MHz}, \mathrm{CDCl}_{3}$ )

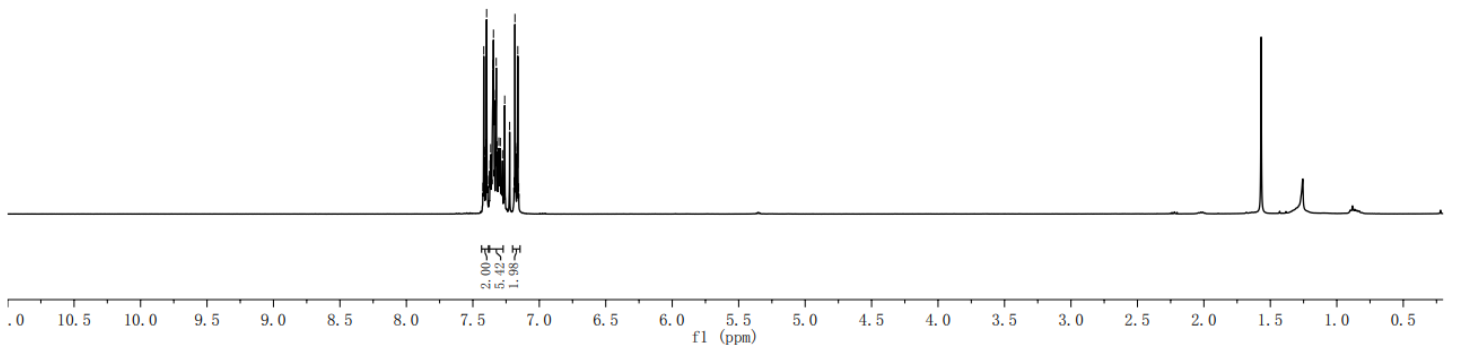

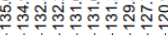

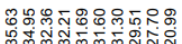<smiles>Brc1ccc(Sc2ccccc2)cc1</smiles>

2s

(100 $\mathrm{MHz}, \mathrm{CDCl}_{3}$ )
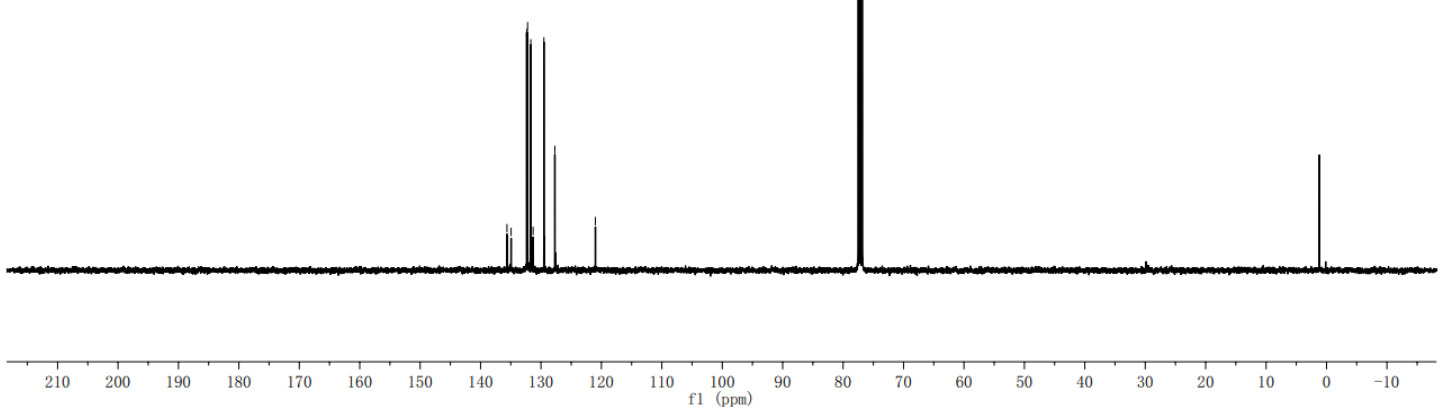

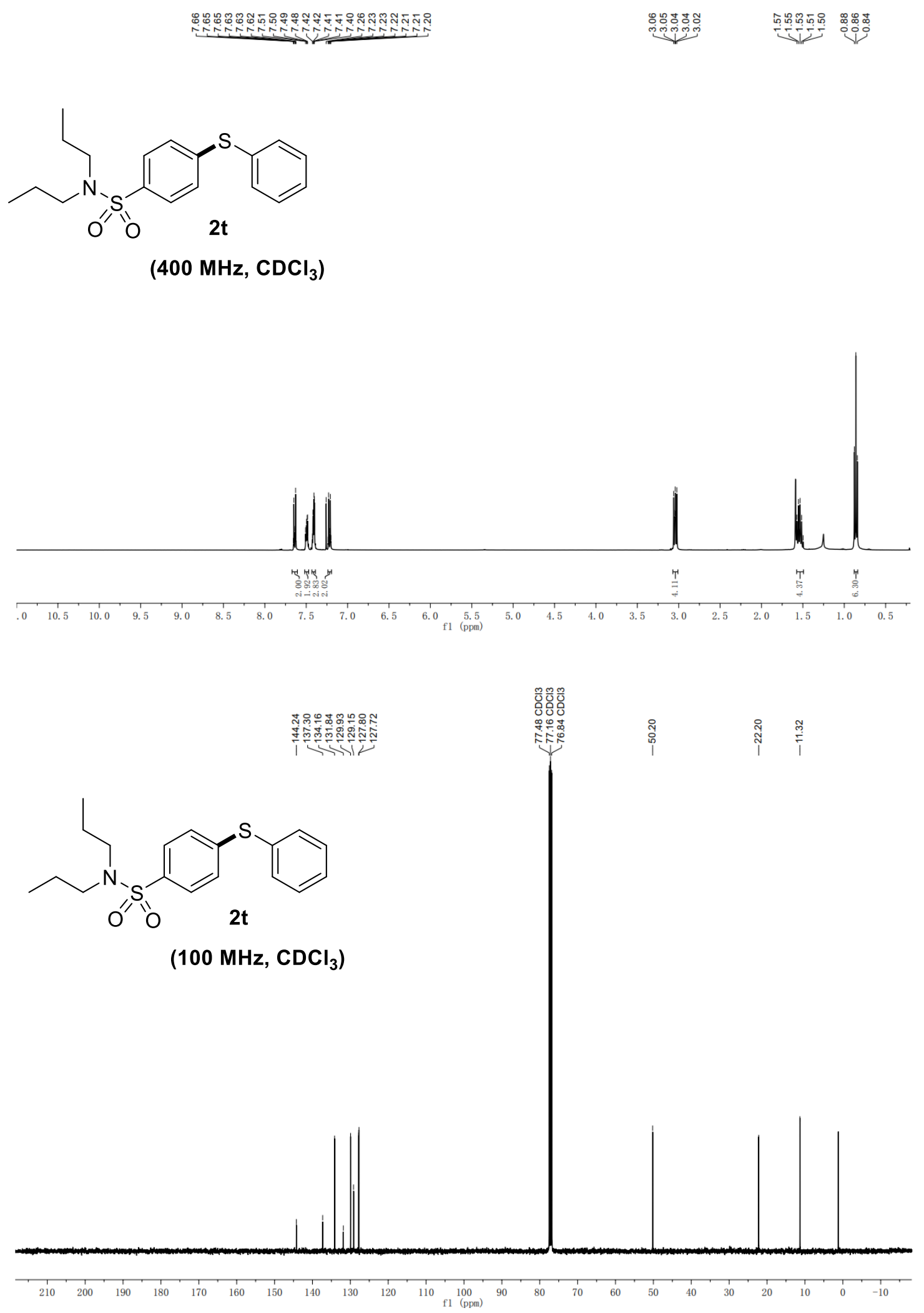


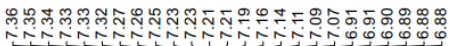
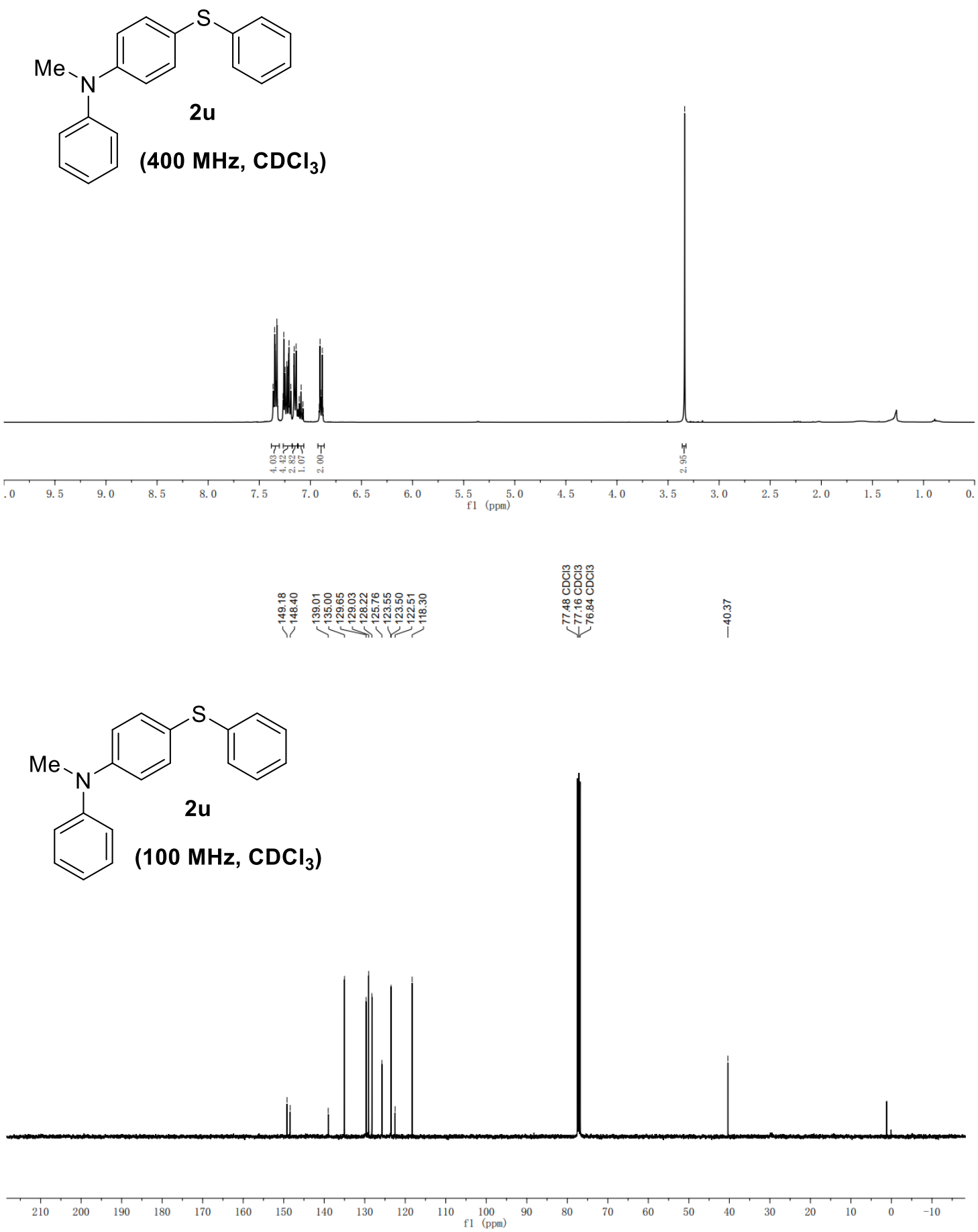